\title{
Characterization of toxicologically significant efflux transporters and their interactions with drugs
}

\author{
$\mathrm{PhD}$ Thesis \\ Zsuzsanna Rajnai \\ University of Szeged \\ Faculty of Pharmacy \\ Institute of Pharmaceutical Chemistry
}




\section{Publications}

Papers covered by the thesis ${ }^{1}$

I. Rajnai, Z., Méhn, D., Beéry, E., Okyar, A., Jani, M., Tóth, G. K., Fülöp, F., Lévi, F. and Krajcsi, P.: ATP-binding cassette B1 transports seliciclib (Rroscovitine), a cyclin-dependent kinase inhibitor, Drug Metab. Dispos., 38:2000-2006, 2010.

II. Beéry, E., Rajnai, Z., Abonyi, T., Makai, I., Bánsághi, S., Erdő, F., Sziráki, I., Herédi-Szabó, K., Kis, E., Jani, M., Márki-Zay, J., Tóth, G. K. and Krajcsi, P.: ABCG2 modulates chlorothiazide permeability in vitro characterization of the interaction, Drug Metab. Pharmacokinet., 27:349-353, 2012.

III. Szolomajer-Csikós, O., Beéry, E., Kósa, L., Rajnai, Z., Jani, M., Hetényi, A., Jakab, K. T., Krajcsi, P and Tóth, G. K.: Synthesis and ABCG2 inhibitory activity of novel fumitremorgin $\mathrm{C}$ analogs - Specificity and structure activity correlations, Med. Chem., 9:494-509, 2013.

\footnotetext{
${ }^{1}$ In the manuscript these papers will be referred to by the roman numbers
} 
Papers not covered by the thesis

IV. Kis, E., Rajnai, Z., Ioja, E., Herédi-Szabó, K., Nagy, T., Méhn, D. and Krajcsi, P.: Mouse Bsep ATPase assay: a nonradioactive tool for assessment of the cholestatic potential of drugs, J. Biomol. Screen., 14:10-15, 2009.

V. Kis, E., Ioja, E., Rajnai, Z., Jani, M., Méhn, D., Herédi-Szabó, K. and Krajcsi, P.: BSEP inhibition: in vitro screens to assess cholestatic potential of drugs, Toxicol. in Vitro, 26:1294-1299, 2012.

VI. Sziráki, I., Erdő, F., Trampus, P., Sike, M., Molnár, P. M., Rajnai, Z., Molnár, J., Wilhelm, I., Fazakas, Cs., Kis, E., Krizbai, I. and Krajcsi, P.: The use of microdialysis techniques in mice to study P-gp function at the blood-brain barrier, J. Biomol. Screen., 18:430-440, 2013.

VII. Fekete, Z., Rajnai, Z., Nagy, T., Jakab, K. T., Kurunczi, A., Gémes, K., Herédi-Szabó, K., Fülöp, F., Tóth, G. K., Czerwinski, M., Loewen, G. and Krajcsi, P.: Membrane assays to characterize interaction of drugs with ABCB1, J. Membr. Biol., 248:967-977, 2015.

VIII. Sáfár, Z., Vaskó, B., Ritchie, T. K., Imre, G., Mogyorósi, K., Erdő, F., Rajnai, Z., Fekete, Z., Szerémy, P., Muka, L., Zolnerciks, J. K., Herédi-Szabó, K., Ragueneau-Majlessi, I. and Krajcsi, P.: Investigating ABCB1-mediated drug-drug interactions: considerations for in vitro and in vivo assay design, Curr. Drug Metab., 17:430-455, 2016.

\section{Conference abstract covered by the thesis}

IX. Rajnai, Z., Méhn, D., Beéry, E., Okyar, A., Jani, M., Fülöp, F., Lévi, F. and Krajcsi, P: The CDK inhibitor roscovitine (Seliciclib) is a selective substrate of human P-glycoprotein (P-gp/ABCB1/MDR1) Drug Metab. Rev. 42:299$300,2010$. 


\section{Abbreviations and symbols}

ABC - ATP-binding cassette transporter

ADME - absorption-distribution-metabolism-excretion

ATP - adenosine triphosphate

BBB - blood-brain-barrier

BCRP - breast cancer resistance protein, (MXR, ABCP, ABCG2)

Caco-2 - colorectal carcinoma cell line

CNS - central nervous system

CSF - cerebrospinal fluid

DDI - drug-drug interaction

DMSO - dimethyl sulfoxide

HBSS - hank's balanced salt solution

HEK293 - human embryonic kidney cells

HL60 - human promyelocytic leukemia cells

HT - high-throughput

K562 - human myelogenous leukemia cells

MCF7 - human breast adenocarcinoma cells

MDCKII - Madin-Darby canine kidney strain II

MDR - multidrug resistance

MDR1 - multidrug resistance protein 1 (P-gp, ABCB1)

MRP1 - multidrug resistance-associated protein 1 (ABCC1)

NBD - nucleotide binding domain

$\mathrm{P}_{\text {app - }} \quad$ apparent permeability co-efficient

PTC - proximal tubule cells

Sf9 - Spodoptera frugiperda ovarian cells

tDDI - transporter dependent drug-drug interaction

TMD - transmembrane domain

VT - vesicular transport 


\section{Table of contents}

1. Introduction .......................................................................... 1

2. Literature survey ............................................................... 2

2.1. Mechanisms of trans-barrier transport ........................................................ 2

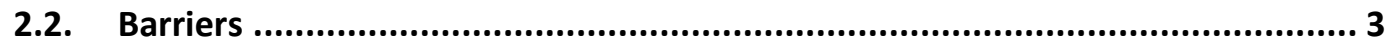

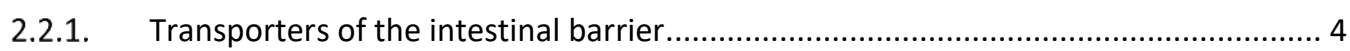

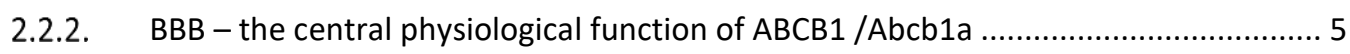

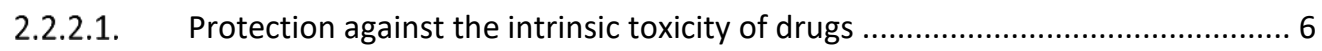

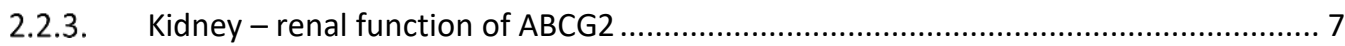

2.2.3.1. Transport of endogenous substrate by ABCG2 - urate ..................................... 9

2.2.4. Liver - a major detoxifying organ......................................................................... 10

2.3. Role / function of barrier-localized transporters in drug ADE and toxicity ....... 11

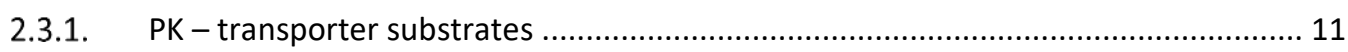

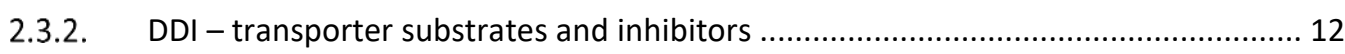

2.3.3. Toxicity - transporter inhibitors and substrates .................................................. 13

2.4. Transporters studied and covered by the thesis ........................................ 14

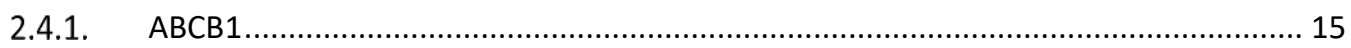

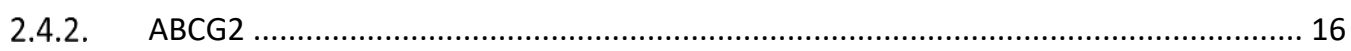

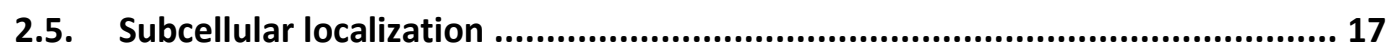

2.6. Properties of different (membrane-based and cellular) methods................... 17

2.6.1. Membranes and membrane-based assays ........................................................... 17

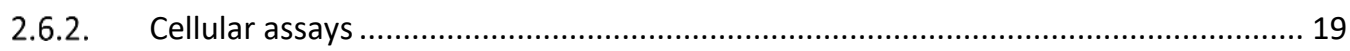

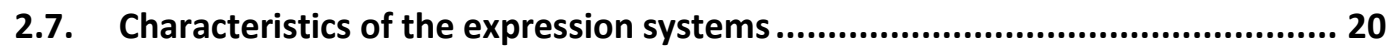

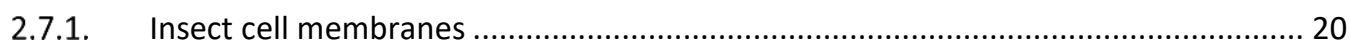

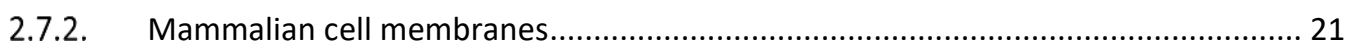

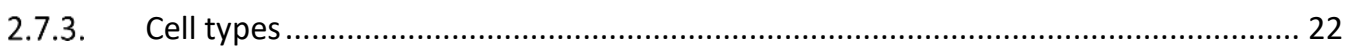

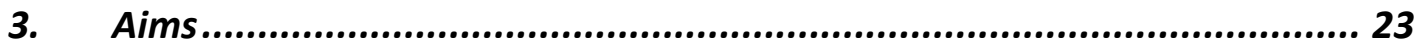

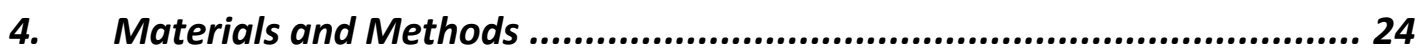

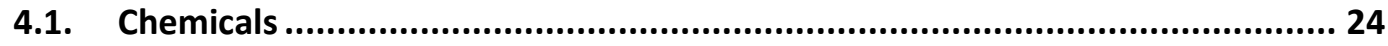

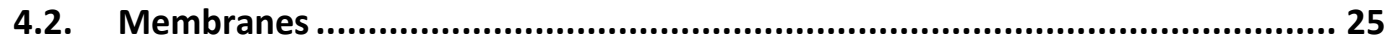

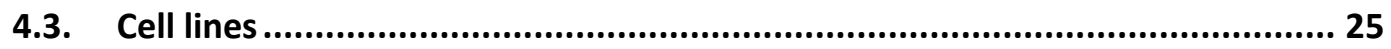

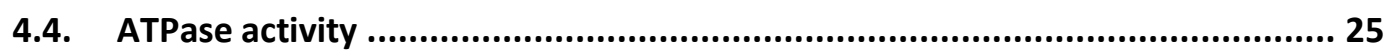

4.5. Vesicular transport assay ............................................................................ 26

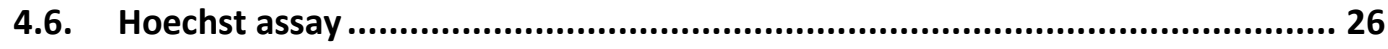

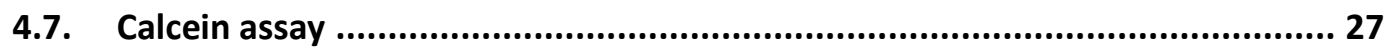

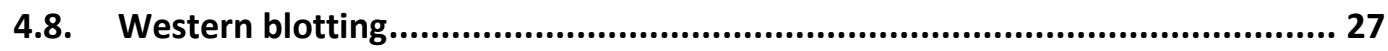

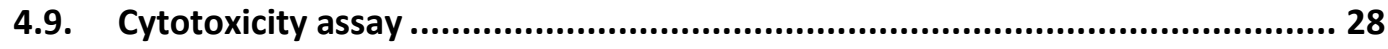




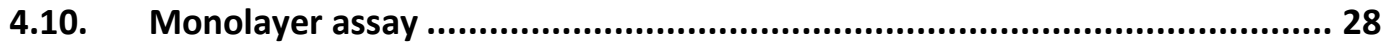

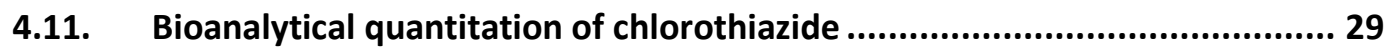

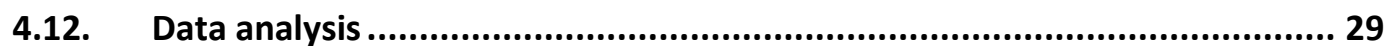

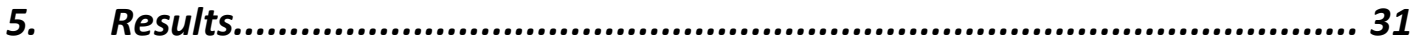

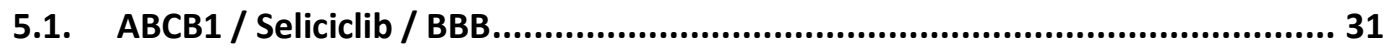

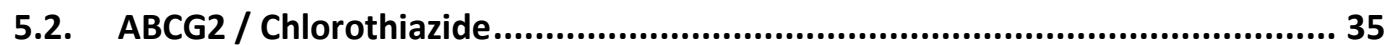

5.3. Fumitremorgin C analogs / Inhibition specificity of ABCG2 ........................... 37

6. Discussion - Applications in drug research and development ................. 41

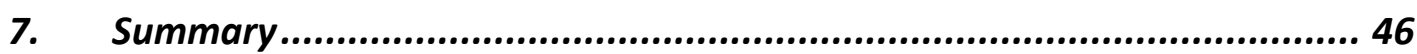

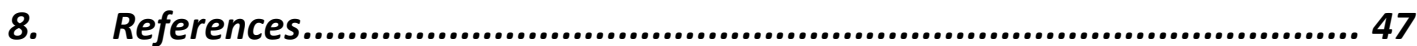

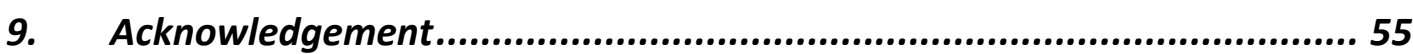




\section{Introduction}

Transporters profoundly affect the homeostasis of physiological substrates, endobiotics and also the pharmacokinetics or ADME properties of drugs, xenobiotics. Therefore, transporters have a profound influence on the plasma and tissue levels of various substrates. Drug-mediated inhibition of transporters, therefore, may lead to increases in both plasma as well as tissue levels of endobiotics and xenobiotics. Victim drugs with narrow therapeutic index are of particular concern, as increases in either plasma or tissue concentrations may lead to toxicity. Drugs as perpetrators can also have detrimental effects if the inhibition of transporters leads to increased level of a co-administered drug (drug-drug interaction) or increased levels of endobiotics (drug-endobiotics interaction).

In this work, we provide examples for a chemotherapeutic agent as a potential victim drug (seliciclib). The compound chlorothiazide, which was also studied, may be a victim on the one hand, as transporters are responsible for renal secretory excretion of the drug. On the other hand, it is a potential perpetrator, as it inhibits the ABCG2 (BCRP) that transports urate and, thus, this may be in the background of chlorothiazide-induced hyperuricemia. In addition, our data shed light on specificity and structure-activity relationship of fumitremorgin $\mathbf{C}$ analogs in which the Ko family contains efficacious and selective inhibitors of the ABCG2 transporter protein. As ABCG2 is a multidrug resistance (MDR) protein that transports several chemotherapeutic agents, these inhibitors are potential reversal agents that can potentiate the toxicity of chemotherapeutics. 


\section{Literature survey}

The ATP-binding cassette (ABC) transporter superfamily and its genes represent one of the largest family of known transmembrane proteins, and its members have been found in almost all living organisms, from bacteria to mammals. In humans, they play an important role in several physiological processes, including the modulation of the permeability of endobiotics or xenobiotics across physiological barriers $[1,2]$.

Drug transporters are widely expressed throughout the body. Two major superfamilies of transporters have been described: the Solute Carriers (SLCs) that mostly support the cellular uptake of various substrates [3, 4] and the ATP Binding Cassette $(\mathrm{ABC})$ transporters that, in contrast, mediate the cellular efflux of substrates. Certain $\mathrm{ABC}$ transporter proteins play a key role in the homeostasis of the human body, and they also provide protection against xenobiotics. These proteins play a critical role in the homeostasis of physiological substrates in cells or tissues and are major determinants of the efficacy and toxicity of drug molecules. Furthermore, they might serve as biomarkers to predict the occurrence or monitor the progression of a given disease, and its response to treatment [5].

The substrate specificity and tissue distribution of these transporters varies on a wide range. Different $\mathrm{ABC}$ transporters can be found in different types of cells, still, they have an overlapping substrate specificity. While some are specific to amino acids, bile acids, peptides, steroids, and sugars, others extrude ions, organic anions or cations - including drug molecules - out of cells $[1,6]$.

It follows that genetic mutations and polymorphisms that cause functional impairment of these proteins lead to disease $[1,5,7]$.

\subsection{Mechanisms of trans-barrier transport}

Ions and molecules may be transported either via the paracellular or the transcellular route. Some molecules (e.g. water) can be transported in both ways. In contrast, the tight junctions are impermeable to some organic molecules. Such molecules are transported exclusively via the transcellular route.

Transcellular transport includes transcellular diffusion, active carrier-mediated transportation, and transcytosis. Transcelluar diffusion is simply the movement of 
solutes driven by a diffusion gradient. In contrast, active transport involves the use of energy to transport specific substrates across barriers, even against the concentration gradient (Figure 1).

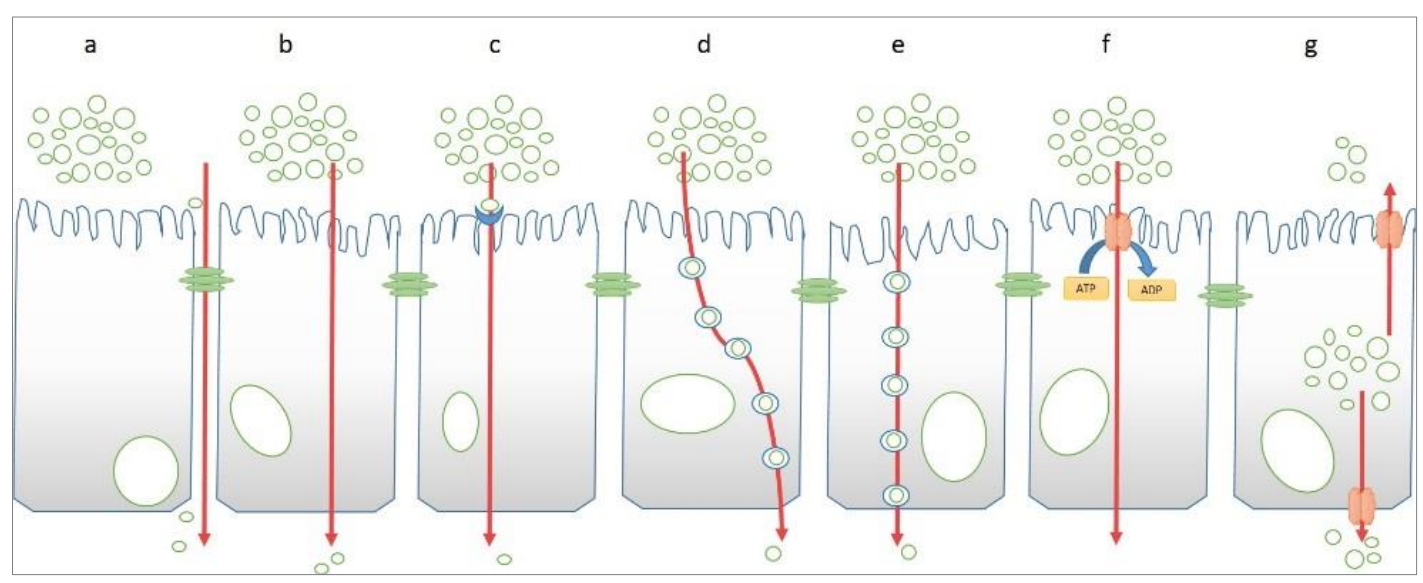

Figure 1. The transport mechanisms of materials through epithelium. (a) paracellular transport, (b) transcellular transport by diffusion, (c) facilitated diffusion, (d) transcytosis, (e) endocytosis, $(f)$ active transport, $(g)$ efflux. [8]

The passive transcellular pathway is still by far the most important absorption pathway for drugs. Drug transport via the passive transcellular route requires that the solute permeates the apical cell membrane. It is generally believed that the apical membrane has a lower permeability than the basolateral membrane. Therefore, the former is considered to be the rate-limiting barrier to passive transcellular drug transport [9].

\subsection{Barriers}

Numerous physiological interfaces exist in the human body. The intestinal, liver, kidney and blood-brain-barriers are considered crucial in terms of the ADE (Absorption-Distribution-Excretion) of a drug. Hence, they also define the bioavailability and pharmacokinetics of drugs [10]. 


\subsubsection{Transporters of the intestinal barrier}

The small intestine is the most important part of the intestinal barrier and forms a major part of the digestive system. Enterocytes are cellular components of the bowel, through which nutrients and drug molecules are absorbed, and which comprise the first barrier in the way of orally administered drugs (Figure 2). Transporter proteins are expressed region-specifically along the full length of the intestinal system [11]. Enzymes and apically located efflux transporters may limit absorption and bioavailability in the small intestine compared to the distal region of the digestive system, where the decreased activity of metabolic enzymes and smaller number of efflux transporters may provide increased reabsorption [12, 13]. Some drug molecules penetrate by passive diffusion, while the absorption of others is facilitated by transporters. ABCB1 and ABCG2 are the two major ABC efflux transporters with high expression levels in the gut. Many studies confirm that they form a barrier against the absorption of drugs through the enterocytes. Abcb1a is expressed in the apical membrane of mouse intestinal epithelial cells [11]. Several publications show the effect of these transporters in the disposition of orally administered drugs. The oral bioavailability of vinblastine, fexofenadine and paclitaxel was found to be increased in both Abcb1a-null and Abcb1a/1b-null mice [11].

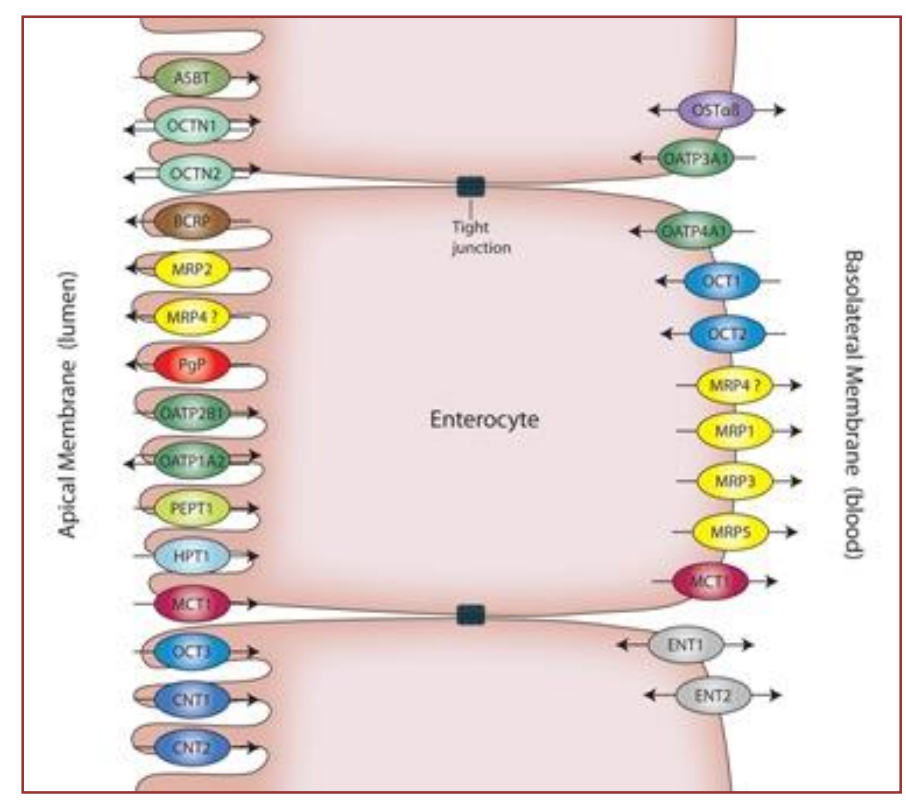

Figure 2. Transporters in the cellular membrane of an enterocyte (SOLVO Biotechnology) 
Abcg2 limits the oral bioavailability of the inflammatory bowel disease and disease modifying antirheumatic drug sulfasalazine and other xenobiotics. In Abcg2-null mice or in wild-type mice treated with known Abcg2 inhibitors the oral absorption of sulfasalazine has increased. Supporting these observations, increased oral bioavailability of sulfasalazine was seen in patients carrying the Q141K polymorphism that leads to decreased ABCG2 expression and function. For drugs that require high oral bioavailability, it is important to check the potential of interactions with $\mathrm{ABCB} 1$ and $\mathrm{ABCG} 2$ [11]. Regulatory recommendations by FDA and EMA also require testing of drugs with these transporters if bioavailability is low, absorption is aberrant or pharmacokinetics is non-linear [6]. An option to bypass intestinal efflux proteins is to formulate orally administered pharmaceuticals with excipients that inhibit the transporter function thus increasing the rate of absorption [14-16].

\subsubsection{BBB - the central physiological function of ABCB1/Abcb1a}

There are two barriers in the central nervous system, namely the blood-brain-barrier (BBB) and the blood-cerebrospinal fluid-barrier (BCSFB). Their task is to protect cerebral homeostasis and to provide optimal operating environment [17]. The former consists of brain microvascular endothelial cells with tight junctions, surrounded by the lipid-rich endfeet of astrocytes. The latter is built up of cubic epithelial cells of the choroid plexus $[18,19]$. The surface area of the BBB is about a hundred times greater than that of BCSFB, which explains why BBB is dominant. The extensive microvascular network of the nervous tissue provides a large interface to exchange substances through the $\mathrm{BBB}$, but the exchange of molecules is still strictly controlled by transporters [20, 21].

The $\mathrm{BBB}$ as a barrier protects the central nervous system from exposure to drug molecules and other, potentially toxic substances. There is little option for paracellular diffusion because tight junctions form close connections between cells, thus, wherefore membrane transporters can efficiently control substance exchange (Figure 3) [17].

There are differences between the protein expression pattern of BBB and BCSFB and the quantity of expressed transporters may vary during postnatal brain maturation. Apically $\mathrm{ABCB} 1, \mathrm{ABCG} 2$ and $\mathrm{ABCC} 4$ are of great significance, while basolaterally 
$\mathrm{ABCC} 1$ is noteworthy. The Gazzin group conducted comparative analysis in rats between the two blood-brain interfaces concerning the relative amount of Abcb1 and Abcc1 protein transporters. These two proteins seem to follow different temporal expression patterns in both barriers. While Abcc1 is already present at adult-like levels in early postnatal ages, the expression of Abcb1 increases during postnatal development. The authors conclude that the mechanism of neuroprotective function is significantly different between the two blood-brain interfaces [22].

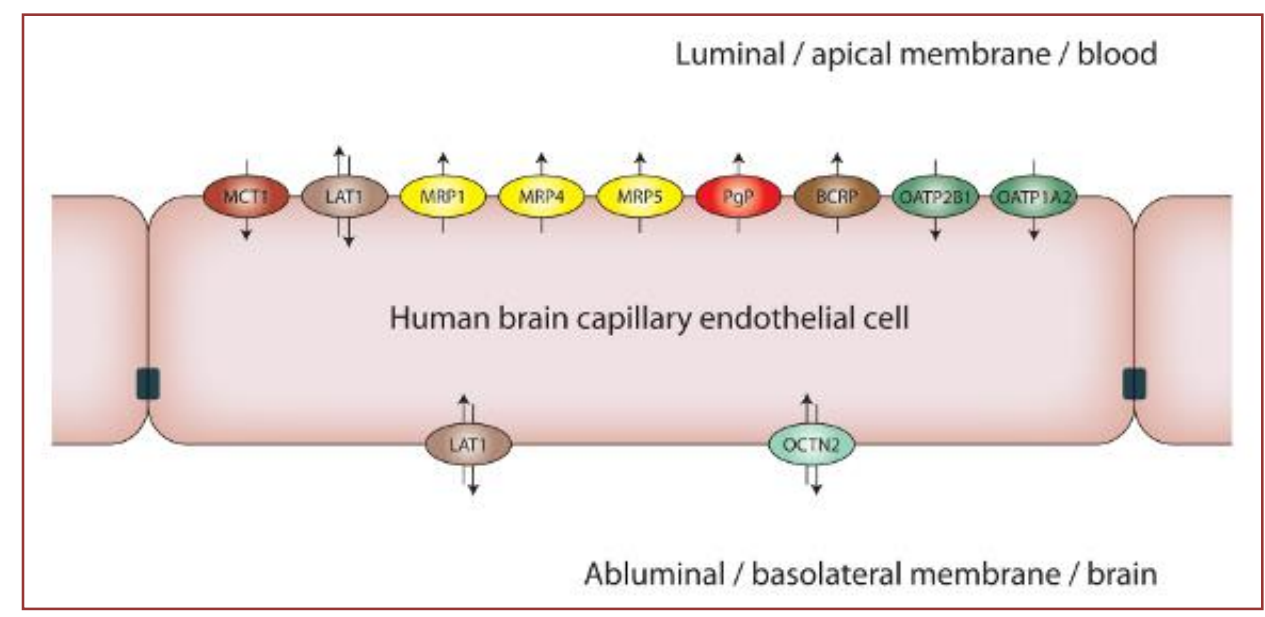

Figure 3. Transporters in the membrane of a human brain microvascular cell (SOLVO Biotechnology)

Regarding the role of $\mathrm{ABCC} 2$ transporter, no agreement has been reached. In humans, it may not be expressed in normal $\mathrm{BBB}$ but pathological conditions might trigger its expression [23].

\subsubsection{Protection against the intrinsic toxicity of drugs ABCB1 /Abcbla-seliciclib}

Medications could easily reach toxic levels in the central nervous system, were it not for the $\mathrm{ABC}$ efflux transporters. Substrates of $\mathrm{ABC}$ transporters include endogenous, biologically active or toxic molecules, such as bilirubin, which can cause encephalopathy in newborns with severe jaundice, as well as, for instance, corticosteroids, which are involved in brain maturation [22]. 
Expression of Abcb1a and Abcg2 in the BBB of rodents can restrict the accumulation of chemicals. Studies have demonstrated that the brain concentrations of the pesticide ivermectin and anti-cancer agent vinblastine increased in Abcb1 knockout mice. Hudachek et al. studied the level of the widely used anti-cancer agent, docetaxel, in different tissues in Abcb1 knockout and wild type mice. They found that loss of Abcb1 function resulted in elevated levels of the drug in all tissues, but not in the plasma. The lowest increase (6\%) was observed in the liver, while the highest (444\%) in the brain [24].

In the recent years, intensive scientific attention has been focused on tyrosine kinase inhibitors as anti-cancer substances [25]. The entry of tyrosine kinase inhibitors into the brain is limited by Abcb1a and Abcg2 and, therefore, these compounds do not appear to be viable therapeutic options in brain tumors, even if BBB permeability in brain tumors is hotly debated [26-29]. A better characterization of transporters responsible for the extrusion of tyrosine kinase inhibitors from the brain may open up new perspectives for the development of inhibitors, so that the accumulation tyrosine kinase inhibitors in the brain could be enhanced [11].

The selective ABCB1 substrate seliciclib, which we tested, can easily pass through the cell membranes due to its high passive permeability and lipophilicity. However, it shows a limited brain exposure in adult rats, which suggests an apically located $\mathrm{ABC}$ transporter that may limit the BBB permeability. Increased brain exposure of seliciclib may be of significance as the drug is a candidate to treat neurodegenerative diseases $[30,31]$.

\subsubsection{Kidney - renal function of $A B C G 2$}

The kidneys comprise one of the four main barriers in the body. Kidneys eliminate metabolites from blood and materials that are no longer needed in the circulation. A huge amount of filtrate is produced every minute, but most of it is reabsorbed, so that the homeostasis of the most important ions and other useful substances does not suffer. Both uptake and efflux transporters found in renal cell membranes are involved in renal secretion and reabsorption of xenobiotics and endogenous molecules circulating in the blood (Figure 4) [11]. The ABCG2 transporter substrates include many drug molecules (e.g. irinotecan, methotrexate, topotecan) and 
endogenous compounds (e.g. estrone-3-sulphate, bile acids) [32-34]. One of the endogenous compounds transported by ABCG2 is urate [35].

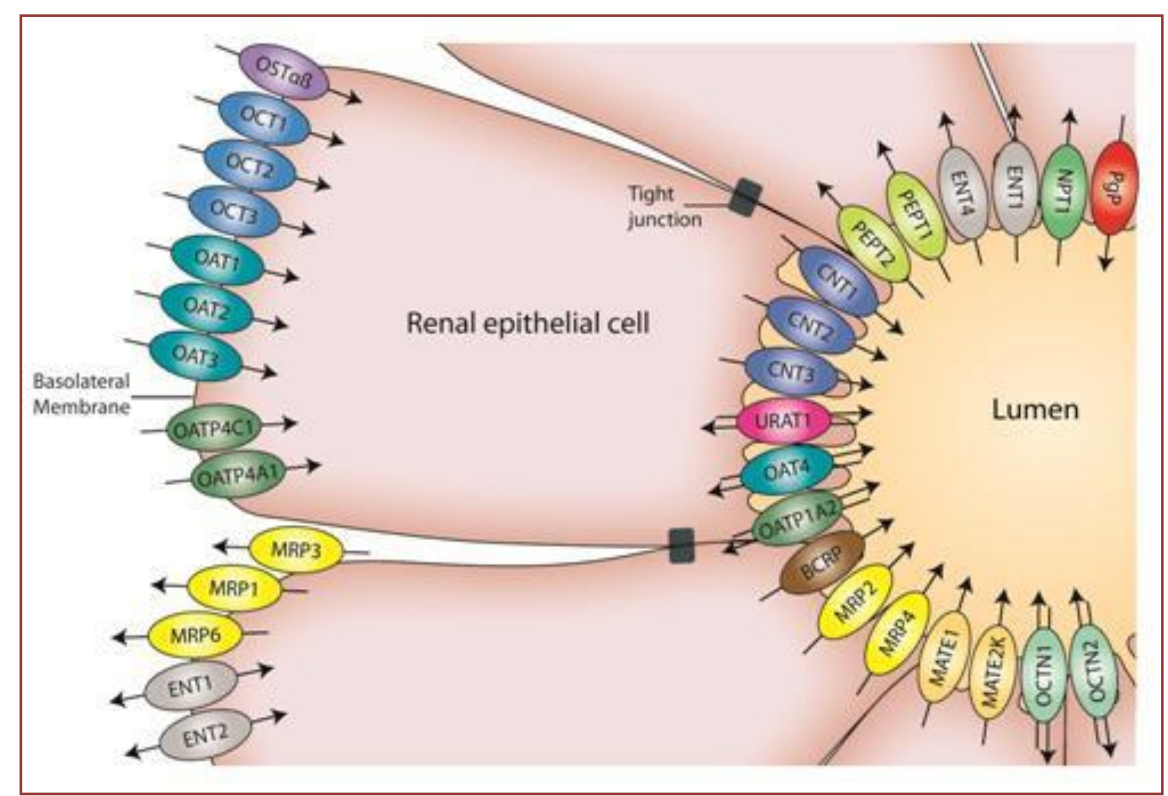

Figure 4. Transporters in the membrane of a renal epithelial cell (SOLVO Biotechnology)

Transporters located in the same membrane region and possessing overlapping substrate specificity may mask the impact of the others. Methotrexate is secreted into the urine, but the exact mechanism was only found out when the gene encoding Abcg2 were also knocked out in Abcc2 (-/-) mice as both transporters transport methotrexate [11]. A similar compensatory effect was suggested for the renal transport of urate as $\mathrm{ABCC} 4$ that is expressed in renal proximal tubule cells along with ABCG2 also transports urate. Pharmacogenomics studies, however, showed that $\mathrm{ABCG} 2$ but not $\mathrm{ABCC} 4$ is the dominant efflux transporter [36]. It is of note that there is a significant non-renal excretion of urate that is also thought to be mediated by ABCG2 [37, 38]. 


\subsubsection{Transport of endogenous substrate by ABCG2 - urate}

In humans, urate is the degradation product of purine nucleotides while in other species, due to the presence of the enzyme uricase, the end product of purine metabolism is allantoin. Urate is produced predominantly in the liver. The primary site of excretion is the kidneys, but recent studies mention the significance of excretion via bile and the intestines, which suggests that a significant portion is removed with the faeces. Almost $90 \%$ of the urate filtered through the kidneys is reabsorbed in the proximal tubule. In the kidneys, there is a complex transport network that modulates the passive filtering via active secretion and active reabsorption of urate in the proximal tubule. A number of Genome Wide Association Studies (GWAS) and functional studies have linked urate secretion and, as a consequence, plasma urate levels with ABCG2 [11].

The elimination of urate is a complex process, which involves several transporter proteins. But the GWAS studies have clearly shown an important role for ABCG2 $[35,36]$. ABCG2 is present in significant quantities in the apical membrane of intestinal enterocytes, and approximately one third of the urate is eliminated via intestinal secretion $[37,38]$. If $\mathrm{ABCG} 2$ function is impaired or inhibited, the amount of poorly soluble urate in serum increases till oversaturation. The ultimate result of this process may be the formation of urate crystals that can deposit around joints as well as in kidneys in the form of sodium salts. This can lead to arthritis, nephropathy, and the formation of kidney stones [36].

The biopharmaceutics drug disposition classification system or BDDCS is an enhanced version of the biopharmaceutics classification system (BCS). Compounds are categorized into four classes according to their solubility and permeability (Figure 5). These characteristics can affect oral absorption [39].

Chlorothiazide is a diuretic, and can cause hyperuricemia [II]. Chlorothiazide is a BDDCS Class IV drug which means that because of its low passive permeability and low solubility transporters possess significant effects in its pharmacokinetics of the drug (Figure 5) [39]. Hyperuricemia is linked to an increased risk of other diseases, including vascular diseases, chronic renal conditions, diabetes and gout [36]. 


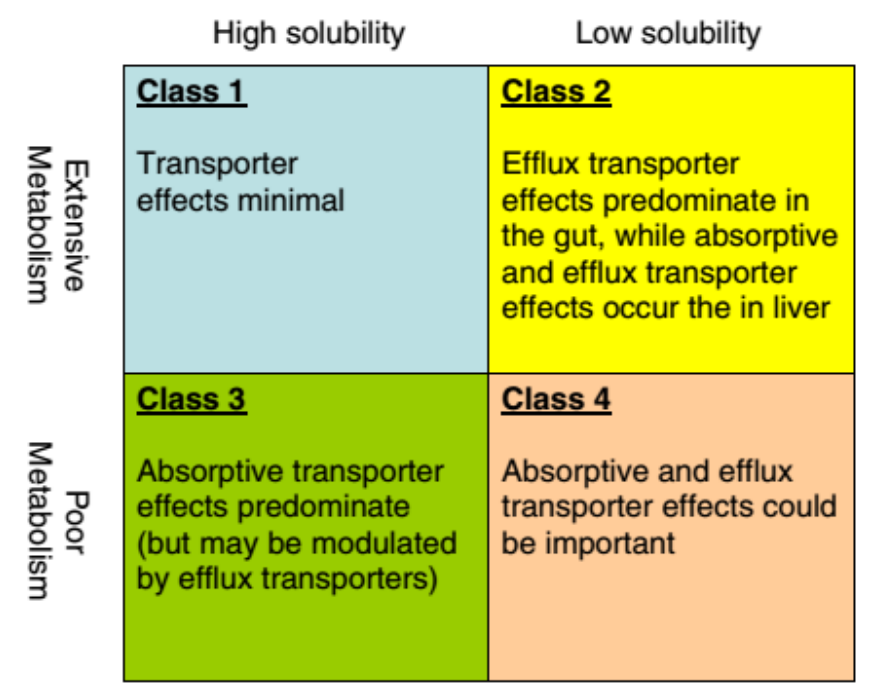

Figure 5. Transporter effects predicted by BDDCS following oral dosing. [39]

\subsubsection{Liver - a major detoxifying organ}

Liver is one of the main detoxifying organs in the body. Endogenous or xenobiotic substances may get extracted and metabolized in hepatocytes before entering the circulation. Uptake transporters of the SLC superfamily are expressed in the basolateral / sinusoidal membrane and mediate the uptake of physiological substrates [40]. In the apical / canalicular membrane efflux transporters such as ABCB1, ABCC2, ABCG2 and most importantly, ABCB11 efflux substrates into the bile (Figure 6). These proteins are expressed most abundantly in the cholesterol-rich regions of the membrane [41].

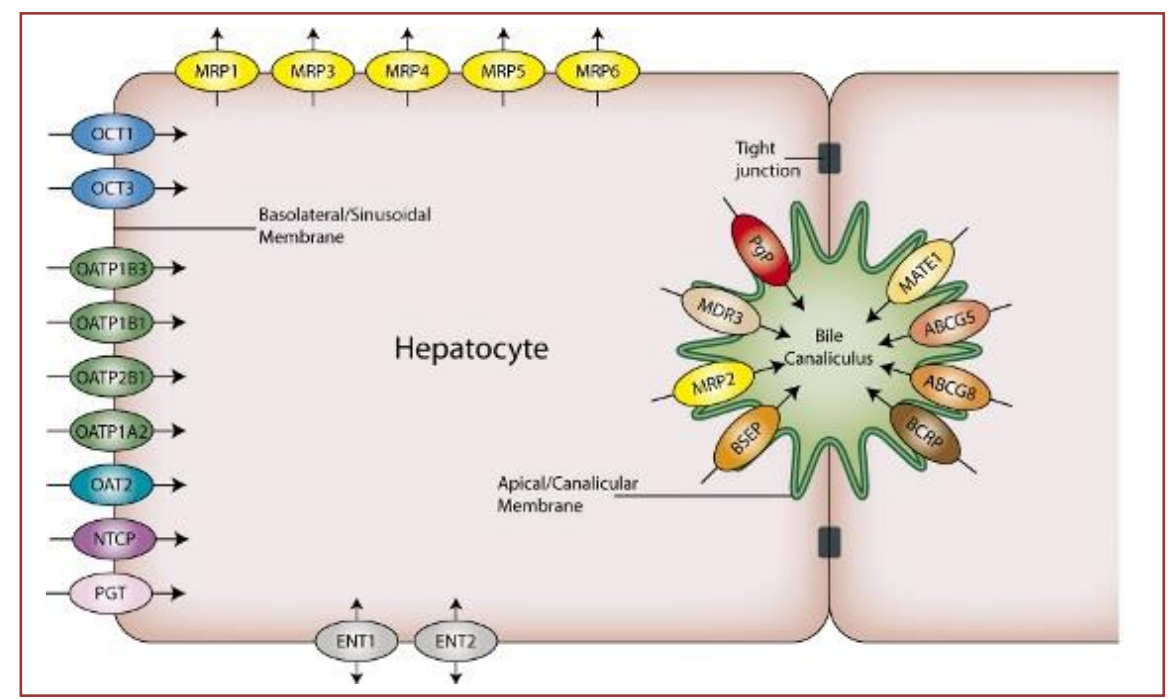

Figure 6. Transporters in the membrane of a hepatocyte (SOLVO Biotechnology) 
$\mathrm{ABCB} 1$ and $\mathrm{ABCG} 2$ play important roles in all barriers. $\mathrm{ABCB} 11$ is the most important canalicular bile salt transporter. Nevertheless, murine Abcb1 has been shown to compensate for Abcb11 knockout in mice [42] and chinese hamster Abcb1 has been shown to transport taurocholate [43]. ABCG2 has also been implicated in transport of bile salts, most importantly the sulfated bile salt species [44]. Liver localized ABCB1 and ABCG2 was included in the transporter white paper [6].

\subsection{Role / function of barrier-localized transporters in drug ADE and toxicity}

Transporters have a profound effect on the pharmacokinetics of substrate drugs. Not less important is the fact that tDDI may lead to an increased exposure of victim drugs, and in some cases, toxicity.

\subsubsection{PK-transporter substrates}

The phases of pharmacokinetics are absorption, distribution, metabolism and excretion. A drug, to exert its effect, must get to the target organ via circulation. There are membrane proteins on the cellular surface which can facilitate or inhibit these processes [39].

The most frequently used pharmacokinetic parameters to describe the effect of transporters are the maximum plasma concentration $\left(\mathrm{C}_{\max }\right)$, the area under the plasma concentration-time curve (AUC) and clearance $(\mathrm{Cl})$.

In general, apically located efflux transporters inhibit absorption and promote excretion. Therefore, they reduce $\mathrm{C}_{\max }$, $\mathrm{AUC}$ and increase $\mathrm{Cl}$. In contrast, basolaterally located efflux transporters promote absorption and limit excretion. Therefore, they increase $\mathrm{C}_{\max }$, AUC and decrease $\mathrm{Cl}$. Apically located uptake transporters promote absorption and reabsorption, and therefore, increase $\mathrm{C}_{\max }$, AUC and decrease $\mathrm{Cl}$. Basolaterally located uptake transporters, on the other hand, inhibit absorption and promote excretion, therefore, reduce $\mathrm{C}_{\max }$, AUC and increase $\mathrm{Cl}$ [39].

FDA and EMA identified ABCB1 as the most significant PK interactor protein of drug molecules. In vitro testing of a drug for substrate type interactions with ABCB1 is an official recommendation for all drug candidates by the FDA and suggested for consideration by EMA. The same applies to ABCG2. ABCG2 substrates have the 
potential to become victims of tDDI, when the transporter function is inhibited (see below) $[6,45]$.

\subsubsection{DDI - transporter substrates and inhibitors}

Membrane drug transporters are well recognized important contributing factors of PK and sites of DDIs. ABC transporter substrates have the potential to become victims of DDI, when the transporter function is inhibited. This is of particular significance for drug molecules that have narrow therapeutic index or low oral bioavailability. An interaction of a drug molecule with a transporter can competitively or non-competitively inhibit the transport of another drug molecule or endogenous substrate [1].

DDI mediated by $\mathrm{ABCB} 1$ has complex effects as the $\mathrm{ABCB} 1$ transporter protein is expressed in all major barriers and therefore the ABCB1- mediated DDI results in increased absorption, and reduced renal and hepatobiliary excretion. In addition, expression of $\mathrm{ABCB} 1$ in the $\mathrm{BBB}$ may also affect the penetration of a drug into the brain. Rifampin is a classic example of inducer molecules causing DDI. As an $\mathrm{ABCB} 1$ inducer, it is capable of reducing absorption across the gut as well as increasing the clearance of co-administered drugs. The cumulative effect manifests in the significantly reduced AUC of the co-administered drug molecules [1].

ABCB1 has broad substrate specificity and many compounds can inhibit it. One of those agents is quinidine. In 2000, Sadeque and colleagues showed in healthy volunteers that inhibition of $\mathrm{ABCB} 1$ with quinidine in the $\mathrm{BBB}$ leads to respiratory depression caused by the opioid and ABCB1 substrate loperamide, while such a problem was not observed when loperamide was administered alone [46]. Numerous drugs have been identifed as ABCB1 substrates, among them the cardiac glycoside digoxin, HIV protease inhibitors, immunosuppressants, beta-blockers, and certain anti-cancer drugs. The oral bioavailability of digoxin is $70 \%$ and is excreted by glomerular filtration. PSC833, also known as valspodar, is a typical ABCB1 inhibitor and have been studied to treat cancer due to its chemo-sensitizing effect. In humans PSC833 has the greatest impact on the amount of digoxin (AUC). Significant decrease $(75 \%)$ was observed in the renal clearance ratio of the glycoside (digoxin). The co-administration of digoxin with quinidine results in increased oral 
bioavailability, decreased renal secretion and reduced bile excretion of digoxin [47, 48].

The inhibition of ABCG2 may cause significant changes in the pharmacokinetics of substrate drugs. Several drug molecules, such as statins (e.g. atorvastatin), antiinfective drugs, anti-tumor agents (e.g. mitoxantrone, topotecan, gefitinib, imatinib) are ABCG2 substrates. Abcg2 knockout mice exhibit 111 times higher systemic sulfasalazine level after oral administration compared to wild-type mice. The oral bioavailability of topotecan is doubling if co-administered with the known ABCG2 inhibitor GF120918 (elacridar) [48]. In a proof-of-concept study, Kruijtzer showed in patients with solid tumors that GF120918 increased the apparent oral bioavailability of topotecan from $40 \%$ (without GF120918) to 97.1\% (with GF120918) [49].

It must be considered, though, that topotecan is both an $\mathrm{ABCB} 1$ and $\mathrm{ABCG} 2$ substrate. To separate the effects of the individual transporters, either specific inhibitors and/or knock-out animals or patients expressing lower activity pharmacogenomics variants should be used. GF120918 increased plasma levels of oral topotecan six-fold in ABCB1 deficient mice, which shows the significant contribution of ABCG2 to limiting the absorption of topotecan [50]. Using zosuquidar (LY335979), an ABCB1 inhibitor and Ko143, an ABCG2 inhibitor in portal vein cannulated rats, the contribution of ABCG2 to limiting oral absorption of topotecan was found to be 3.5 times greater than that of ABCB1 [51]. For humans, the simplest option is genotyping patients. In a limited study (two patients) in heterozygotes carrying the low activity ABCG2 allele was associated with a 1.34fold increase of bioavailability of oral topotecan [52].

\subsubsection{Toxicity - transporter inhibitors and substrates}

According to recent analysis data of the attrition of drug candidates, toxicity and lack of efficacy in Phase II are the two leading causes of clinical stage failures of compounds [53-55]. An article published in 2000 claims that hepatotoxicity has the second highest clinical termination rate among all studied toxicities. Forty-five percent of drug candidates causing human hepatotoxicity did not have such an effect in classical in vivo animal studies [56, 57]. 
Drug molecules interacting with $\mathrm{ABC}$ transporters can cause toxicity via a number of different mechanisms. The inhibition of efflux function can modify the distribution of co-administered drugs, thus changing their toxicity profile. It is to be noted that unlike toxicity in non-target cells / tissues, target cell toxicity is not always unwanted (e.g. toxicity in cancer cells) [1].

Some cytotoxic drugs have a safety profile tolerable by CNS, because efflux transporters can protect against their penetration into the central nervous system. The ABCB1 substrate ivermectin, a neurotoxic pesticide, shows CNS toxicity when coadministered with ABCB1 inhibitor drug molecules. For example, Abcb1a knockout mice showed a 100-fold elevation in sensitivity to the toxic effect of ivermectin, and it appeared in the brain tissue in significantly higher amounts. Therefore, efflux transporters that limit BBB permeability and brain exposure to cytotoxic drugs is immensely important in limiting the central toxicity of drugs [1].

ABCC 3 transporters can contribute to the toxicological protective function, because they eliminate numerous toxic substances and their conjugates from epithelial tissues. A marked upregulation of $\mathrm{ABCC} 3$ was observed in the liver of $\mathrm{ABCC} 2$ deficient patients and animals indicating that the basolateral ABCC3-mediated efflux of toxic agents plays a key role when ABCC2- interacting medications are administered. A similar upregulation has been described in connection with to other transporters, too [1].

\subsection{Transporters studied and covered by the thesis}

$\mathrm{ABC}$ transporter proteins pump substrates against concentration gradient, that is, they enable active transport across biological membranes. The energy required for this process comes from the hydrolysis of ATP [1].

Structurally, these proteins consist of conserved ATP-binding domains (NBD) and transmembrane domains (TMD) (Figure 7). In mammals, four domains, two of each, form a transporter. This structure is called a 'full transporter' if the domains are within one polypeptide chain or 'half transporter' if the polypeptide chains harboring one NBD and one TMD domain are separate. Half transporters require dimerization to reach the appropriate structure for operation. Two polypeptides can form homo- or heterodimers. Each TMD forms six membrane-spanning alpha-helices. A total of 12 
helices form a pore-like structure and thus form a channel across the lipid bilayer. $\mathrm{ABC}$ transporters may take up an open or a closed conformation, which is regulated by ATP binding and hydrolysis [1].

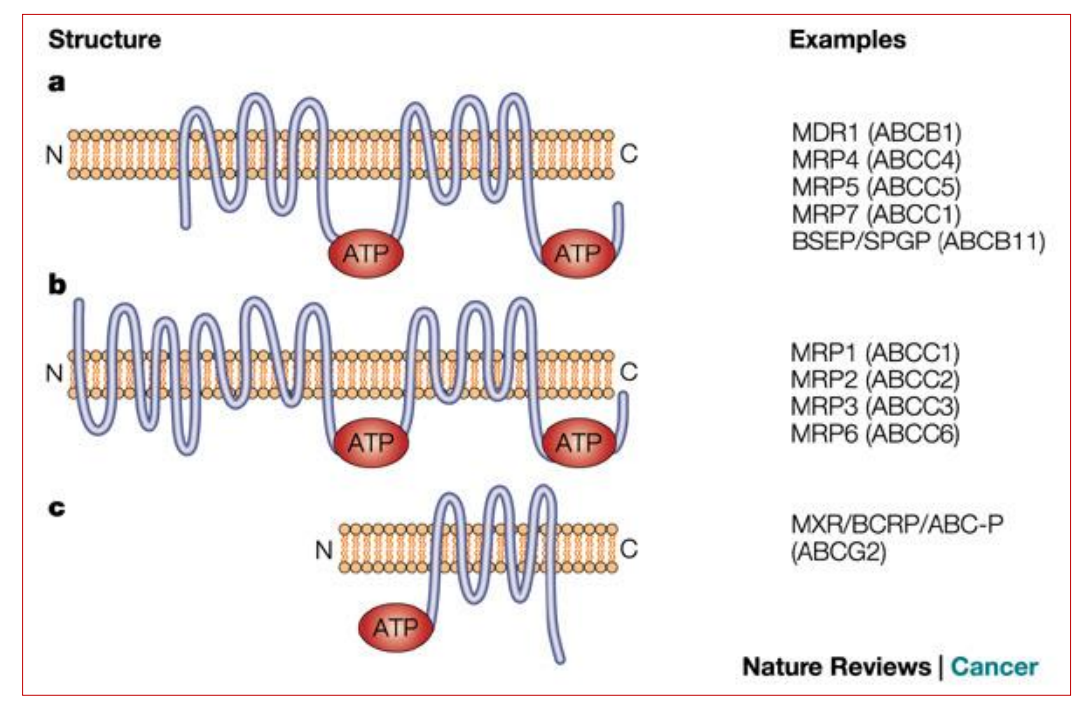

Figure 7. Structure of ABC transporters in the membrane [58]

In humans, there are $49 \mathrm{ABC}$ transporter genes [59, 60]. Based on the organization of domains and amino acid sequence homology, $\mathrm{ABC}$ transporters are classified into 7 distinct subfamilies, ranging from ABCA to ABCG [1].

Several human diseases can be traced back to mutations of the genes that code these proteins. These include Tangier disease and familial high-density lipoprotein (HDL) deficiency (ABCA1), Stargardt macular degeneration (ABCA4), cystic fibrosis (ABCC7), neurodegenerative diseases (ABCD1), atherosclerotic cardiovascular problems (ABCG5, ABCG8) or even defects in cholesterol and bile acid transport $(\mathrm{ABCC} 2, \mathrm{ABCB} 11)[1,7]$.

In this thesis only $\mathrm{ABCB} 1$ and $\mathrm{ABCG} 2$ are discussed in detail, as they have a remarkable role from a toxicological point of view.

\subsection{1. $A B C B 1$}

This protein (also known as P-gp/MDR1/ABCB1) was described in 1976 [61]. Structurally, it is TMD-NBD-TMD-NBD, as described above. The protein is glycosylated and localized in the apical/luminal membrane of polarized cells $[62,63]$. In the past 40 years, it has become the best characterized $\mathrm{ABC}$ transporter. 
It is present in secretory or barrier-forming cells like proximal tubule cells in the kidney, endothelial cells in the blood-brain barrier, enterocytes in the small intestine, hepatocytes in the liver or in cortical epithelial cells of adrenal glands [64]. Beyond the protective physiological functions against toxic compounds, overexpression of ABCB1 can lead to multidrug resistance in cancer cells $[1,2]$. Several studies found that $\mathrm{ABCB} 1$ overexpressing cells show a resistant phenotype to a range of drugs, including vincristine (mitotic inhibitor, chemotherapeutic agent), daunorubicin (chemotherapeutic agent), doxorubicin (chemotherapeutic agent) and, last but not least, colchicine (anti-inflammatory and cytostatic agent used in the therapy of gout) [11].

\subsection{2. $A B C G 2$}

ABCG2 (MXR/BCRP/ABCP) is one of the five half transporters belonging to the ABCG subfamily. The ABCG2 gene encodes a unique domain arrangement where, unlike in the case of ABCB1, the TMD is on the carboxyl-terminal side while NBD is located on the amino-terminal side [1,2]. ABCG2 functions as a dimer, although multimeric structures have also been suggested.

ABCG2 is one of the three transporters causing drug resistance in mammalian cells. ABCG2 protein is located in the apical membrane in polarized cells, where they mediate uni-directional active efflux [33].

This transporter protein serves two main functions. On the one hand, ABCG2 limits the distribution of its substrates into tissues / organs like the brain, the intestines or the placenta, while on the other hand, it mediates the elimination of drugs and endogenous substrates in kidneys and in the liver. Typically, ABCG2 is co-expressed with $\mathrm{ABCB} 1$ throughout the body. They share their substrates, inhibitors and inducers. The substrates of ABCG2 are clinically important, structurally diverse drugs, including antibiotics, antiviral agents, statins or carcinogens. Furthermore, ABCG2 effectively transports conjugated organic anions and partial sulphate conjugates like estradiol-17-ß-glucuronide, estrone-3-sulphate or dehydroepiandrosterone-sulphate $[2,11,33]$.

The most data are available on the wild type ABCG2 protein. Nevertheless, more than 80 single nucleotide polymorphisms have been described in humans. Based on 
the results, fortunately, only a few of them affect the transport activity of ABCG2. One and possibly the most studied variant is Q141K, which is a glutamine to lysine amino acid exchange in position 141, which affects a significant proportion of the Japanese and Chinese population $[11,33]$.

\subsection{Subcellular localization}

The proper lipid environment is important for the optimal function of proteins. The phospholipid composition of the cells affects the physicochemical properties of the membrane. The hidden rigid cholesterol molecules reduce membrane fluidity and stabilize lipid packing. Transporters are dynamic membrane proteins with an extensive protein-lipid interface. The physicochemical properties of the membrane can affect the folding and conformational changes of these proteins.

Several kinds of efflux transporters are localized in cholesterol rich membrane microdomains (rafts, caveoli) [41, 65]. Studies demonstrate that the cholesterol content of mammalian membranes is about $20 \%$, and in rafts and caveoli it is significantly higher. Insect membranes contain very low levels of cholesterol; therefore, it is a suboptimal expression environment for these ABC transporters. Loading insect membranes with cholesterol improves protein function in the membrane. Several transporters have been shown to interact with proteins localized specifically in the caveoli (e.g. caveolin-1).

\subsection{Properties of different (membrane-based and cellular) methods}

The estimation of renal and hepatic elimination rate and the characterization of transport mechanisms of drugs are usually based on in vitro studies applying animalderived tissues, cells and membrane vesicles. These in vitro experiments are used as complements of or partial substitutes for in vivo animal studies during drug discovery and development.

\subsubsection{Membranes and membrane-based assays}

Membrane preparations should be made of cells overexpressing the protein of interest. These cells can originate from insect or mammalian cells. Insect cell-based expression utilizes baculovirus vectors and usually uses Spodoptera frugiperda, Sf9 cells. In the case of mammalian cells, there are two ways to reach protein 
overexpression: drug selection and transfection/infection. The advantage of the application of insect cells is the yield. Extremely high expression rates are achievable with Sf9 cells, much higher than with mammalian cells. On the other hand, the latter system provides a more physiological environment and higher turnover. Membranebased assays have been extensively covered by recent reviews [66, 67]. Here I revisit only the basics.

\section{- The ATPase assay}

The principle of this method is that $\mathrm{ABC}$ transporter proteins actively transport molecules against the concentration gradient using ATP hydrolysis as energy source, which leads to the generation of inorganic phosphate $(\mathrm{Pi})$. This phosphate can be detected by colorimetric reaction (Figure 8). This method provides information only about the presence or absence of interaction, therefore, complementary studies (transport assays) are required to explore the mechanism of drug - substrate interactions. $\mathrm{EC}_{50}$ is the concentration of a drug that elicits half-maximal response and $\mathrm{IC}_{50}$ defines the concentration of an inhibitor at which the response is reduced by half.

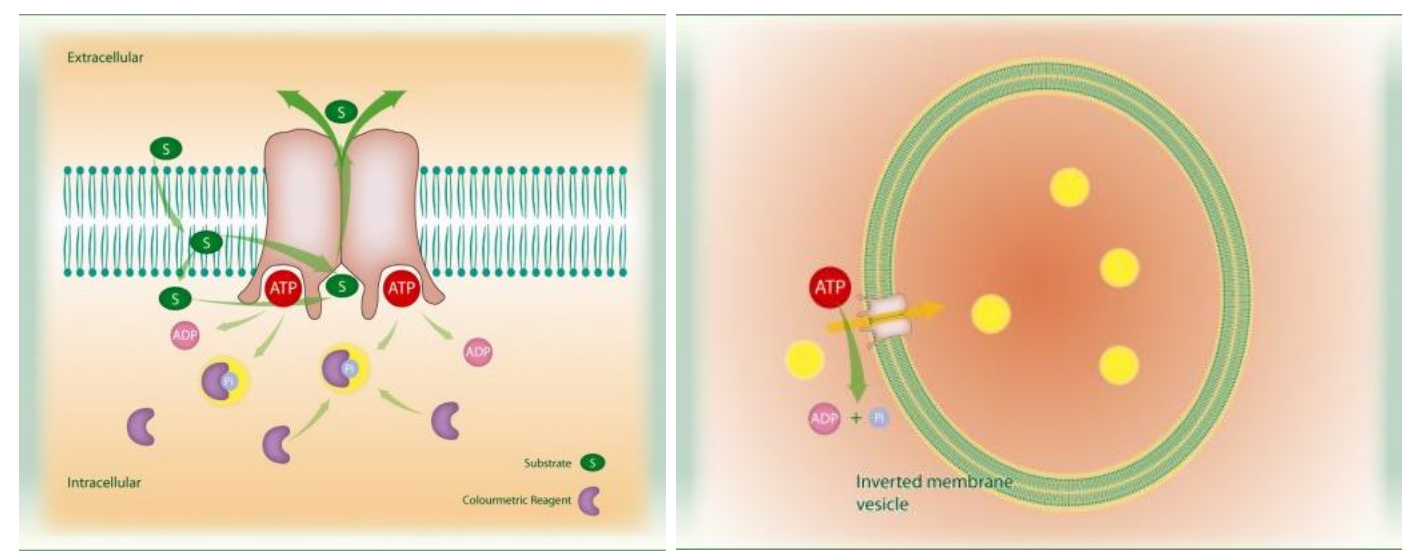

Figure 8. The working principle of the (A) ATPase assay (B) vesicular transport assay (SOLVO Biotechnology)

\section{- The vesicular transport (VT) assay}

Membrane preparations made under appropriate conditions always contain inside-out vesicles. Substrates of the transporter are taken up into vesicles in an ATP dependent manner (Figure 8). 
There are two setups available. Which of the two is used depends on the desired result. In substrate assays, the direct transport of the substrate is measured, while in inhibitor assays, inhibition of the transport of the reporter substrate is determined. The former setup is suitable for measuring drug-transporter interactions, while the latter one is optimal for drug-drug interaction studies. However, the nature of the interaction cannot be determined from the result of an inhibition type VT measurement [66].

\subsubsection{Cellular assays}

These methods can provide fast, reproducible and comparable results compared to in vivo assays. At the same time, limitations could be the stability of the cell line, the variability of the expression level of proteins, the possible presence of an endogenous transporter in parental cells (unless it is an immortalized cell where endogenous transporters are studied), or the in vivo relevance of the results in certain cases.

\section{- Cellular efflux}

In this type of assay, the effect of a test article on $\mathrm{ABC}$ efflux transporter-expressing cells is measured (e.g. hematological tumor cells). Cells are incubated with the compound of interest. Than an easily detectable, preferably fluorescent (reporter) substrate is added. Then the fluorescence of the cell population is measured. Cells that express more efflux transporters extrude substrate faster, thus, give lower fluorescence signal. The use of positive control is highly recommended [67].

\section{- Cytotoxicity}

In these experiments, the effect of a molecule on $\mathrm{ABC}$ transporter overexpressing and non-overexpressing parental cells is examined. ABC transporters can protect cells from the toxic impact, therefore transporter-overexpressing cells remain viable even at higher drug concentrations than controls. Furthermore, application of a transporterspecific reversing agent could reverse the protective function of the transporter protein.

\section{- Dye efflux}

This is an inhibition assay and a dye is the reporter substrate. In the presence of the active efflux transporter, the amount of the cell-associated dye is low. In the presence of a transporter inhibitor, the rate of dye efflux decreases, hence, the amount of the cell-associated dye increases. The inhibitor is the test drug and is applied at different 
concentrations. The use of fluorescent dyes is preferable. Application of a nonfluorescent precursor makes washing unnecessary and makes the application of multiwell plates possible.

For example, in the case of $\mathrm{ABCB} 1$ and $\mathrm{ABCC} 1 \mathrm{Calcein} A \mathrm{M}$ is used [68-70], while in the case of ABCG2, the most frequently applied dye is Hoechst 33342 [71].

\section{- Monolayer assay}

Monolayer assays are regarded as the most sophisticated in vitro tools for medium to high throughput modeling of important pharmacokinetic barriers. Appropriate cells polarize in culture on the semipermeable plastic membrane surface and form a tight monolayer via tight junctions. In this type of assay, the cell layer creates two definitely demarcated compartments, the upper or apical (A) and lower or basolateral (B) compartments. Any material movement across the cell layer will be defined by interactions with expressed transporters. The unidirectional flux of the test drug is determined by adding it to one compartment and monitoring the time-resolved redistribution of the test molecule between the two compartments. In a bidirectional assay, the test molecule is administered to one compartment and sampled from the other in the presence or absence of a specific inhibitor on control and transporter overexpressing cells. With a bidirectional setup, the efflux ratio (ER) can be determined $[66,67,72]$.

\subsection{Characteristics of the expression systems}

\subsubsection{Insect cell membranes}

The functional expression of $\mathrm{ABC}$ transporters within insect cell membranes meant a significant step forward [73]. The detection of ATPase activity of ABC transporters expressed in insect cell systems was pioneered by a Hungarian researcher, Balázs Sarkadi [74].

Insect cell membranes have both advantages and disadvantages. The lack of background transport by other human transporters and the very high expression levels are advantages. The high expression levels make insect cell membranes expressing ABC transporters ideal for ATPase assays. The divergence from the mammalian membrane environment is a definite disadvantage. This should be kept in mind when data are analyzed. 


\subsubsection{Mammalian cell membranes}

Mammalian membranes have a higher cholesterol content than insect membranes, which provides a better environment for the function of $\mathrm{ABC}$ transporters. Furthermore, the glycosylation pattern and the structure are both physiologically relevant. Membrane preparations from mammalian cells or even more from human cells are ideal for vesicular transport assays, as the expression level does not need to be that high and with the higher turnover number for most meaningful transportersubstrate pairs the transport rate provided by this system makes this method applicable. There are several methods to modify mammalian cells in a way that they express the transporter of interest:

\section{- Simple transfection (pcDNA3.1)}

During simple transfection, foreign genetic material is transferred into cells. The easiest way is to use a virus or a plasmid. The known gene sequence of the protein of interest can be packed into the viral genome to elicit its expression within the host cell. Alternatively, transporter cDNAs can be cloned into a plasmid that can be transfected into recipient cells by various methods $[75,76]$.

- $\quad$ The FlpIn system

The FlpIn system reduces the chance of ad hoc insertion by providing a specific 'Flp Recombination Target' site for genes, which ensures that they are inserted into the same position in the host cell genome [77-79].

\section{- Lentiviral constructs}

Lentiviruses are retroviruses. While most retroviruses are only able to infect dividing cells, lentiviruses, due to their ability to actively penetrate through the nuclear membrane, can infect both dividing and non-dividing cells. They can be used both in vivo and in vitro. Lentiviruses integrate into the host cell genome. For further details, see Sadelain [80].

\section{- Adenoviral constructs}

Recombinant adenoviral vectors are among the most effective vectors for transient infection/transfection. They are popular because they are easy to manufacture, high viral titers can be reached, and it does not matter if the cell is dividing. Furthermore, relatively large inserts can be applied. Adenoviral vectors do not integrate into the 
cellular genome. They remain episomal, and thus, provide a transient expression system $[81,82]$.

\subsubsection{Cell types}

There are several kind and type of cells which are used in cell-based experiments by researchers. Normally cells are unable to replicate after several rounds of proliferation due to shortening of telomeres after each round of proliferation. When telomeres reach a critically reduced length, DNA damage is triggered leading to cellular senescence [83]. Cells must be manipulated to become immortal. Below the three main categories of cells are mentioned.

\section{- Primary cells}

Cells isolated from tissues or organs are called primary cells. These are normal, nontransformed and non-immortalized cells with heterogeneous appearance and limited lifetime. Genetically and functionally, primary cells are more similar to in vivo cells than to immortalized cell lines.

\section{- Immortalized cells}

Immortalized cell lines are very important for biochemical, biotechnological and cell biological studies of multicellular organisms. Due to natural or induced mutations, these immortalized cells are capable of undergoing a high number of cell divisions. As an advantage, they can be cultured in vitro for a long period of time via their unlimited passaging.

\section{- Transfected cells}

The principle of transfection is the same as that of transformation, but while in the latter case the target cells are bacteria, transfection works with mammalian cells. The most common method is chemical transfection, where the negatively charged DNA binds to a cationic carrier and this complex enters into the cell [84]. 


\section{Aims}

This thesis consists of three parts. In each part, the effects of drug molecules on barriers made up of MDR transporters are described.

The first part is about the interaction of the BBB with seliciclib. In this part, the aim was i) to identify the transporter responsible for the low brain exposure of seliciclib, and ii) to characterize seliciclib's interaction with ABCB1.

In the second part, we focused on the interactions of chlorothiazide and the impact of this diuretic on the kidney barrier. We investigated i) if the three major apically located intestinal efflux transporters, $\mathrm{ABCB} 1, \mathrm{ABCG} 2$ or $\mathrm{ABCC} 2$ can modulate the permeability of chlorothiazide, ii) the impact of interaction(s) with the abovementioned efflux transporters, iii) the effect of chlorothiazide on ABCG2-mediated urate transport.

Finally, in the third part, FTC-Ko analogs were synthesized, in which the ester linkage was replaced by amide or alkyl chains. We studied the specificity and structure-activity relationships of the molecules. This part was carried out in cooperation with Professor Gábor Tóth's group at the Department of Medical Chemistry, University of Szeged. 


\section{Materials and Methods}

\subsection{Chemicals}

Seliciclib (CYC202, R-roscovitine [2-(1-ethyl-2-hydroxyethylamino)-6benzylamino-9-isopropylpurine]) powder was kindly provided by the Institute de Chimie Organique, Université René Descartes, Paris, France (Hervé Galons). [(2R)Anti-5-\{3-[4-(10,11-difluoromethanodibenzosuber-5-yl)piperazin-1-yl]-2hydroxypropoxy quinoline (LY335979) was synthesized as described previously [85]. [3H]N-methyl-quinidine (NMQ) was provided by Dr. Csaba Tömböly (Biological Research Center, Szeged, Hungary). [3H]Estradiol-17-ß-D-glucuronide $(\mathrm{E} 217 ß \mathrm{G})(41.8 \mathrm{Ci} / \mathrm{mmol})$ and $[3 \mathrm{H}]$ Estrone-3-sulfate $(\mathrm{E} 3 \mathrm{~S})(54.3 \mathrm{Ci} / \mathrm{mmol})$ (PerkinElmer Life and Analytical Sciences, Boston, MA, USA) were purchased from Medinspect Kft. (Fót, Hungary). Ko134 was provided by Solvo Biotechnology (Szeged, Hungary), while Ko143 was obtained from Professor Gerrit-Jan Koomen (U. Amsterdam, Amsterdam, The Netherlands). Advanced RPMI 1640 (Invitrogen, Carlsbad, CA) was purchased from Csertex Kft. (Budapest, Hungary). Fetal bovine serum (Lonza, Basel, Switzerland), Eagle's Minimum Essential Medium (EMEM, Lonza), Dulbecco's modified Eagle's medium (Lonza), and penicillin-streptomycin (Lonza) were purchased from Biocenter Kft. (Szeged, Hungary). The mouse antiABCB1 monoclonal antibody C-219 (Abcam) was purchased from Biomarker Kft., and the anti-mouse IgG-horseradish peroxidase (HRP) secondary antibody, an HRPconjugated, species-specific whole antibody was purchased from Sigma Hungary (Budapest, Hungary). Western Lightning Plus-ECL (PerkinElmer Life and Analytical Sciences, Waltham, MA) was ordered from Per-Form Hungary Kft. (Budapest, Hungary). Calcein AM (Invitrogen) was purchased from Invitrogen Hungary (Budapest, Hungary), chlorothiazide, verapamil, Hoechst 33342, and other chemicals were all purchased from Sigma Hungary (Budapest, Hungary), and were of analytical grade.

Fumitremorgin analogs belong to the class of indolyl diketopiperazine alkaloids containing 1,4-dioxo-2,3,6,7,12,12a-hexahydropyrazino[1'2':1,6]pyrido[3,4-b]indole skeleton. The solid- or solution-phase synthesis of fumitremorgin analogs are detailed in the article written by Szolomajer-Csikós in 2013 [III]. 


\subsection{Membranes}

Membrane vesicle preparations expressing the human ABCB1, ABCC2, and ABCG2 transporters were produced by Solvo Biotechnology (Szeged, Hungary) from baculovirus-infected Sf9 cells (MDR1-Sf9, MRP2-Sf9, and BCRP-HAM-Sf9, respectively) and from ABCG2-overexpressing mammalian cells (BCRP-M) and its control (M-Ctrl).

\subsection{Cell lines}

The ABCB1-overexpressing chronic myeloid leukemia cell line K562-MDR, the ABCC1-overexpressing human promyelocytic leukemia HL60-MRP cells and the ABCG2-overexpressing human breast cancer epithelial cells MCF7-MX were kindly provided by Professor Balázs Sarkadi (National Blood Transfusion Service, Budapest, Hungary); MDCKII-MDR1, PLB985-BCRP [71], and parental cells were kindly provided by Dr. Katalin Német (National Blood Transfusion Service). MDCKII-BCRP cells originally obtained from Professor Heyo Klaus Kroemer at University of Greifswald (Greifswald, Germany). MDCKII cells were kindly provided by Professor Kai Simons at Max Planck Institute (Dresden, Germany). The Caco-2 cell line was obtained from American Type Culture Collection (ATCC). K562-MDR and HL60-MRP cells were maintained in Advanced RPMI 1640, MCF7MX, MDCKII, MDCKII-BCRP and MDCKII-MDR1 cells were cultured in Dulbecco's modified Eagle's medium (DMEM) supplemented with $1 \mathrm{~g} / \mathrm{L}$ glucose and $1 \%$ non-essential amino acids. Caco-2 cells were kept in EMEM containing 1\% non-essential amino acids. All media were supplemented with $10 \%$ (v/v) heatinactivated fetal bovine serum, $2 \mathrm{mM}$ L-glutamine, and $100 \mu \mathrm{g} / \mathrm{ml}$ penicillinstreptomycin and were grown under standard conditions $\left(5 \% \mathrm{CO}_{2}\right.$ and $\left.37^{\circ} \mathrm{C}\right)$.

\subsection{ATPase activity}

$\mathrm{ABC}$ transporter-overexpressing membrane preparations show vanadate-sensitive ATPase activity that is modulated by interacting compounds. ATPase activity was measured as described previously [72]. In brief, the rate of ATP hydrolysis was determined by measuring the liberation of inorganic phosphate using PREDEASY ATPase kits for ABCB1, ABCC1, ABCC2, ABCG2 and ABCG2-HAM from SOLVO Biotechnology and used according to the manufacturer's instructions. Membrane vesicles were incubated with various concentrations of test drugs with or 
without $1.2 \mathrm{mM}$ sodium orthovanadate. ATPase activities were determined as the difference of inorganic phosphate liberation measured in the presence and absence of $1.2 \mathrm{mM}$ sodium orthovanadate, an inhibitor of $\mathrm{ABC}$ efflux pumps. Results are presented as vanadate-sensitive ATPase activities.

\subsection{Vesicular transport assay}

The interaction of seliciclib with the transporter was detected as the modulation of the initial rate of $[3 \mathrm{H}]$ NMQ transport into the membrane vesicles. The vesicular transport assay was performed using a PREDIVEZ kit for human ABCB1, according to the manufacturer's recommendations. Chlorothiazide inhibition experiments using vesicular transport and employing $\mathrm{ABCB} 1-, \mathrm{ABCC} 2-$ and $\mathrm{ABCG} 2$-overexpressing Sf9 membranes were performed according to the manufacturer's suggestions, using $4 \mathrm{mM}$ ATP and $[3 \mathrm{H}] \mathrm{NMQ},[3 \mathrm{H}] \mathrm{E} 217 ß \mathrm{G}$, and $[3 \mathrm{H}] \mathrm{E} 3 \mathrm{~S}$ as probe substrates for $\mathrm{ABCB} 1, \mathrm{ABCC} 2$, and $\mathrm{ABCG} 2$, respectively. In brief, membrane fractions containing inside-out membrane vesicles were incubated in a 96-well plate in the presence or absence of ATP using [3H] NMQ, [3H] E217ßG or [3H] E3S as the probe substrate. The transport was stopped by addition of cold washing buffer and consecutive rapid filtration through Millipore B glass fiber filters of a 96-well filter plate (Millipore Corporation, Billerica, MA). Filters were washed five times with $200 \mu 1$ of ice-cold wash buffer and dried, and the retained radioactivity was measured in scintillation cocktail (Packard UltimaGold; PerkinElmer Life and Analytical Sciences) using a Wallac MicroBeta TriLux liquid scintillation analyzer. ATP-dependent transport was calculated by subtracting the values obtained in the absence of ATP from those in the presence of ATP. Quantitation of chlorothiazide was done by LC/MS as described below.

\subsection{Hoechst assay}

Hoechst 33342 intercalates DNA, yielding a fluorescent product that can be detected. The presence of ABCG2 in the cell membrane strongly reduces Hoechst 33342 accumulation because Hoechst 33342 is a substrate of ABCG2. Inhibitors of ABCG2 induce an increased rate of accumulation. The Hoechst assay was performed as described earlier [71]. In brief, accumulation of Hoechst 33342 dye was measured in a fluorimeter (Fluoroskan Ascent Type 374; Thermo Labsystems, Helsinki, Finland) at $350 \mathrm{~nm}$ (excitation) and $460 \mathrm{~nm}$ (emission) by using PLB985-BCRP cells. The 
cells were preincubated at $37^{\circ} \mathrm{C}$ in $150 \mu \mathrm{l} 1 \mathrm{x}$ HBSS with drugs for $30 \mathrm{~min}$. The Hoechst 33342 dye was added in $50 \mu \mathrm{l}$ at a final concentration of $12.5 \mu \mathrm{M}$. Fluorescence intensities were recorded for $15 \mathrm{~min}$. Positive control measurements to determine $100 \%$ inhibition were performed in the presence of $400 \mathrm{nM}$ Ko134, a specific ABCG2 inhibitor [86], for seliciclib and $1 \mu \mathrm{M}$ Ko134 for chlorothiazide.

\subsection{Calcein assay}

Calcein AM penetrates the plasma membrane by passive diffusion. Intracellularly, calcein AM is hydrolyzed by endogenous esterases, yielding a fluorescent product, calcein, which can be detected. The presence of ABCB1 or ABCC1 in the cell membrane strongly reduces calcein accumulation because calcein AM is a substrate of these both transporters. Inhibitors of $\mathrm{ABCB} 1$ and $\mathrm{ABCC} 1$ induce an increased rate of accumulation. The calcein assay was performed as described earlier [72]. In brief, accumulation of the calcein dye was measured in a fluorimeter (Fluoroskan Ascent Type 374) at $485 \mathrm{~nm}$ (excitation) and $538 \mathrm{~nm}$ (emission) by using K562-MDR or HL60-MRP cells. Cells (80,000/well) were incubated in $100 \mu \mathrm{l}$ of Hanks' balanced salt solution in the presence of the test compound or positive control for $15 \mathrm{~min}$. After the incubation, calcein AM in $100 \mu 1$ of HBSS was added at a final concentration of $0.25 \mu \mathrm{M}$. Fluorescence intensities were recorded for $8 \mathrm{~min}$. Positive control measurements to determine $100 \%$ inhibition were obtained in the presence of $60 \mu \mathrm{M}$ verapamil.

\subsection{Western blotting}

The proteins were separated using a $10 \%$ polyacrylamide gel and transferred to polyvinylidene difluoride membrane (Immobilon-P; Millipore Corporation) at 350 $\mathrm{mA}$ in a transfer buffer composed of $25 \mathrm{mM}$ Tris, $192 \mathrm{mM}$ glycine, and 15\% (v/v) methanol, $\mathrm{pH}$ 8.3. The membrane was treated with blocking buffer (5\% nonfat dry milk powder and $0.5 \%$ bovine serum albumin in phosphate-buffered saline with $0.05 \%$ Tween 20) for $2 \mathrm{~h}$ at room temperature. The membrane was then incubated with the primary antibody, a mouse anti-ABCB1 monoclonal antibody C-219, diluted 1:3000 in blocking buffer for $2 \mathrm{~h}$ at room temperature. The membrane was washed three times for 10 min each with phosphate-buffered saline- $0.05 \%$ Tween 20 at room temperature. It was then incubated with the secondary antibody, anti-mouse IgGHRP, a horseradish peroxidase-conjugated species-specific whole antibody diluted 
1:5000 in blocking buffer for $1 \mathrm{~h}$ at room temperature. The membrane was subsequently washed as described above, and immunoreactive bands were visualized with enhanced chemiluminescence.

\subsection{Cytotoxicity assay}

Cytotoxicity assays were performed by seeding HL60 (50,000 cells/well), HL60MDR1 (50,000 cells/well), K562 (50,000 cells/well), K562-MDR (50,000 cells/well), MDCKII-wt (1000 cells/well), and MDCKII-MDR1 (1000 cells/well) in 96-well plates containing the culture medium (200 $\mu \mathrm{l} /$ well). After $24 \mathrm{~h}$, drugs were prediluted in medium and added to the cells at different concentrations as shown in the figures. The cells were further incubated with the drug in a humidified tissue culture chamber $\left(37^{\circ} \mathrm{C}\right.$ and $\left.5 \% \mathrm{CO}_{2}\right)$ for $96 \mathrm{~h}$. Surviving cells were detected by the MTS method [87]. IC $_{50}$ values were calculated from dose-response curves (i.e., cell survival versus drug concentration) obtained in triplicate experiments.

\subsection{Monolayer assay}

Transport assays across MDCKII-wt and MDCKII-MDR1 cells were performed described previously [72]. Cells were seeded on Millicell 24 (Millipore, Carrigtwohil, Ireland) devices according to the manufacturer's instructions. Seliciclib $(5 \mu \mathrm{M})$ was added without the ABCB1 inhibitor, LY335979 $(1 \mu \mathrm{M})$, to the medium at either the basolateral or apical compartment. Samples were taken from the receptor chamber at 15, 30, 60, and $120 \mathrm{~min}$. Concentrations of seliciclib were determined using an Agilent 1100 series high-performance liquid chromatograph equipped with a mass selective detector (Quad VL System, Agilent, Waldbronn, Germany). Samples from the 60-min point were used for the determination of the apparent permeability coefficient $\left(\mathrm{P}_{\mathrm{app}}\right)$ calculations.

In the case of the chlorothiazide monolayer studies, MDCKII and MDCKII-BCRP cells $(500,000$ cells/well) were plated onto permeable polycarbonate supports with $0.7 \mathrm{~cm}^{2}$ filter area and $0.4 \mu \mathrm{m}$ pore size (Millipore Millicell, Millipore Hungary, Budapest, Hungary). Media were replaced with fresh media on day three, and transport experiments were conducted on day four. When using Caco- 2 cells $(60,000$ cells/well) were plated, as described above. Media were replaced three times per week, and the transport experiments were conducted on days 21-25. All reaction mixtures were prepared in Hank's Balanced Saline Solution (HBSS), pH 7.4. 
Compounds were diluted from dimethyl sulfoxide (DMSO) stocks to $100 \mu \mathrm{M}$ (chlorothiazide) and $1 \mu \mathrm{M}$ (Ko143) final concentration. DMSO content was leveled below $0.5 \%(\mathrm{v} / \mathrm{v})$ in all wells. Ko143 was applied to both the donor and the receiver compartments. Media were removed, and filters were rinsed twice with prewarmed $\left(37^{\circ} \mathrm{C}\right) \mathrm{HBSS}$. After a $15-\mathrm{min}$ incubation period, HBSS was removed and the reaction was started with addition of the appropriate reaction mixtures. Transport lasted for $120 \mathrm{~min}$. Samples from the donor compartments were taken at $0 \mathrm{~min}$, samples from the receptor compartments were taken at 15, 30, 60 and 120 min. Determination of chlorothiazide is described below in the bioanalytical quantification section.

\subsection{Bioanalytical quantitation of chlorothiazide}

Concentration of chlorothiazide in the samples was determined with the Agilent 1100-Series HPLC System equipped with a mass selective detector (Quad VL System Agilent, Santa Clara, CA, USA). The analytical column was a Synergy $2.5 \mu$ FusionRP 100 ångström Mercury, 20 x 4.0 mm (Phenomenex, Torrance, CA, USA) in combination with a Zorbax Eclipse Plus-C8 Narrow Bore Guard Column, 2.1 x 12.5 $\mathrm{mm}, 5 \mu$ (Agilent Santa Clara, CA, USA). The mobile phases were 0.05\% (v/v) acetic acid (A) and acetonitrile (B) with an isocratic elution $(\mathrm{B}=10 \%)$. The flow rate was $0.5 \mathrm{ml} / \mathrm{min}$ and the column oven temperature was $25^{\circ} \mathrm{C}$. Single ion monitoring was used for data acquisition (negative mode, $\mathrm{m} / \mathrm{z}=293.7$ ).

\subsection{Data analysis}

All assays were run in duplicate unless indicated otherwise. $\mathrm{K}_{\mathrm{m}}$ and $\mathrm{V}_{\max }$ values from direct transport measurements were calculated using the Michaelis-Menten equation:

$$
V=\frac{V_{\max } x[S]}{[S]+K_{m}}
$$

where $\mathrm{V}$ is velocity (picomoles of substrate per milligram of protein per minute), Vmax is maximal velocity, $[\mathrm{S}]$ is substrate concentration (micromolar), and $\mathrm{K}_{\mathrm{m}}$ is the Michaelis-Menten constant. 
The calcein and the Hoechst assays were analyzed using the slope of the curve determined without inhibitors $\left(R_{\text {base }}\right)$, the slope of the curve in the presence of the inhibitor $\left(R_{\max }\right)$, and the slope of the curve determined for any drug at the given drug concentration $\left(R_{\mathrm{drug}}\right)$. The inhibition of dye extrusion is expressed as:

$$
\operatorname{Inhibition}(\%)=\frac{R_{\text {drug }}-R_{\text {base }}}{R_{\text {max }}-R_{\text {base }}} \times 100
$$

$\mathrm{IC}_{50}$ values were derived from these curves.

For the calculation of $P_{\text {app }}$, the following equation was used:

$$
P_{a p p}=\frac{d Q}{d T} x \frac{1}{A x C_{0}}
$$

where $\mathrm{dQ} / \mathrm{dT}$ is the amount of drug transported per time. $C_{0}$ is the initial concentration of the compound in the donor compartment, and $A$ is the membrane surface area in square centimeters (standard: 0.7 ). The efflux ratio is given as the $P_{\text {app }} \mathrm{B}-\mathrm{A} / P_{\text {app }} \mathrm{A}-\mathrm{B}$ apparent permeability ratio, where A means apical and B basolateral.

For curve fitting and $\mathrm{IC}_{50}$ calculations, GraphPad Prism 4.0 (GraphPad Software Inc., San Diego, CA) was used. For the statistical analyses, unpaired $t$ test was used [I].

Three levels of significance were used, and indicated as follows: $*$ : $<0.05 ; * *$ : $<<$ 0.01 ; ***: $\mathrm{p}<0.001$. 


\section{Results}

\subsection{ABCB1 / Seliciclib / BBB}

The following results demonstrate which BBB efflux transporters are in interaction with seliciclib.

ATPase assays were carried out on ABCB1-, ABCC1-, ABCC2- and ABCG2overexpressing insect membranes to test interactions of seliciclib with efflux transporters present in the BBB. Figure 9 shows that seliciclib interacts with ABCB1, $\mathrm{ABCC} 1$ and $\mathrm{ABCG} 2$, but not with $\mathrm{ABCC} 2$. The shapes of the curves show that seliciclib is an activator of ABCB1 (Figure 9A) but an inhibitor of ABCC1 (Figure 9B) and ABCG2 (Figure 9D). In the former case, however, the effect is elicited at very high concentrations. As for the ABCB1 transporter, the vanadate-sensitive ATPase activity was activated to the level of the positive control (verapamil) with an EC $_{50}$ value of $4.2 \mu \mathrm{M}$ (Table 1). The vanadate-sensitive ATPase activity in membranes overexpressing ABCG2 was not activated by seliciclib (Figure 9D). In addition, the activated ABCG2 as well as the basal vanadate-sensitive ABCG2 ATPase were inhibited by seliciclib (Figure 9D), albeit in a suprapharmacological concentration range (Table 1).

\begin{tabular}{|c|l|c|c|}
\hline $\begin{array}{c}\text { ABC } \\
\text { transporters }\end{array}$ & \multicolumn{1}{|c|}{ Assays } & EC $50(\boldsymbol{\mu M})$ & IC \\
\hline \multirow{3}{*}{ MDR1 $(\boldsymbol{\mu M})$} \\
\cline { 2 - 4 } & ATPase assay & 4.2 & - \\
\cline { 2 - 4 } & Vesicular transport assay & - & 35.5 \\
\cline { 2 - 4 } & Calcein assay & - & 11.5 \\
\hline \multirow{2}{*}{ BCRP } & ATPase assay & - & 63 \\
\cline { 2 - 4 } & Hoechst assay & - & 38 \\
\hline
\end{tabular}

Table 1. IC 50 and EC 50 values of seliciclib transport.

To verify that seliciclib interacts with $\mathrm{ABCB} 1$, vesicular transport assay (VT) and calcein assay were carried out. Seliciclib inhibited the transport of the probe substrate, $\mathrm{N}$-methyl-quinidine (NMQ) in the VT experiment with an $\mathrm{IC}_{50}$ of $35.5 \mu \mathrm{M}$ (Figure $10 \mathrm{~B})$. The drug showed interaction also in the calcein assay with an $\mathrm{IC}_{50}$ of $11.5 \mu \mathrm{M}$ (Figure 10A). The Hoechst assay confirmed the inhibition of ABCG2 by seliciclib with an $\mathrm{IC}_{50}$ of $38 \mu \mathrm{M}$ (Figure 10C) (Table 1). 


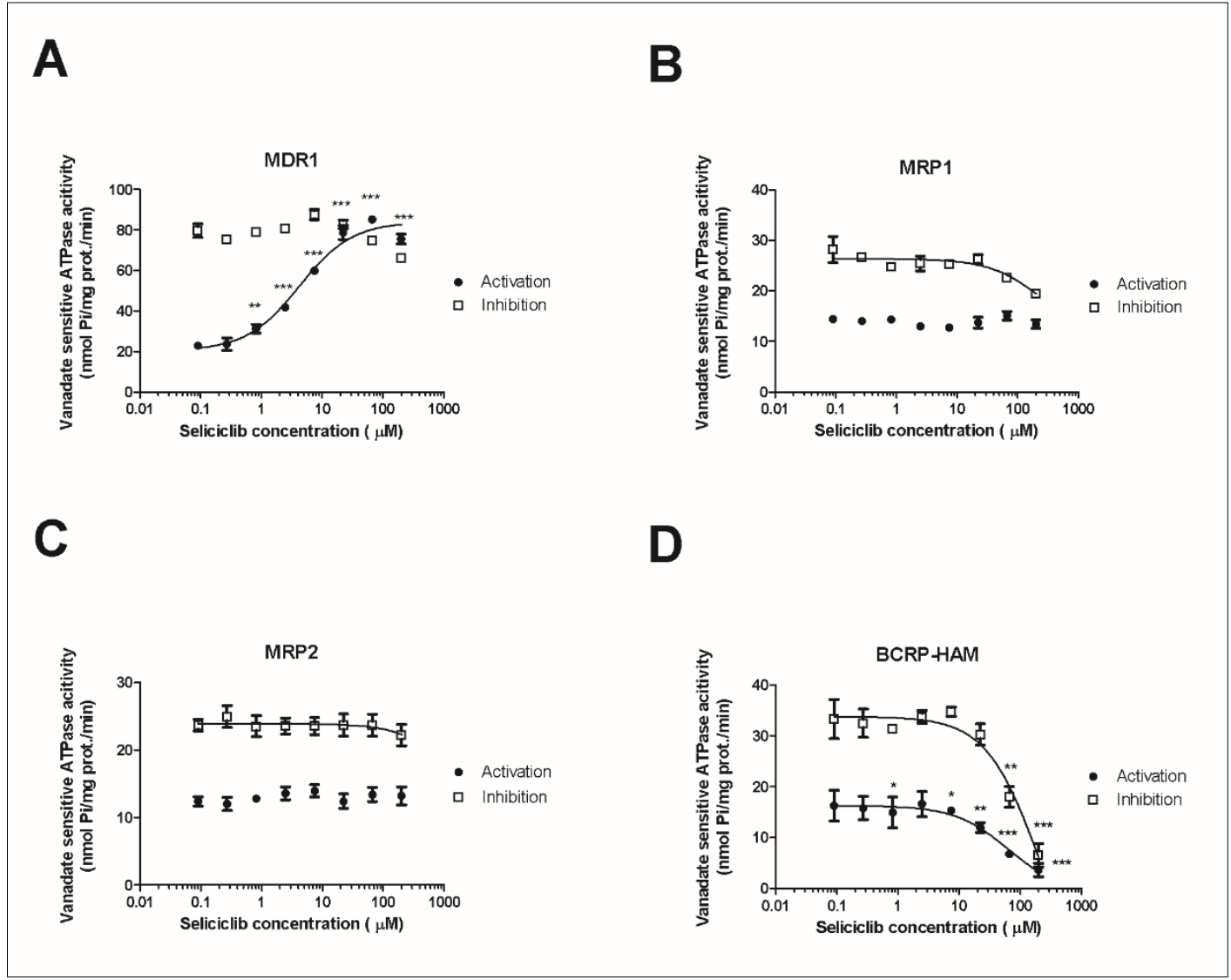

Figure 9. The vanadate-sensitive ATPase activity of (A) MDRl-Sf9, (B) MRP1-Sf9, (C) MRP2-Sf9 and (D) BCRP-HAM-Sf9 membrane preparations in the presence of seliciclib in activation (solid lines) and inhibition (dotted lines) experiments.

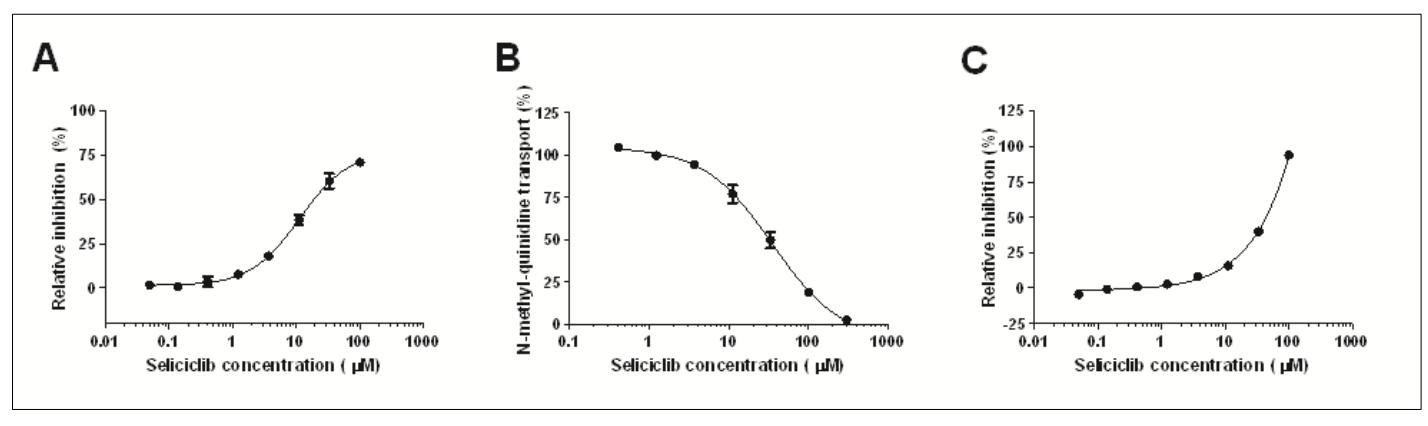

Figure 10. Inhibition of (A) calcein AM efflux from K562-MDR cells, (B) ATPdependent NMQ transport into MDRI-K inside-out vesicles and (C) Hoechst 33342 dye efflux from PLB985-BCRP cell by seliciclib. Inhibition of $(A)$ calcein AM efflux from K562-MDR cells, (B) ATP-dependent NMQ transport into MDR1-K inside-out vesicles and (C) Hoechst 33342 dye efflux from PLB985-BCRP cell by seliciclib. 
After having demonstrated that seliciclib is a transported substrate of ABCB1, we used MDCKII-MDR1 cells to confirm the transport. As Figure 11A indicates, MDCKII-MDR1 cells, unlike the parent cell line, significantly overexpress ABCB1. To further show the presence of ABCB1 in MDCKII-MDR1 cells, LY335979, an ABCB1-specific inhibitor, was used, in a calcein efflux assay [88]. Figure 11B shows that calcein fluorescence in MDCKII-MDR1 cells at the lowest applied LY335979 concentration was much lower than calcein fluorescence in the control cells. Furthermore, the curve of MDCKII-MDR1 reached approximately the same level as MDCKII wt cells in the presence of the highest concentration of LY335979.

A

MW MDCKII wt MDCKII-MDR1

$\underline{250}$

150

$\underline{100}$

75

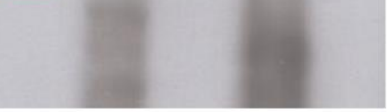

C
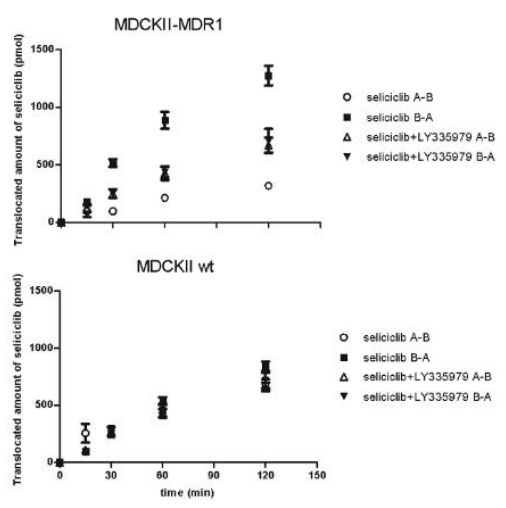

B

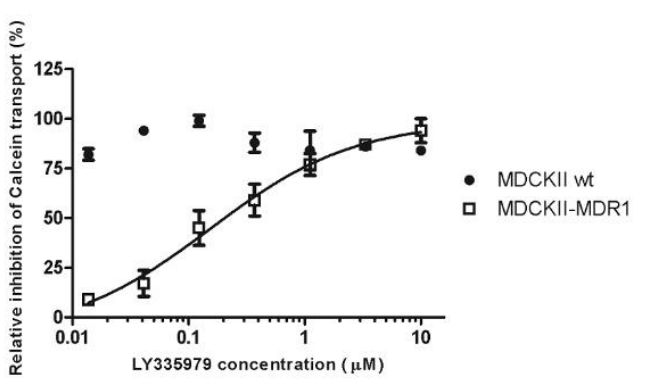

D

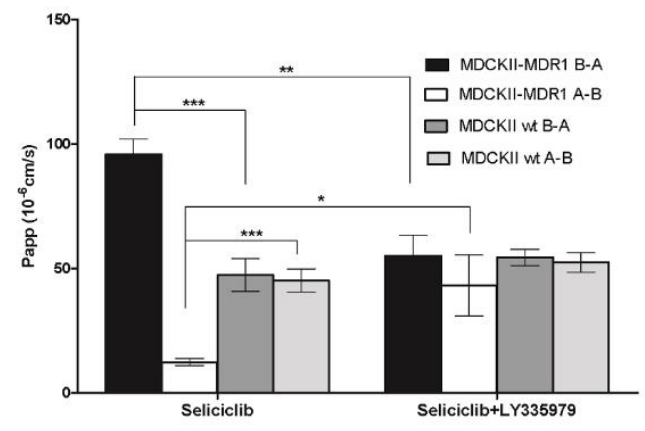

Figure 11. (A) characterization of MDCKII-MDRl cells in the calcein assay; (B, C) demonstration of the vectorial transport of seliciclib in monolayer efflux assays in MDCKII-MDR1 cells; (D) The Effect of ABCB1 on the apparent permeability of seliciclib determined by bidirectional transport across MDCKII-MDRI and control monolayers in the presence or absence of the specific ABCB1 inhibitor LY335979. 
In Figure $11 \mathrm{C}$ and D, the results of the vectorial transport assays using MDCKII wild type and MDCKII-MDR1 cells are shown. The permeability of seliciclib was comparable in both directions in wild type cells. However, in ABCB1-expressing cells, it was much higher in the basolateral to apical direction than the other way around. The efflux ratio of approximately 8 decreased to 1.2 when LY335979 was applied.

Thereafter, we wished to find out whether overexpression of ABCB1 leads to resistance against seliciclib. For this purpose, we used HL60-MDR1, K562-MDR, MDCKII-MDR1, and their parental cell lines. Our results show that the increased presence of $\mathrm{ABCB} 1$ does not imply resistance to seliciclib. The $\mathrm{IC}_{50}$ values of MDCKII-wt, $4.9 \pm 1.3 \mu \mathrm{M}$, and MDCKII-MDR1 cells, $7.1 \pm 1.6 \mu \mathrm{M}$ in cytotoxicity experiments were quite similar. Furthermore, the presence of LY335979 had no effect on the susceptibility to seliciclib in either cell line. In contrast, susceptibility to doxorubicin and paclitaxel showed considerable difference. No statistically significant difference was observed in the $\mathrm{IC}_{50}$ values for seliciclib in $\mathrm{K} 562$ and K562-MDR (45.9 \pm 5.94 versus $47.1 \pm 33.5 \mu \mathrm{M}$, respectively) or in HL60 and HL60MDR1 (12.6 \pm 4.6 versus $17.5 \pm 7.5 \mu \mathrm{M}$, respectively) cells.

Based on these, we can declare that although seliciclib is a transported substrate of $\mathrm{ABCB} 1$, this does not lead to resistance against the drug even if the protein is overexpressed. 


\subsection{ABCG2 / Chlorothiazide}

Chlorothiazide gets absorbed rapidly following oral administration, yet metabolically stable. Instead of being metabolized, it is eliminated rapidly by the kidneys in the human body [89]. Since this is a BCS/BDDCS Class IV drug, transporter proteins can considerably influence its ADE properties (Figure 7).

We tested in a vesicular transport inhibition assay whether it interacts with $A B C$ efflux transporters found in the intestine (Figure 12).

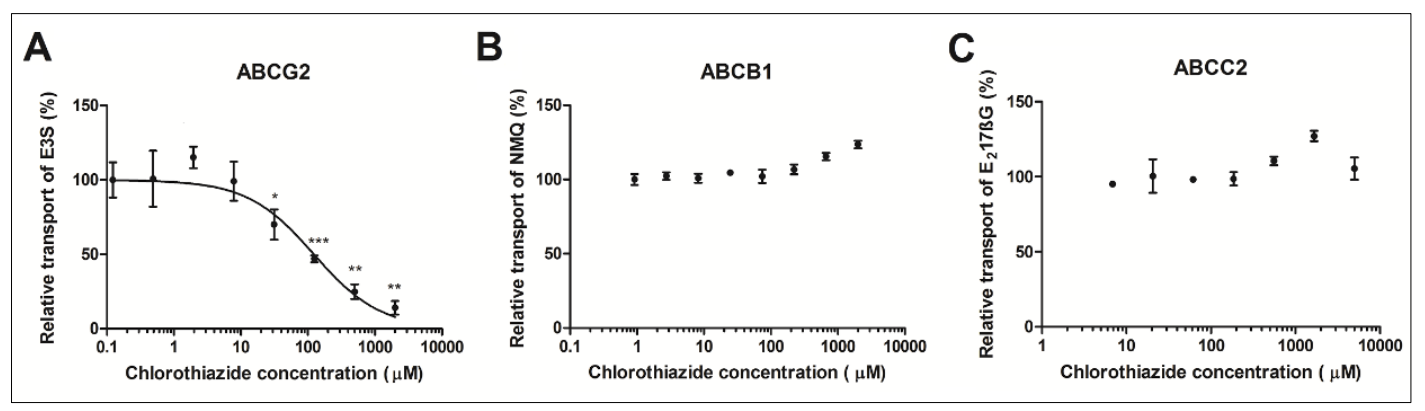

Figure 12. ATP dependent transport of [3H] Estrone-3-sulfate, [3H] N-methylquinidine, and [3H] Estradiol-17- $\beta$-D-glucuronide into (A) BCRP-HAM-Sf9, (B) $M D R 1-S f 9$ and $(C)$ MRP2-Sf9 vesicles, respectively, was measured in the presence of chlorothiazide at concentrations indicated in the figure.

Neither $\mathrm{ABCB} 1$ nor $\mathrm{ABCC} 2$ showed interaction with chlorothiazide. Nevertheless, specific interaction was revealed with ABCG2 (Figure 12).

For further characterization of the interaction of chlorothiazide with ABCG2, we carried out ATPase and VT assays (Figure 13). These experiments confirmed that this diuretic is a transported substrate of ABCG2. It activated the basal vanadatesensitive ATPase activity of $\mathrm{ABCG}_{2}$ with an $\mathrm{EC}_{50}$ value of $327.2 \pm 9.4 \mu \mathrm{M}$. In addition, it was characterized by a saturable vesicular transport curve in the direct type VT experiment, where the $\mathrm{K}_{\mathrm{m}}$ was $334.6 \pm 325.0 \mu \mathrm{M}$. These numbers show good correlation with the $\mathrm{IC}_{50}$ value $212.3 \pm 210.8 \mu \mathrm{M}$ of the previously mentioned vesicular transport inhibition assay. Membrane assays are the best in vitro option to determine $\mathrm{K}_{\mathrm{m}}$ values not affected by passive permeability. Chlorothiazide is a lowpermeability drug molecule and due to the properties of membrane assays the aforementioned $\mathrm{K}_{\mathrm{m}}$ value likely reflects the affinity of chlorothiazide to ABCG2. 


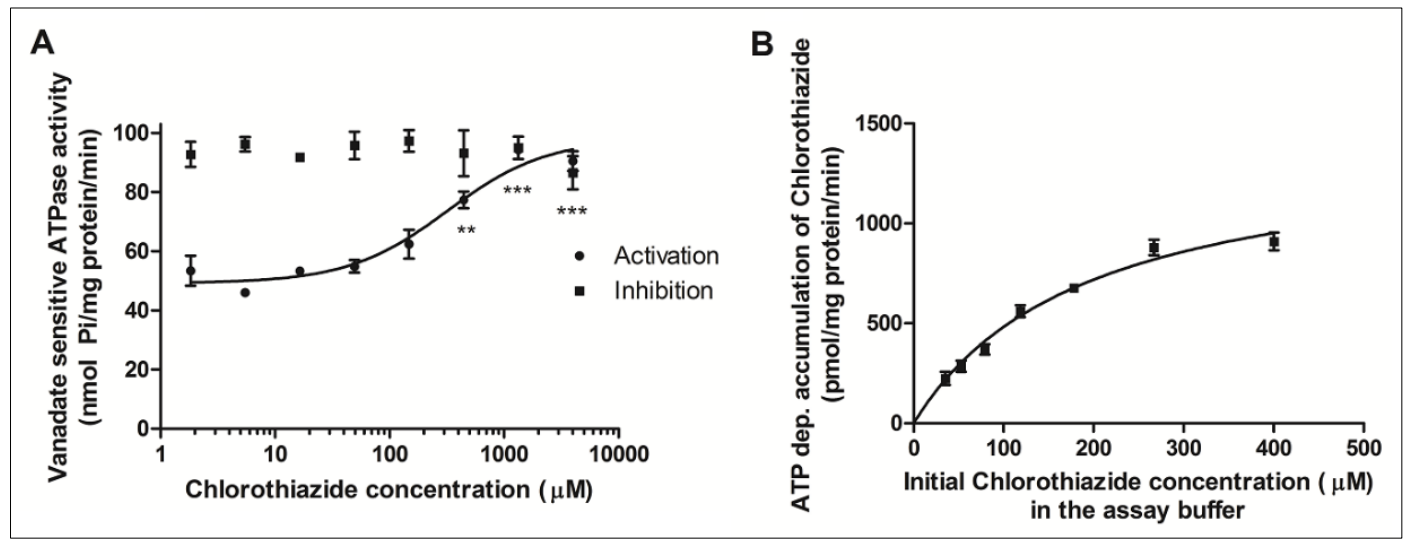

Figure 13. ABCG2-overexpressing BCRP-M membranes were incubated with increasing concentrations of chlorothiazide and (A) vanadate-sensitive ATPase activity in activation (filled circles) and inhibition mode (filled squares) as well as (B) ATP-dependent chlorothiazide transport into inside-out membrane vesicles was determined.

Cellular monolayer tests confirmed that the interaction with ABCG2 may modulate the ADME properties of chlorothiazide (Figure 14). In the monolayer efflux experiments MDCKII and Caco-2 cells were used. Both of these monolayer test systems are extensively characterized. Moreover, they are the most commonly used in vitro tools to predict the absorption of orally administered drugs. These experiments confirmed that $\mathrm{ABCG} 2$, an apical efflux transporter in the intestines, is likely to be limiting the absorption of chlorothiazide, contributing to its low bioavailability. ABCG2 is also expressed in the proximal tubular cells of the kidneys, and may, thus, contribute to renal secretion of the drug.

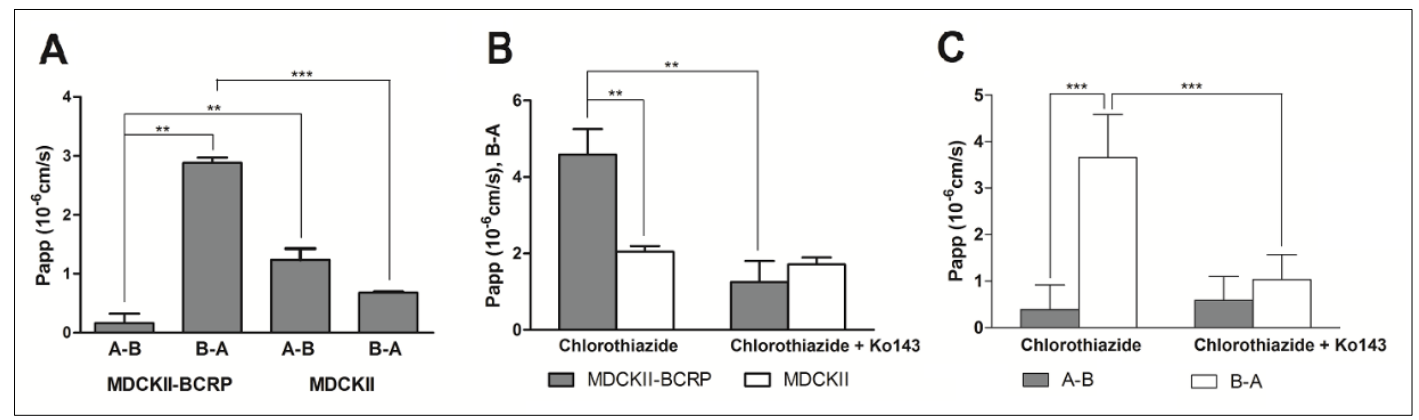

Figure 14. (A) Bidirectional permeability of chlorothiazide in ABCG2 transfected and parental MDCKII monolayers; $(B)$ the effect of Ko143, an ABCG2-specific inhibitor, on the B-A permeability of chlorothiazide in ABCG2-transfected and parental $M D C K I I$ monolayers and on $(C)$ the bidirectional permeability of chlorothiazide in Caco-2 monolayers. 


\subsection{Fumitremorgin $C$ analogs / Inhibition specificity of ABCG2}

ABCG2-inhibitory activity

Professor Gábor K Tóth's group at the Department of Medical Chemistry at the University of Szeged synthetized 16 tricyclic and 28 tetracyclic novel analogs devoid of ester linkages and we tested them for ABCG2 inhibition potency and specificity. Hoechst assay was used for the measurement of the ABCG2-inhibitory activity of the synthetized compounds. We used Ko134, a well-known specific ABCG2 inhibitor, as a positive control. In our study inhibition by $1 \mu \mathrm{M}$ Ko134 meant $100 \%$ inhibition. Initially, we applied compounds in $10 \mu \mathrm{M}$ as final concentration.

No inhibitory activity was found among the tricyclic analogs, compounds IIIa-IIId (data not shown). The inhibitory potencies of tetracyclic derivatives, compounds 1c $(3 \mathrm{~S}, 6 \mathrm{~S}, 12 \mathrm{aS}), \quad 2 \mathrm{c} \quad(3 \mathrm{~S}, 6 \mathrm{~S}, 12 \mathrm{aS}), \quad 3 \mathrm{e} 1 \quad(3 \mathrm{~S}, 6 \mathrm{~S}, 12 \mathrm{aS}), \quad 3 \mathrm{e} 2 \quad(3 \mathrm{~S}, 6 \mathrm{~S}, 12 \mathrm{aS}), \quad 3 \mathrm{e} 4$ (3S,6S,12aS), 3e5 (3S,6S,12aS), 3e6 (3S,6S,12aS), 4d $(3 \mathrm{~S}, 6 \mathrm{~S}, 12 \mathrm{aS})$ and the diastereoisomeric mixtures 1c'(3S,6S, 12aS; 3S,6R, 12aS) as well as 2c' $(3 \mathrm{~S}, 6 \mathrm{~S}, 12 \mathrm{aS}$; $3 \mathrm{~S}, 6 \mathrm{R}, 12 \mathrm{aS}$ ) were comparable to that of Ko134 (Table 2). All the stereochemically pure compounds in this group had an absolute configuration of $3 \mathrm{~S}, 6 \mathrm{~S}, 12 \mathrm{aS}$. Their diastereoisomeric counterparts (3S, 6R, 12aS) showed no inhibitory activity, except for $3 \mathrm{e} 6$. One compound of the $3 \mathrm{~S}, 6 \mathrm{~S}, 12 \mathrm{aS}$ absolute configuration, 3e3, showed partial activity.

Next, we focused on compounds which showed potent inhibition of ABCG2 and calculated $\mathrm{IC}_{50}$ values. Additionally, we determined the $\mathrm{IC}_{50}$ values of the diastereoisomeric pairs of some of the active compounds. Compounds 1c $(3 \mathrm{~S}, 6 \mathrm{~S}, 12 \mathrm{aS}), \quad 2 \mathrm{c} \quad(3 \mathrm{~S}, 6 \mathrm{~S}, 12 \mathrm{aS}), \quad 3 \mathrm{e} 2 \quad(3 \mathrm{~S}, 6 \mathrm{~S}, 12 \mathrm{aS}), \quad 3 \mathrm{e} 4 \quad(3 \mathrm{~S}, 6 \mathrm{~S}, 12 \mathrm{aS}), \quad 3 \mathrm{e} 5$ (3S,6S,12aS), $3 \mathrm{e} 6(3 \mathrm{~S}, 6 \mathrm{~S}, 12 \mathrm{aS})$, and $4 \mathrm{~d}(3 \mathrm{~S}, 6 \mathrm{~S}, 12 \mathrm{aS})$ had $\mathrm{IC}_{50}$ values in the nanomolar range. Among the compounds $3 \mathrm{e} 2$ (3S,6R,12aS), $3 \mathrm{e} 5$ (3S,6R,12aS), and $3 \mathrm{e} 6(3 \mathrm{~S}, 6 \mathrm{R}, 12 \mathrm{aS})$, that are diastereoisomeric pairs of $3 \mathrm{e} 2(3 \mathrm{~S}, 6 \mathrm{~S}, 12 \mathrm{aS}), 3 \mathrm{e} 5$ (3S,6S,12aS), 3e6 (3S,6S,12aS), respectively, only 3e5 (3S,6R,12aS) proved to be inhibitory, with a 16-fold difference (Table 2). 
The dye efflux calcein assays helped us to determine specificity of ABCG2 inhibition over $\mathrm{ABCB} 1$ and $\mathrm{ABCC} 1$ inhibitory activity.

Compounds 1c (3S,6S,12aS), 2c (3S,6S,12aS), 3e2 (3S,6S,12aS), 3e4 (3S,6S,12aS), $3 \mathrm{e} 5(3 \mathrm{~S}, 6 \mathrm{~S}, 12 \mathrm{aS}), 3 \mathrm{e} 6(3 \mathrm{~S}, 6 \mathrm{~S}, 12 \mathrm{aS}), 4 \mathrm{~d}(3 \mathrm{~S}, 6 \mathrm{~S}, 12 \mathrm{aS})$ that had $\mathrm{IC}_{50}$ values in the nanomolar range, the diastereoisomeric mixtures 1c' $(3 \mathrm{~S}, 6 \mathrm{~S}, 12 \mathrm{aS} ; 3 \mathrm{~S}, 6 \mathrm{R}, 12 \mathrm{aS})$ as well as 2c' (3S,6S,12aS; 3S,6R,12aS) and compounds 3e2 (3S,6R,12aS), 3e5 (3S,6R,12aS), $3 \mathrm{e} 6(3 \mathrm{~S}, 6 \mathrm{R}, 12 \mathrm{aS})$, the diastereoisomeric pairs of $3 \mathrm{e} 2(3 \mathrm{~S}, 6 \mathrm{~S}, 12 \mathrm{aS})$, $3 \mathrm{e} 5(3 \mathrm{~S}, 6 \mathrm{~S}, 12 \mathrm{aS}), 3 \mathrm{e} 6(3 \mathrm{~S}, 6 \mathrm{~S}, 12 \mathrm{aS})$, respectively, were tested. Compound 3e4 (3S, $6 \mathrm{~S}, 12 \mathrm{aS})$ proved to be 19 and 62 times more specific to ABCG2 than to ABCC1 and $\mathrm{ABCB} 1$, respectively. Interestingly, the tested compounds were characterized by very similar $\mathrm{IC}_{50}$ values for both $\mathrm{ABCB} 1$ and $\mathrm{ABCC} 1$ (Table 2, Figure 15). The only exception was compound 3e2 (3S,6S,12aS), which inhibited ABCC1 about 8-fold more potently than it inhibited ABCB1 (Table 2). More importantly, the noteworthy stereospecificity (3S, $6 \mathrm{~S}, 12 \mathrm{aS}$ vs. $3 \mathrm{~S}, 6 \mathrm{R}, 12 \mathrm{aS})$ observed regarding the inhibition of ABCG2 was completely absent for the inhibition of ABCB1 and ABCC1. In addition, ABCG2 specificity over $\mathrm{ABCB} 1$ and $\mathrm{ABCC} 1$ was not found for compounds with $3 \mathrm{~S}$, $6 \mathrm{R}, 12 \mathrm{aS}$ configuration.

As expected [90], the racemate compounds 1c' (3S,6R,12aS; 3S,6S,12aS) and 2c' (3S,6R,12aS; 3S,6S,12aS) having phenyl or benzyl instead of isobutyl sidechain at C-6 did not specifically inhibit ABCG2 over ABCB1 and ABCC1 either (Table 2). 


\begin{tabular}{|c|c|c|c|c|}
\hline Molecule number & ABCG2 inhibition & ABCG2 inhibition & ABCB1 inhibition & ABCC1 inhibition \\
\hline Compound & $10 \mathrm{uM}(\%)$ & IC50 (uM) & IC50 (uM) & IC50 (uM) \\
\hline $1 \mathrm{c}(3 S, 6 S, 12 a S)$ & 118 & $0.05 \pm 0.03$ & $0.75 \pm 0.02$ & $0.82 \pm 0.04$ \\
\hline $2 \mathrm{c}(3 S, 6 S, 12 a S)$ & 113 & $0.06 \pm 0.24$ & $0.84 \pm 0.07$ & $0.92 \pm 0.08$ \\
\hline $3 \mathrm{e} 1(3 S, 6 R, 12 a S)$ & 0 & $>100$ & $>100$ & $86.0 \pm 7.07$ \\
\hline $3 \mathrm{e} 1(3 S, 6 S, 12 a S)$ & 113 & $1.73 \pm 0.01$ & $>100$ & $83.5 \pm 8.91$ \\
\hline $3 \mathrm{e} 2(3 S, 6 R, 12 a S)$ & 7 & $>100$ & $40.3 \pm 5.94$ & $37.6 \pm 15.4$ \\
\hline $3 \mathrm{e} 2(3 S, 6 S, 12 a S)$ & 131 & $0.41 \pm 0.28$ & $33.4 \pm 20.9$ & $4.16 \pm 0.82$ \\
\hline $3 \mathrm{e} 3(3 S, 6 R, 12 a S)$ & 1 & $>100$ & $>100$ & $>100$ \\
\hline 3e3 $(3 S, 6 S, 12 a S)$ & 59 & $24.7 \pm 4.4$ & $>100$ & $52.3 \pm 10.7$ \\
\hline 3e $4(3 S, 6 R, 12 a S)$ & 4 & $>100$ & $28.8 \pm 6.21$ & $33.6 \pm 0.74$ \\
\hline $3 \mathrm{e} 4(3 S, 6 S, 12 a S)$ & 110 & $0.14 \pm 0.03$ & $8.74 \pm 2.08$ & $2.66 \pm 0.32$ \\
\hline $3 \mathrm{e} 5(3 S, 6 R, 12 a S)$ & 101 & $7.49 \pm 1.12$ & $28.6 \pm 14.0$ & $42.9 \pm 6.27$ \\
\hline $3 \mathrm{e} 5(3 S, 6 S, 12 a S)$ & 121 & $0.45 \pm 0.12$ & $13.1 \pm 2.40$ & $12.1 \pm 2.02$ \\
\hline $3 \mathrm{e} 6(3 S, 6 R, 12 a S)$ & 42 & $16.1 \pm 2.25$ & $0.99 \pm 0.23$ & $1.34 \pm 0.25$ \\
\hline $3 \mathrm{e} 6(3 S, 6 S, 12 a S)$ & 117 & $0.14 \pm 0.06$ & $2.58 \pm 1.19$ & $0.88 \pm 0.09$ \\
\hline $4 \mathrm{~d}(3 S, 6 S, 12 a S)$ & 110 & $0.32 \pm 0.24$ & $8.38 \pm 1.56$ & $6.21 \pm 3.81$ \\
\hline $1 \mathrm{c}^{\prime}(3 S, 6 S, 12 a S ; 3 S, 6 S, 12 a S)$ & 88 & $5.50 \pm 4.10$ & $1.79 \pm 0.35$ & $2.99 \pm 0.25$ \\
\hline $2 c^{\prime}(3 S, 6 S, 12 a S ; 3 S, 6 S, 12 a S)$ & 96 & $3.00 \pm 2.20$ & $2.75 \pm 0.53$ & $3.53 \pm 0.44$ \\
\hline KO134 & 111 & $0.06 \pm 0.03$ & $2.04 \pm 0.06$ & $5.51 \pm 0.88$ \\
\hline KO143 & 118 & $0.06 \pm 0.01$ & $8.74 \pm 0.29$ & $9.13 \pm 1.07$ \\
\hline
\end{tabular}

Table 2. Dye efflux inhibition. Data are given as mean $\pm S D$. 


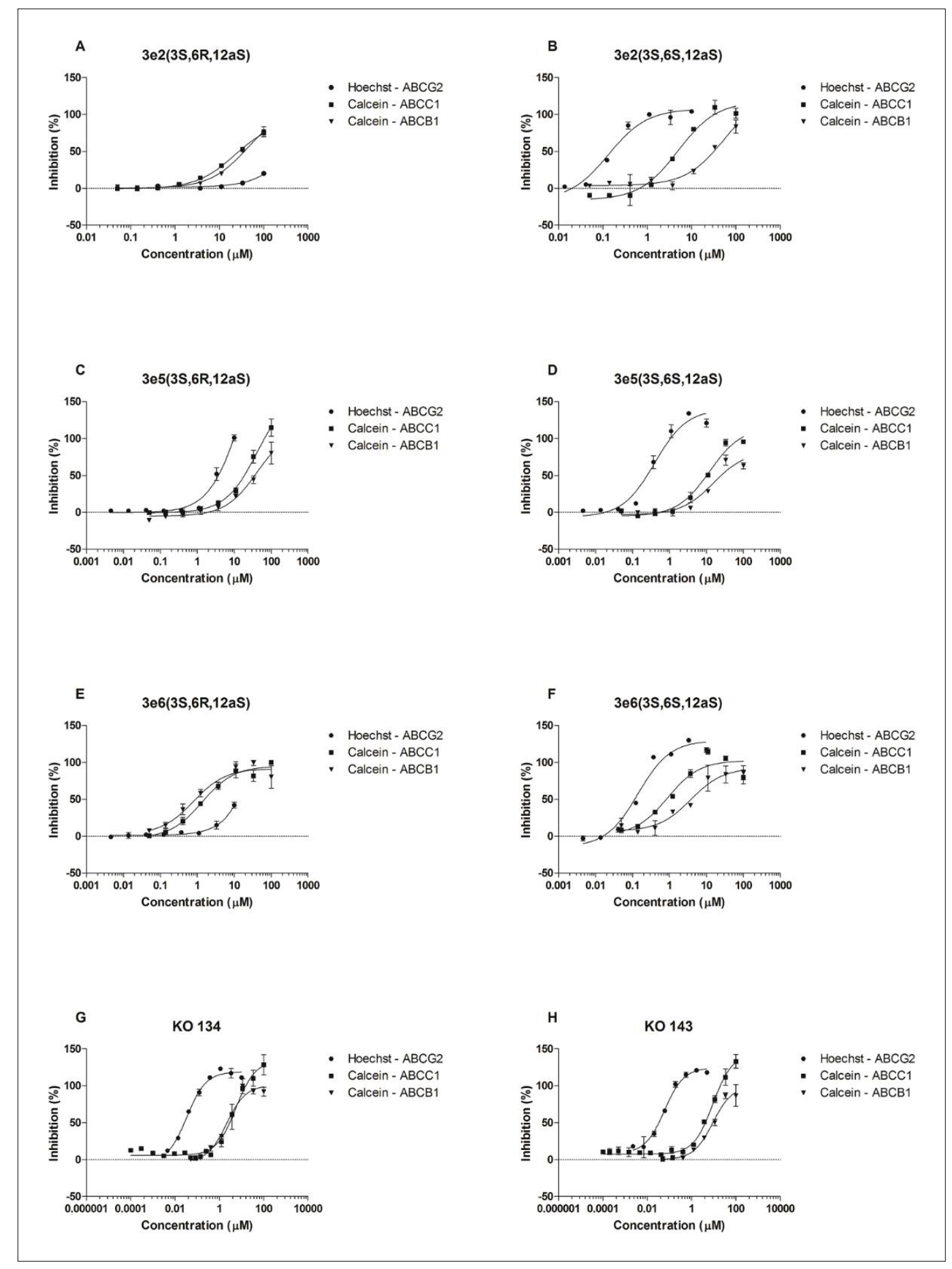

Figure 15. The results of the specificity studies with cell-based dye efflux assays. MCF7-MX cells (100,000 cells/well), K562-MDR cells (100,000 cells/well) or HL60MRP cells (100,000 cells/well) were used for Hoechst assay, Calcein assay for $A B C B 1$ and Calcein assay for ABCC1, respectively, as described in the Materials and Methods section. The inhibition values (\%) were calculated and plotted against drug concentrations. Inhibition of $A B C G 2$ by $1 \mu M$ Kol34 and $A B C B 1$ or $A B C C 1$ by $60 \mu \mathrm{M}$ verapamil was considered $100 \%$. 


\section{Discussion - Applications in drug research and development}

Seliciclib is a selective substrate of $A B C B 1$ but no resistance develops

Seliciclib is rapidly cleared from plasma and distributed to organs. This distribution pattern is probably due to the lipophilic character and low molecular weight of the drug [91]. Sallam and his colleagues tested the brain exposure of seliciclib in rats. The brain/plasma AUC was $100 \%$ in rat pups compared to $20 \%$ found in adult rats [92]. It is commonly accepted that ABC transporters can modify the ADME properties of drug molecules. This difference may stem from the transporter profile differences of an adult and an immature brain.

A part of the work covered in this thesis was to determine whether efflux transporters, thought to limit brain exposure to drugs, would play a role in limiting the brain exposure of seliciclib. We tested seliciclib's interaction with four transporters, $\mathrm{ABCB} 1, \mathrm{ABCG} 2, \mathrm{ABCC} 1$ and $\mathrm{ABCC} 2$. There are several studies to confirm the functional expression of $\mathrm{ABCB} 1 / \mathrm{Abcb} 1 \mathrm{~b}$ and $\mathrm{ABCG} 2 / \mathrm{Abcg} 2$ in the luminal membrane of brain microcapillary endothelial cells and that these transporters limit the penetration of their substrate drugs [93, 94]. The barrier function of $\mathrm{ABCC} 1 / \mathrm{Abcc} 1$ and $\mathrm{ABCC} 2 / \mathrm{Abcc} 2$ is, however, a matter of debate. According to one study from 2004, ABCC1 localizes in the luminal membrane in humans [95]. Roberts and his colleagues found Abcc1 in the luminal membrane of rat brain microcapillary endothelial cells [93]. At the same time, it is generally accepted that Abcc1 is expressed in the basolateral membrane of murine choroid plexus epithelial cells [93] to protect the brain from toxic stimuli [96]. There is evidence to suggest that $\mathrm{ABCC} 2 / \mathrm{Abcc} 2$ is up-regulated under pathological conditions [23].

Our data clearly show that seliciclib is a selective substrate of ABCB1, as it activates the ABCB1 in ATPase assay (Figure 9A), and it shows an ABCB1-dependent vectorial transport in MDCKII-MDR1 cells (Figure 11C, D). Seliciclib, in phase I clinical trials, reached a plasma concentration of approximately $10 \mu \mathrm{M}, 90 \%$ of which was protein-bound [97]. Our studies yielded an $\mathrm{EC}_{50}$ value of $4.2 \mu \mathrm{M}$ for ABCB1. That phase I value is significantly below the $\mathrm{EC}_{50}$ value we measured. 
In that low concentration range, transporters can have remarkable effect on the transcellular permeability of their substrates [98].

We tested whether seliciclib induces cytotoxicity in three different cell lines, namely K562-MDR, HL60-MDR1 and MDCKII-MDR1. These cell lines show ABCB1dependent resistance to substrate drugs but no $\mathrm{ABCB} 1$-mediated resistance to seliciclib-induced cell killing. The lack of a protective effect of ABCB1 against cell death may simply be explained by the passive permeability of the drug. Based on the permeability data (approximately $5 \times 10^{-5} \mathrm{~cm} / \mathrm{s}$; Figure 11D) seliciclib is a moderate to high passive permeability compound with high bioavailability [97]. Cappellini showed that MCF7 MDR cells are susceptible to seliciclib-induced apoptosis. MCF7 MDR cells were significantly $(\mathrm{p}<0.05)$ more sensitive to seliciclib than MCF7 WT cells [99]. There are compounds called ABCB1-inverse because when they are applied, the presence of ABCB1 sensitizes cells to cytotoxicity [100]. So probably ABCB1 plays a dual role in HL60-MDR1, K562-MDR, and MDCKII-MDR1 cells. On the one hand, it reduces intracellular drug concentration but on the other hand, sensitizes cells to seliciclib. The two opposing effects might effectively have cancelled each other out in the cell lines used in the present study.

Seliciclib also interacts with ABCG2 (Figure 9, Figure 10), most likely in an inhibitory manner, as observed in connection with vanadate-sensitive ATPase activity. The clinical free drug concentrations under current schedules [101] are way below the $\mathrm{IC}_{50}$ values for seliciclib-mediated ABCG2 inhibition, so this interaction is unlikely to be clinically relevant.

In summary, seliciclib is a high-affinity, selective substrate of ABCB1. This interaction is likely to affect disposition of the drug. At the same time, ABCB1 overexpression does not lead to resistance to seliciclib. This means that the drug may be a promising candidate to treat $\mathrm{ABCB} 1$ transporter-overexpressing tumors. 
Based upon studies from the 1980s, chlorothiazide, in general, is not well absorbed following oral administration. Furthermore, the absorption of chlorothiazide from the gastrointestinal tract is saturable [102-104]. Chlorothiazide has bioavailabilities around $20-50 \%$. All these indicate the potential role of apically located efflux transporter(s) which may limit the bioavailability of the compound. Based on these, we tested whether chlorothiazide interacted with any of the three most important, apically located efflux ABC transporters found in enterocytes: ABCB1, ABCG2 and ABCC2. First, we verified that chlorothiazide specifically interacted with ABCG2 in a vesicular transport inhibition experiment (Figure 12). Next, we sought to characterize this interaction. Chlorothiazide activated ABCG2 in ATPase assay, and the transport in VT assay proved to be saturable. These findings confirm that chlorothiazide is an $\mathrm{ABCG} 2$ substrate (Figure 13). Both the $\mathrm{EC}_{50}$ value from the ATPase assay and the $K_{m}$ value calculated from vesicular transport assay $(327.2+$ $9.4 \mu \mathrm{M}$ and $334.6+325.0 \mu \mathrm{M}$, respectively) correlated well. This $\mathrm{K}_{\mathrm{m}}$ value is likely to reflect the affinity of chlorothiazide to ABCG2, since the low permeability of the tested drug did not confound the kinetic values of membrane assays.

Further, we verified in monolayer efflux experiments that chlorothiazide is a transported substrate of ABCG2. We saw difference in transport values both with MDCKII-BCRP as well as with Caco-2 cells in the presence or absence of Ko143, an ABCG2-specific inhibitor (Figure 14).

The Caco-2 cell line has become the most widely used and most extensively characterized model of intestinal absorption. Based on this and on our results, we can declare that the ABCG2-mediated modulation of chlorothiazide permeability is a significant contribution to the low bioavailability of the drug. Note that chlorothiazide has low permeability even when ABCG2 is inhibited (Figure 14).

To sum this up, ABCG2 interfered with the permeability of chlorothiazide in all the three studied assays. As the experimental systems used in this study comply with the current regulatory guidelines, the results suggest that chlorothiazide is a legitimate ABCG2 probe candidate for regulatory studies. Furthermore, potential inhibition of ABCG2-mediated urate transport may be behind hyperuricaemic activity of chlorothiazide. 
FTC-Ko analogues: specificity is limited to a single chiral center - the C-6 and a $3 S, 6 S, 12 a S$ configuration is essential

One of the most widely studied mechanisms underlying MDR is the expression of membrane transporter proteins that inhibit the cellular accumulation of drugs by a process of active efflux. ABCG2 has a broad substrate specificity [33]. A substantial part of these are chemotherapeutic agents. Molecules that inhibit the function of ABC transporters may improve the efficacy of anticancer agents. Taking all these into account, reversal of ABCG2-mediated transport is a promising area of research.

Since its discovery in 1998, the role of ABCG2 in MDR has been the subject of several investigations. Overexpression of the transporter is associated with a high level of resistance to a wide variety of cytostatics. Especially because of this, the specific inhibition of $\mathrm{ABCG} 2$ in combination with administering a cytostatic which is a substrate of ABCG2, appears to be a logical anticancer approach - provided that the target cells do express ABCG2. Another interesting strategy might be the coadministration of potent $\mathrm{ABCG} 2$ inhibitors with drugs that are substrates of the efflux pump to increase drug levels e.g. in the brain. ABCG2 inhibitors might be useful for cancer treatment with respect to reversal of MDR [105].

Mechanism of transport by ABCG2 is complex as it displays multiple binding sites $[106,107]$. In addition, potentiation of transport of a substrate by modulators have also been shown for $\mathrm{ABC}$ transporters, such as $\mathrm{ABCB} 1$ and $\mathrm{ABCC} 2$ [108, 109]. Therefore, the ideal inhibitor with MDR reversal potential must comply with a number of criteria. It is required to inhibit the transport of most ABCG2 substrates that due to multiple binding sites of $\mathrm{ABCG} 2$ it understandably poses challenges. It should not display trans-stimulatory activity and have favorable pharmacokinetic properties and no toxicity.

We chose the Hoechst assay to test our set of compounds with ABCG2 in a high throughput assay. ABCG2-mediated transport of compounds binding to the prazosin [110, 111], rhodamine [112] and mitoxantrone [110-113] sites are inhibited by the FTC-Ko family. Therefore, being a general inhibitor for further members of this segment of the chemical space is conceivable. The other challenge is the specificity of inhibition. The more specific an inhibitor is, the less toxicity it causes. Since members of the FTC-Ko family displayed worthy of attention specificity these 
compounds turned out to be a good starting point (Figure 15). The latter was confirmed in this study.

As the tricyclic analogues IIIa-IIId showed no activity in the Hoechst assay, it became clear that the FTC type diketo-piperazine ring structure is fundamental for activity, especially that compounds having the diketo-piperazine ring structure were all active. The C-6 and a 3S, 6S, 12aS configuration is essential (Figure 15). Compounds with $3 \mathrm{~S}, 6 \mathrm{R}, 12 \mathrm{aS}$ configuration were inactive as expected [90]. The $3 \mathrm{e} 6(3 \mathrm{~S}, 6 \mathrm{R}, 12 \mathrm{aS})$ might be the only exception with its partial activity. But even in that case, the diastereoisomeric pair, 3e6 (3S,6S,12aS), was more than 115-fold more potent (Table 2). Noticeably, the stereospecific $(3 \mathrm{~S}, 6 \mathrm{~S}, 12 \mathrm{aS}$ vs $3 \mathrm{~S}, 6 \mathrm{R}, 12 \mathrm{aS})$ inhibition seen in case of $\mathrm{ABCG} 2$ was missing with $\mathrm{ABCB} 1$ and $\mathrm{ABCC} 1$ (Figure 15). In addition, ABCG2 specificity over $\mathrm{ABCB} 1$ and $\mathrm{ABCC} 1$ was not observed in case of compounds with the $3 \mathrm{~S}, 6 \mathrm{R}, 12 \mathrm{aS}$ configuration. The fact that configuration at position 6 alone ensures specificity for $\mathrm{ABCG} 2$ over $\mathrm{ABCB} 1$ and $\mathrm{ABCC} 1$ has not been described before. Taking into consideration the broad and overlapping substrate specificity of the above-mentioned $\mathrm{ABC}$ transporters, it is striking and quite unexpected that this specificity is limited to a single chiral center $[114,115]$. 


\section{Summary}

Seliciclib (R-roscovitine) is a cyclin-dependent kinase inhibitor and a chemotherapeutic drug candidate. The brain level of seliciclib was about $20 \%$ of that measured in the plasma, while it was $100 \%$ in newborn rats with an immature BBB [91]. This suggested that an efflux transporter expressed in the BBB might be at play. Bachmeier and Miller demonstrated seliciclib-ABCB1 transporter interactions in BBMEC monolayers using a rhodamine 123 transport inhibition assay [116]. However, no further information was available on whether seliciclib was substrate or only an inhibitor of $\mathrm{ABCB} 1$. A potential role of the MDR transporter ABCB1 in seliciclib resistance has not been evaluated either. We have shown that seliciclib is a selective substrate of $\mathrm{ABCB} 1$ and discussed how this seliciclib-ABCB1 interaction affected seliciclib disposition.

Chlorothiazide is a thiazide type diuretic [117]. Chlorothiazide has low solubility and low permeability with little to no metabolism. Its bioavailability is low [102]. The low bioavailability of chlorothiazide suggested a possible role of apically located efflux transporters. We, therefore, tested if any of the three major intestinal, apically located efflux transporters - $\mathrm{ABCB} 1, \mathrm{ABCG} 2$ or $\mathrm{ABCC} 2$ - modulated permeability of the drug in vitro. ABCG2 modulated the permeability of chlorothiazide in all three experimental systems tested.

The Ko family of fumitremorgin $\mathrm{C}$ analogs include potent and selective ABCG2 inhibitors. However, the most potent Ko compounds carry an ester linkage in their side-chain that makes them chemically and metabolically less stable. We have tested novel 16 tricyclic and 28 tetracyclic Fumitremorgin $\mathrm{C}$ analogs for ABCG2 inhibition potency and specificity. Among the tetracyclic analogs, we discovered efficacious ABCG2-inhibiting compounds. Compounds with the $3 \mathrm{~S}, 6 \mathrm{~S}, 12 \mathrm{aS}$ configuration showed stereospecificity. Diastereoisomeric pairs with a 3S,6R,12aS configuration showed at least 18 -fold less potent inhibition. Such stereospecificity was not observed in $\mathrm{ABCB} 1$ and $\mathrm{ABCC} 1$ inhibition. 


\section{References}

1. Glavinas, H., Krajcsi, P., Cserepes, J., and Sarkadi, B., The role of ABC transporters in drug resistance, metabolism and toxicity, Curr Drug Deliv, 1:27-42, 2004.

2. Dean, M., Hamon, Y., and Chimini, G., The human ATP-binding cassette (ABC) transporter superfamily, J Lipid Res, 42:1007-1017, 2001.

3. Kusuhara, H., and Sugiyama, Y., Active efflux across the blood-brain barrier: role of the solute carrier family, NeuroRx, 2:73-85, 2005.

4. Hediger, M. A., Romero, M. F., Peng, J. B., Rolfs, A., Takanaga, H., and Bruford, E. A., The ABCs of solute carriers: physiological, pathological and therapeutic implications of human membrane transport proteinsIntroduction, Pflugers Arch, 447:465-468, 2004.

5. Stefkova, J., Poledne, R., and Hubacek, J. A., ATP-binding cassette (ABC) transporters in human metabolism and diseases, Physiol Res, 53:235-243, 2004.

6. International Transporter, C., Giacomini, K. M., Huang, S. M., Tweedie, D. J., Benet, L. Z., Brouwer, K. L., Chu, X., Dahlin, A., Evers, R., Fischer, V., Hillgren, K. M., Hoffmaster, K. A., Ishikawa, T., Keppler, D., Kim, R. B., Lee, C. A., Niemi, M., Polli, J. W., Sugiyama, Y., Swaan, P. W., Ware, J. A., Wright, S. H., Yee, S. W., Zamek-Gliszczynski, M. J., and Zhang, L., Membrane transporters in drug development, Nat Rev Drug Discov, 9:215236, 2010.

7. Theodoulou, F. L., and Kerr, I. D., ABC transporter research: going strong 40 years on, Biochem Soc Trans, 43:1033-1040, 2015.

8. Price, D., Ackland, L., and Suphioglu, C., Nuts 'n' guts: transport of food allergens across the intestinal epithelium, Asia Pac Allergy, 3:257-265, 2013.

9. Artursson, P., Neuhoff, S., Matsson, P., and Tavelin, S., 5.11 - Passive Permeability and Active Transport Models for the Prediction of Oral Absorption, 5:259-278, 2007.

10. Szakacs, G., Varadi, A., Ozvegy-Laczka, C., and Sarkadi, B., The role of $\mathrm{ABC}$ transporters in drug absorption, distribution, metabolism, excretion and toxicity (ADME-Tox), Drug Discov Today, 13:379-393, 2008.

11. Klaassen, C. D., and Aleksunes, L. M., Xenobiotic, bile acid, and cholesterol transporters: function and regulation, Pharmacol Rev, 62:1-96, 2010.

12. Berggren, S., Gall, C., Wollnitz, N., Ekelund, M., Karlbom, U., Hoogstraate, J., Schrenk, D., and Lennernas, H., Gene and protein expression of Pglycoprotein, MRP1, MRP2, and CYP3A4 in the small and large human intestine, Mol Pharm, 4:252-257, 2007.

13. Krajcsi, P., Drug-transporter interaction testing in drug discovery and development, World J Pharmacol, 2:35-46, 2013.

14. $\mathrm{Xu}, \mathrm{W}$., Ling, P., and Zhang, T., Polymeric micelles, a promising drug delivery system to enhance bioavailability of poorly water-soluble drugs, $J$ Drug Deliv, 2013:340315, 2013.

15. Werle, M., Natural and synthetic polymers as inhibitors of drug efflux pumps, Pharm Res, 25:500-511, 2008.

16. Rege, B. D., Yu, L. X., Hussain, A. S., and Polli, J. E., Effect of common excipients on Caco-2 transport of low-permeability drugs, J Pharm Sci, 90:1776-1786, 2001. 
17. Krajcsi, P., Jani, M., Toth, B., Erdo, F., Kis, E., Beery, E., and Sziraki, I., Efflux transporters in the blood-brain interfaces--in vitro and in vivo methods and correlations, Expert Opin Drug Metab Toxicol, 8:419-431, 2012.

18. Redzic, Z., Molecular biology of the blood-brain and the blood-cerebrospinal fluid barriers: similarities and differences, Fluids Barriers CNS, 8:3, 2011.

19. Liddelow, S. A., Development of the choroid plexus and blood-CSF barrier, Front Neurosci, 9:32, 2015.

20. Pardridge, W. M., Drug and gene targeting to the brain with molecular Trojan horses, Nat Rev Drug Discov, 1:131-139, 2002.

21. Keep, R. F., and Jones, H. C., A morphometric study on the development of the lateral ventricle choroid plexus, choroid plexus capillaries and ventricular ependyma in the rat, Brain Res Dev Brain Res, 56:47-53, 1990.

22. Gazzin, S., Strazielle, N., Schmitt, C., Fevre-Montange, M., Ostrow, J. D., Tiribelli, C., and Ghersi-Egea, J. F., Differential expression of the multidrug resistance-related proteins $\mathrm{ABCb} 1$ and $\mathrm{ABCc} 1$ between blood-brain interfaces, J Comp Neurol, 510:497-507, 2008.

23. Hoffmann, K., Gastens, A. M., Volk, H. A., and Loscher, W., Expression of the multidrug transporter MRP2 in the blood-brain barrier after pilocarpineinduced seizures in rats, Epilepsy Res, 69:1-14, 2006.

24. Hudachek, S. F., and Gustafson, D. L., Incorporation of ABCB1-mediated transport into a physiologically-based pharmacokinetic model of docetaxel in mice, J Pharmacokinet Pharmacodyn, 40:437-449, 2013.

25. Shukla, S., Chen, Z. S., and Ambudkar, S. V., Tyrosine kinase inhibitors as modulators of ABC transporter-mediated drug resistance, Drug Resist Updat, 15:70-80, 2012.

26. On, N. H., and Miller, D. W., Transporter-based delivery of anticancer drugs to the brain: improving brain penetration by minimizing drug efflux at the blood-brain barrier, Curr Pharm Des, 20:1499-1509, 2014.

27. Jia, W., Lu, R., Martin, T. A., and Jiang, W. G., The role of claudin-5 in bloodbrain barrier (BBB) and brain metastases (review), Mol Med Rep, 9:779-785, 2014.

28. Hong, C. S., Ho, W., Piazza, M. G., Ray-Chaudhury, A., Zhuang, Z., and Heiss, J. D., Characterization of the blood brain barrier in pediatric central nervous system neoplasms, J Interdiscip Histopathol, 4:29-33, 2016.

29. Nduom, E. K., Yang, C., Merrill, M. J., Zhuang, Z., and Lonser, R. R., Characterization of the blood-brain barrier of metastatic and primary malignant neoplasms, J Neurosurg, 119:427-433, 2013.

30. Oumata, N., Bettayeb, K., Ferandin, Y., Demange, L., Lopez-Giral, A., Goddard, M. L., Myrianthopoulos, V., Mikros, E., Flajolet, M., Greengard, P., Meijer, L., and Galons, H., Roscovitine-derived, dual-specificity inhibitors of cyclin-dependent kinases and casein kinases 1, J Med Chem, 51:5229-5242, 2008.

31. Patrick, C., Crews, L., Desplats, P., Dumaop, W., Rockenstein, E., Achim, C. L., Everall, I. P., and Masliah, E., Increased CDK5 expression in HIV encephalitis contributes to neurodegeneration via tau phosphorylation and is reversed with Roscovitine, Am J Pathol, 178:1646-1661, 2011.

32. Hegedus, C., Szakacs, G., Homolya, L., Orban, T. I., Telbisz, A., Jani, M., and Sarkadi, B., Ins and outs of the ABCG2 multidrug transporter: an update on in vitro functional assays, Adv Drug Deliv Rev, 61:47-56, 2009. 
33. Jani, M., Ambrus, C., Magnan, R., Jakab, K. T., Beery, E., Zolnerciks, J. K., and Krajcsi, P., Structure and function of BCRP, a broad specificity transporter of xenobiotics and endobiotics, Arch Toxicol, 88:1205-1248, 2014.

34. Janvilisri, T., Shahi, S., Venter, H., Balakrishnan, L., and van Veen, H. W., Arginine-482 is not essential for transport of antibiotics, primary bile acids and unconjugated sterols by the human breast cancer resistance protein (ABCG2), Biochem J, 385:419-426, 2005.

35. Woodward, O. M., Kottgen, A., Coresh, J., Boerwinkle, E., Guggino, W. B., and Kottgen, M., Identification of a urate transporter, ABCG2, with a common functional polymorphism causing gout, Proc Natl Acad Sci U S A, 106:10338-10342, 2009.

36. Ishikawa, T., Aw, W., and Kaneko, K., Metabolic Interactions of Purine Derivatives with Human ABC Transporter ABCG2: Genetic Testing to Assess Gout Risk, Pharmaceuticals (Basel), 6:1347-1360, 2013.

37. Bach, M. H., and Simkin, P. A., Uricosuric drugs: the once and future therapy for hyperuricemia?, Curr Opin Rheumatol, 26:169-175, 2014.

38. Basseville, A., and Bates, S. E., Gout, genetics and ABC transporters, F1000 Biol Rep, 3:23, 2011.

39. Shugarts, S., and Benet, L. Z., The role of transporters in the pharmacokinetics of orally administered drugs, Pharm Res, 26:2039-2054, 2009.

40. Faber, K. N., Muller, M., and Jansen, P. L., Drug transport proteins in the liver, Adv Drug Deliv Rev, 55:107-124, 2003.

41. Kis, E., Ioja, E., Nagy, T., Szente, L., Heredi-Szabo, K., and Krajcsi, P., Effect of membrane cholesterol on BSEP/Bsep activity: species specificity studies for substrates and inhibitors, Drug Metab Dispos, 37:1878-1886, 2009.

42. Wang, R., Chen, H. L., Liu, L., Sheps, J. A., Phillips, M. J., and Ling, V., Compensatory role of P-glycoproteins in knockout mice lacking the bile salt export pump, Hepatology, 50:948-956, 2009.

43. Lam, P., Wang, R., and Ling, V., Bile acid transport in sister of P-glycoprotein (ABCB11) knockout mice, Biochemistry, 44:12598-12605, 2005.

44. Blazquez, A. G., Briz, O., Romero, M. R., Rosales, R., Monte, M. J., Vaquero, J., Macias, R. I., Cassio, D., and Marin, J. J., Characterization of the role of ABCG2 as a bile acid transporter in liver and placenta, Mol Pharmacol, 81:273-283, 2012.

45. Research, C. f. D. E. a., FDA's Guidances (Drugs) - Clinical Pharmacology, Center for Drug Evaluation and Research (2017).

46. Sadeque, A. J., Wandel, C., He, H., Shah, S., and Wood, A. J., Increased drug delivery to the brain by P-glycoprotein inhibition, Clin Pharmacol Ther, 68:231-237, 2000.

47. Fenner, K. S., Troutman, M. D., Kempshall, S., Cook, J. A., Ware, J. A., Smith, D. A., and Lee, C. A., Drug-drug interactions mediated through Pglycoprotein: clinical relevance and in vitro-in vivo correlation using digoxin as a probe drug, Clin Pharmacol Ther, 85:173-181, 2009.

48. Konig, J., Muller, F., and Fromm, M. F., Transporters and drug-drug interactions: important determinants of drug disposition and effects, Pharmacol Rev, 65:944-966, 2013.

49. Kruijtzer, C. M., Beijnen, J. H., Rosing, H., ten Bokkel Huinink, W. W., Schot, M., Jewell, R. C., Paul, E. M., and Schellens, J. H., Increased oral bioavailability of topotecan in combination with the breast cancer resistance 
protein and P-glycoprotein inhibitor GF120918, J Clin Oncol, 20:2943-2950, 2002.

50. Jonker, J. W., Smit, J. W., Brinkhuis, R. F., Maliepaard, M., Beijnen, J. H., Schellens, J. H., and Schinkel, A. H., Role of breast cancer resistance protein in the bioavailability and fetal penetration of topotecan, J Natl Cancer Inst, 92:1651-1656, 2000.

51. Matsuda, Y., Konno, Y., Hashimoto, T., Nagai, M., Taguchi, T., Satsukawa, M., and Yamashita, S., In vivo assessment of the impact of efflux transporter on oral drug absorption using portal vein-cannulated rats, Drug Metab Dispos, 41:1514-1521, 2013.

52. Sparreboom, A., Loos, W. J., Burger, H., Sissung, T. M., Verweij, J., Figg, W. D., Nooter, K., and Gelderblom, H., Effect of ABCG2 genotype on the oral bioavailability of topotecan, Cancer Biol Ther, 4:650-658, 2005.

53. Arrowsmith, J., and Miller, P., Trial watch: phase II and phase III attrition rates 2011-2012, in Nat Rev Drug Discov, Vol. 12, England, pp. 569 (2013).

54. Waring, M. J., Arrowsmith, J., Leach, A. R., Leeson, P. D., Mandrell, S., Owen, R. M., Pairaudeau, G., Pennie, W. D., Pickett, S. D., Wang, J., Wallace, O., and Weir, A., An analysis of the attrition of drug candidates from four major pharmaceutical companies, Nat Rev Drug Discov, 14:475-486, 2015.

55. Basavaraj, S., and Betageri, G. V., Can formulation and drug delivery reduce attrition during drug discovery and development-review of feasibility, benefits and challenges, Acta Pharm Sin B, 4:3-17, 2014.

56. Olson, H., Betton, G., Robinson, D., Thomas, K., Monro, A., Kolaja, G., Lilly, P., Sanders, J., Sipes, G., Bracken, W., Dorato, M., Van Deun, K., Smith, P., Berger, B., and Heller, A., Concordance of the toxicity of pharmaceuticals in humans and in animals, Regul Toxicol Pharmacol, 32:56-67, 2000.

57. Kola, I., and Landis, J., Can the pharmaceutical industry reduce attrition rates?, Nat Rev Drug Discov, 3:711-715, 2004.

58. Gottesman, M. M., Fojo, T., and Bates, S. E., Multidrug resistance in cancer: role of ATP-dependent transporters, Nat Rev Cancer, 2:48-58, 2002.

59. Vasiliou, V., Vasiliou, K., and Nebert, D. W., Human ATP-binding cassette (ABC) transporter family, Hum Genomics, 3:281-290, 2009.

60. ATP binding cassette transporters | HUGO Gene Nomenclature Committee (2017).

61. Juliano, R. L., and Ling, V., A surface glycoprotein modulating drug permeability in Chinese hamster ovary cell mutants, Biochim Biophys Acta, 455:152-162, 1976.

62. Thiebaut, F., Tsuruo, T., Hamada, H., Gottesman, M. M., Pastan, I., and Willingham, M. C., Cellular localization of the multidrug-resistance gene product P-glycoprotein in normal human tissues, Proc Natl Acad Sci U S A, 84:7735-7738, 1987.

63. Klein, I., Sarkadi, B., and Varadi, A., An inventory of the human ABC proteins, Biochim Biophys Acta, 1461:237-262, 1999.

64. Toth, K., Vaughan, M. M., Slocum, H. K., Arredondo, M. A., Takita, H., Baker, R. M., and Rustum, Y. M., New immunohistochemical "sandwich" staining method for mdr1 P-glycoprotein detection with JSB-1 monoclonal antibody in formalin-fixed, paraffin-embedded human tissues, Am J Pathol, 144:227-236, 1994. 
65. Kis, E., Rajnai, Z., Ioja, E., Heredi Szabo, K., Nagy, T., Mehn, D., and Krajcsi, P., Mouse Bsep ATPase assay: a nonradioactive tool for assessment of the cholestatic potential of drugs, J Biomol Screen, 14:10-15, 2009.

66. Glavinas, H., Mehn, D., Jani, M., Oosterhuis, B., Heredi-Szabo, K., and Krajcsi, P., Utilization of membrane vesicle preparations to study drug-ABC transporter interactions, Expert Opin Drug Metab Toxicol, 4:721-732, 2008.

67. Jani, M., and Krajcsi, P., In vitro methods in drug transporter interaction assessment, Drug Discov Today Technol, 12:e105-112, 2014.

68. Glavinas, H., von Richter, O., Vojnits, K., Mehn, D., Wilhelm, I., Nagy, T., Janossy, J., Krizbai, I., Couraud, P., and Krajcsi, P., Calcein assay: a highthroughput method to assess P-gp inhibition, Xenobiotica, 41:712-719, 2011.

69. Hollo, Z., Homolya, L., Davis, C. W., and Sarkadi, B., Calcein accumulation as a fluorometric functional assay of the multidrug transporter, Biochim Biophys Acta, 1191:384-388, 1994.

70. Szeremy, P., Pal, A., Mehn, D., Toth, B., Fulop, F., Krajcsi, P., and HerediSzabo, K., Comparison of 3 assay systems using a common probe substrate, calcein AM, for studying P-gp using a selected set of compounds, J Biomol Screen, 16:112-119, 2011.

71. Kis, E., Nagy, T., Jani, M., Molnar, E., Janossy, J., Ujhellyi, O., Nemet, K., Heredi-Szabo, K., and Krajcsi, P., Leflunomide and its metabolite A771726 are high affinity substrates of BCRP: implications for drug resistance, Ann Rheum Dis, 68:1201-1207, 2009.

72. von Richter, O., Glavinas, H., Krajcsi, P., Liehner, S., Siewert, B., and Zech, K., A novel screening strategy to identify ABCB1 substrates and inhibitors, Naunyn Schmiedebergs Arch Pharmacol, 379:11-26, 2009.

73. Germann, U. A., Willingham, M. C., Pastan, I., and Gottesman, M. M., Expression of the human multidrug transporter in insect cells by a recombinant baculovirus, Biochemistry, 29:2295-2303, 1990.

74. Sarkadi, B., Price, E. M., Boucher, R. C., Germann, U. A., and Scarborough, G. A., Expression of the human multidrug resistance cDNA in insect cells generates a high activity drug-stimulated membrane ATPase, J Biol Chem, 267:4854-4858, 1992.

75. Ning, B. T., and Tang, Y. M., Establishment of the cell line, HeLa-CD14, transfected with the human CD14 gene, Oncol Lett, 3:871-874, 2012.

76. Feinbaum, R., Vectors derived from plasmids, in Current Protocols in Molecular Biology, Ausubel, F. M., Brent, R., Kingston, R. E., Moore, D. D., Seidman, J. G., Smith, J. A., and Struhl, K., Eds., John Wiley \& Sons, Inc. (2003).

77. Craig, N. L., The mechanism of conservative site-specific recombination, Annu Rev Genet, 22:77-105, 1988.

78. Gronostajski, R. M., and Sadowski, P. D., Determination of DNA sequences essential for FLP-mediated recombination by a novel method, J Biol Chem, 260:12320-12327, 1985.

79. Sauer, B., Site-specific recombination: developments and applications, Curr Opin Biotechnol, 5:521-527, 1994.

80. Sadelain, M., and Isabelle, R., Gene Therapy of Cancer - (Second Edition) - CHAPTER 6: The Advent of Lentiviral Vectors: Prospects for Cancer Therapy, Academic press, Elsevier Inc (2002).

81. Kaplan, J. M., Adenovirus-based cancer gene therapy, Curr Gene Ther, 5:595-605, 2005. 
82. Adenoviral Vectors for Gene Therapy - ScienceDirect, Curiel, D. T., and Douglas, J. T., Eds., Elsevier Inc., Elsevier (2002).

83. Ennour-Idrissi, K., Maunsell, E., and Diorio, C., Telomere Length and Breast Cancer Prognosis: A Systematic Review, Cancer Epidemiol Biomarkers Prev, 26:3-10, 2017.

84. Van Craenenbroeck, K., Vanhoenacker, P., and Haegeman, G., Episomal vectors for gene expression in mammalian cells, Eur J Biochem, 267:56655678, 2000.

85. Barnett, C. J., Huff, B., Kobierski, M. E., Letourneau, M., and Wilson, T. M., Stereochemistry of C-6 nucleophilic displacements on 1,1difluorocyclopropyldibenzosuberanyl substrates. An improved synthesis of multidrug resistance modulator LY335979 trihydrochloride, J Org Chem, 69:7653-7660, 2004.

86. Allen, J. D., van Loevezijn, A., Lakhai, J. M., van der Valk, M., van Tellingen, O., Reid, G., Schellens, J. H., Koomen, G. J., and Schinkel, A. H., Potent and specific inhibition of the breast cancer resistance protein multidrug transporter in vitro and in mouse intestine by a novel analogue of fumitremorgin C, Mol Cancer Ther, 1:417-425, 2002.

87. Sekhon, B. K., Roubin, R. H., Tan, A., Chan, W. K., and Sze, D. M., Highthroughput screening platform for anticancer therapeutic drug cytotoxicity., Assay Drug Dev Technol., 6:711-721, 2008.

88. Dantzig, A. H., de Alwis, D. P., and Burgess, M., Considerations in the design and development of transport inhibitors as adjuncts to drug therapy, Adv Drug Deliv Rev, 55:133-150, 2003.

89. Kirkendall, W. M., Clinical evaluation of chlorothiazide, Circulation, 19:933941, 1959.

90. van Loevezijn, A., Allen, J. D., Schinkel, A. H., and Koomen, G. J., Inhibition of BCRP-mediated drug efflux by fumitremorgin-type indolyl diketopiperazines, Bioorg Med Chem Lett, 11:29-32, 2001.

91. Vita, M., Abdel-Rehim, M., Olofsson, S., Hassan, Z., Meurling, L., Siden, A., Siden, M., Pettersson, T., and Hassan, M., Tissue distribution, pharmacokinetics and identification of roscovitine metabolites in rat, Eur J Pharm Sci, 25:91-103, 2005.

92. Sallam, H., Jimenez, P., Song, H., Vita, M., Cedazo-Minguez, A., and Hassan, M., Age-dependent pharmacokinetics and effect of roscovitine on Cdk5 and Erk1/2 in the rat brain, Pharmacol Res, 58:32-37, 2008.

93. Roberts, L. M., Black, D. S., Raman, C., Woodford, K., Zhou, M., Haggerty, J. E., Yan, A. T., Cwirla, S. E., and Grindstaff, K. K., Subcellular localization of transporters along the rat blood-brain barrier and blood-cerebral-spinal fluid barrier by in vivo biotinylation, Neuroscience, 155:423-438, 2008.

94. Enokizono, J., Kusuhara, H., and Sugiyama, Y., Regional expression and activity of breast cancer resistance protein (Bcrp/Abcg2) in mouse intestine: overlapping distribution with sulfotransferases, Drug Metab Dispos, 35:922928, 2007.

95. Nies, A. T., Jedlitschky, G., Konig, J., Herold-Mende, C., Steiner, H. H., Schmitt, H. P., and Keppler, D., Expression and immunolocalization of the multidrug resistance proteins, MRP1-MRP6 (ABCC1-ABCC6), in human brain, Neuroscience, 129:349-360, 2004.

96. Wijnholds, J., deLange, E. C., Scheffer, G. L., van den Berg, D. J., Mol, C. A., van der Valk, M., Schinkel, A. H., Scheper, R. J., Breimer, D. D., and 
Borst, P., Multidrug resistance protein 1 protects the choroid plexus epithelium and contributes to the blood-cerebrospinal fluid barrier, $J$ Clin Invest, 105:279-285, 2000.

97. Benson, C., White, J., De Bono, J., O'Donnell, A., Raynaud, F., Cruickshank, C., McGrath, H., Walton, M., Workman, P., Kaye, S., Cassidy, J., GianellaBorradori, A., Judson, I., and Twelves, C., A phase I trial of the selective oral cyclin-dependent kinase inhibitor seliciclib (CYC202; R-Roscovitine), administered twice daily for 7 days every 21 days, Br J Cancer, 96:29-37, 2007.

98. Shirasaka, Y., Sakane, T., and Yamashita, S., Effect of P-glycoprotein expression levels on the concentration-dependent permeability of drugs to the cell membrane, J Pharm Sci, 97:553-565, 2008.

99. Cappellini, A., Chiarini, F., Ognibene, A., McCubrey, J. A., and Martelli, A. M., The cyclin-dependent kinase inhibitor roscovitine and the nucleoside analog sangivamycin induce apoptosis in caspase-3 deficient breast cancer cells independent of caspase mediated P-glycoprotein cleavage: implications for therapy of drug resistant breast cancers, Cell Cycle, 8:1421-1425, 2009.

100. Szakacs, G., Annereau, J. P., Lababidi, S., Shankavaram, U., Arciello, A., Bussey, K. J., Reinhold, W., Guo, Y., Kruh, G. D., Reimers, M., Weinstein, J. N., and Gottesman, M. M., Predicting drug sensitivity and resistance: profiling ABC transporter genes in cancer cells, Cancer Cell, 6:129-137, 2004.

101. Weingrill, E., Wolfler, A., Strunk, D., Linkesch, W., Sill, H., and Liebmann, P. M., Roscovitine in B-chronic lymphocytic leukemia cells: high apoptosisinducing efficacy and synergism with alemtuzumab independent of the patients' pretreatment status, Haematologica, 92:1286-1288, 2007.

102. Straughn, A. B., Melikian, A. P., and Meyer, M. C., Bioavailability of chlorothiazide tablets in humans, J Pharm Sci, 68:1099-1102, 1979.

103. Osman, M. A., Patel, R. B., Irwin, D. S., Craig, W. A., and Welling, P. G., Bioavailability of chlorothiazide from 50, 100, and 250 MG solution doses, Biopharm Drug Dispos, 3:89-94, 1982.

104. Adebayo, G. I., and Mabadeje, A. F., Chlorothiazide absorption in humans-possible example of Michaelis-Menten kinetics, Pharmacology, 31:181-188, 1985.

105. Kuhnle, M., Egger, M., Muller, C., Mahringer, A., Bernhardt, G., Fricker, G., Konig, B., and Buschauer, A., Potent and selective inhibitors of breast cancer resistance protein $(\mathrm{ABCG} 2)$ derived from the p-glycoprotein $(\mathrm{ABCB} 1)$ modulator tariquidar, J Med Chem, 52:1190-1197, 2009.

106. Laszlo, L., Sarkadi, B., and Hegedus, T., Jump into a New Fold-A Homology Based Model for the ABCG2/BCRP Multidrug Transporter, PLoS One, 11:e0164426, 2016.

107. Ni, Z., Bikadi, Z., Rosenberg, M. F., and Mao, Q., Structure and function of the human breast cancer resistance protein (BCRP/ABCG2), Curr Drug Metab, 11:603-617, 2010.

108. Heredi-Szabo, K., Glavinas, H., Kis, E., Mehn, D., Bathori, G., Veres, Z., Kobori, L., von Richter, O., Jemnitz, K., and Krajcsi, P., Multidrug resistance protein 2-mediated estradiol-17beta-D-glucuronide transport potentiation: in vitro-in vivo correlation and species specificity, Drug Metab Dispos, 37:794801, 2009. 
109. Shapiro, A. B., and Ling, V., Positively cooperative sites for drug transport by P-glycoprotein with distinct drug specificities, Eur J Biochem, 250:130137, 1997.

110. Giri, N., Agarwal, S., Shaik, N., Pan, G., Chen, Y., and Elmquist, W. F., Substrate-Dependent Breast Cancer Resistance Protein (Bcrp1/Abcg2)Mediated Interactions: Consideration of Multiple Binding Sites in in Vitro Assay Design, in Drug Metab Dispos, Vol. 37, pp. 560-570 (2009).

111. Robey, R. W., Honjo, Y., van de Laar, A., Miyake, K., Regis, J. T., Litman, T., and Bates, S. E., A functional assay for detection of the mitoxantrone resistance protein, MXR (ABCG2), Biochim Biophys Acta, 1512:171-182, 2001.

112. Minderman, H., Suvannasankha, A., O'Loughlin, K. L., Scheffer, G. L., Scheper, R. J., Robey, R. W., and Baer, M. R., Flow cytometric analysis of breast cancer resistance protein expression and function, Cytometry, 48:5965, 2002.

113. Ozvegy-Laczka, C., Hegedus, T., Varady, G., Ujhelly, O., Schuetz, J. D., Varadi, A., Keri, G., Orfi, L., Nemet, K., and Sarkadi, B., High-affinity interaction of tyrosine kinase inhibitors with the ABCG2 multidrug transporter, Mol Pharmacol, 65:1485-1495, 2004.

114. Matsson, P., Englund, G., Ahlin, G., Bergstrom, C. A., Norinder, U., and Artursson, P., A global drug inhibition pattern for the human ATP-binding cassette transporter breast cancer resistance protein (ABCG2), J Pharmacol Exp Ther, 323:19-30, 2007.

115. Matsson, P., Pedersen, J. M., Norinder, U., Bergstrom, C. A., and Artursson, P., Identification of novel specific and general inhibitors of the three major human ATP-binding cassette transporters P-gp, BCRP and MRP2 among registered drugs, Pharm Res, 26:1816-1831, 2009.

116. Bachmeier, C. J., and Miller, D. W., A fluorometric screening assay for drug efflux transporter activity in the blood-brain barrier, Pharm Res, 22:113-121, 2005.

117. Novello, F. C., and Sprague, J. M., Benzothiadiazine dioxides as novel diuretics, J. Am. Chem. Soc., 79:2028-2029, 1957. 


\section{Acknowledgement}

This work was carried out in Solvo Biotechnology's Szeged Laboratory between 2009 and 2013.

I would like to express my sincere thanks and deep gratitude to my supervisors Dr. Péter Krajcsi (Solvo) and Prof. Dr. Ferenc Fülöp Fülöp (Institute of Pharmaceutical Chemistry, University of Szeged). Without them this work could never have been realized.

I wish to express my thanks to the whole staff at the laboratory of Solvo Biotechnology for their support, help and friendship and for providing me with a pleasant working atmosphere.

I am grateful to Dr. Gábor Braunitzer for revising the final English manuscript.

Last, but not least, I would like to express my whole-hearted thanks to my family (my husband and mum) who have always ensured circumstances for me to do my work conscientiously. I also appreciate their care, magnificent help and endless patience during my $\mathrm{PhD}$ years. Without their assistance, this work would not have been completed.

Finally, I would like to thank my children their support. I'm indescribably grateful to them being with us and letting my personality develop day by day. 
ANNEX 
I. 


\title{
ATP-Binding Cassette B1 Transports Seliciclib (R-Roscovitine), a Cyclin-Dependent Kinase Inhibitor
}

\author{
Zsuzsanna Rajnai, Dóra Méhn, Erzsébet Beéry, Alper Okyar, Márton Jani, Gábor K. Tóth, \\ Ferenc Fülöp, Francis Lévi, and Peter Krajcsi
}

Solvo Biotechnology, Szeged, Hungary (Z.R., D.M., E.B., M.J., P.K.); Institut National de la Santé et de la Recherche Médicale

U776 "Rythmes Biologiques et Cancers," Hôpital Paul Brousse, Villejuif, France (A.O., F.L.); University Paris-Sud 11, Unité

Mixte de Recherche-S0776, Orsay, France (A.O., F.L.); Istanbul University Faculty of Pharmacy, Department of Pharmacology, Istanbul, Turkey (A.O.); Department of Medical Chemistry (G.K.T.) and Institute of Pharmaceutical Chemistry (F.F.), University of Szeged, Szeged, Hungary; and Assistance Publique-Hôpitaux de Paris, Unité de Chronothérapie, Département de Cancérologie, Hôpital Paul Brousse, Villejuif, France (F.L.)

Received February 16, 2010; accepted August 10, 2010

\begin{abstract}
:
Seliciclib, a cyclin-dependent kinase inhibitor, is a promising candidate to treat a variety of cancers. Pharmacokinetic studies have shown high oral bioavailability but limited brain exposure to the drug. This study shows that seliciclib is a high-affinity substrate of ATP-binding cassette B1 (ABCB1) because it activates the ATPase activity of the transporter with an $E_{50}$ of $4.2 \mu \mathrm{M}$ and shows
\end{abstract}

vectorial transport in MDCKII-MDR1 cells, yielding an efflux ratio of 8. This interaction may be behind the drug's limited penetration of the blood-brain barrier. ABCB1 overexpression, on the other hand, does not confer resistance to the drug in the models tested. These findings should be considered when treatment strategies using seliciclib are designed.

\section{Introduction}

Seliciclib (CYC202, R-roscovitine [2-(1-ethyl-2-hydroxyethylamino)6-benzylamino-9-isopropylpurine]), a 2,6,9-trisubstituted purine analog, is a second-generation cyclin-dependent kinase (CDK) inhibitor (Meijer et al., 2006). It arrests cellular proliferation and induces apoptosis through molecular interactions with the heterodimers of CDKs and cyclins. It is a potent inhibitor of the human CDK2/cyclin E, CDK1/cyclin B, CDK7/cyclin H, and CDK9/cyclin T1 (Meijer et al., 2006; Okyar and Lévi, 2008). Seliciclib binds to the ATP binding site of the respective kinases in a competitive fashion as shown in structural and kinetic studies (De Azevedo et al., 1997). A few other enzymes such as calmodulin-dependent kinase isoforms, casein kinase $1 \alpha$, casein kinase $1 \delta / \varepsilon$, dual-specificity tyrosine-(Y)-phosphorylation-regulated kinase $1 \mathrm{~A}$, elk-related tyrosine kinase 2, extracellular signal-regulated kinase 1, extracellular signal-regulated kinase 2, focal adhesion kinase, and interleukin-1 receptor-associated kinase 4 were

The work was supported by Hungarian National Office for Research and Technology [Grant XTTPSRT1]; and the European Community [Grants LSHB-CT2004-005137, LSHB-CT-2006-037499, LSHB-CT-2006-518246, LSHGCT-2006037543, LSSG-CT-2006-037654]. A.O. was a recipient of a postdoctoral fellowship from the Scientific and Technological Research Council of Turkey.

Article, publication date, and citation information can be found at http://dmd.aspetjournals.org.

doi:10.1124/dmd.110.032805. also inhibited at micromolar concentrations (Meijer et al., 2006). In addition, seliciclib also bound pyridoxal kinase and reduced the level of pyridoxal phosphate in human erythrocytes (Bach et al., 2005). Seliciclib has displayed activity against human non-smallcell lung, colon, breast, and prostate cancer cell lines in xenografted mouse models as well as against mouse Glasgow osteosarcoma (Iurisci et al., 2006; Meijer et al., 2006). Phase I and II clinical trials have shown adequate drug tolerability (Benson et al., 2007) and recently revealed high activity in patients with chronic lymphocytic leukemia or nasopharyngeal carcinoma (Weingrill et al., 2007; Hsieh et al., 2009).

Limited information exists on the resistance of cancer cells to seliciclib. One study in chronic lymphocytic leukemia in vitro models showed that CD40 stimulation up-regulated antiapoptotic Bcl-xL, A1/Bfl-1, and Mcl-1 proteins and afforded resistance to seliciclib among several agents in various pharmacologic classes (Hallaert et al., 2008).

Although seliciclib has been shown to inhibit ABCB1-mediated transport of rhodamine 123 (Bachmeier and Miller, 2005), the nature of the seliciclib-ABCB1 interaction, namely substrate versus inhibitor, is unknown as yet. The potential role of the MDR transporter ABCB1 in seliciclib resistance has not been evaluated either. A further indication of the possible role of ABCB1 in seliciclib transport stems from the observation of its limited brain uptake, which was estimated to be $25 \%$ in adult rats (Vita et al., 2005). In this study, we show that seliciclib is a selective substrate

ABBREVIATIONS: CDK, cyclin-dependent kinase; ABC, ATP-binding cassette transporter; MDR, multidrug resistance protein; LY335979, [(2R)-anti-5-\{3-[4-(10,11-difluoromethanodibenzo-suber-5-yl)piperazin-1-yl]-2-hydroxypropoxy\}quinoline; NMQ, N-methylquinidine; calcein AM, calcein acetoxymethylester; MDCKII, Madin-Darby canine kidney strain II; BCRP, breast cancer resistance protein; HRP, horseradish peroxidase; $P_{\text {app }}$, apparent permeability coefficient; MDCKII-MDR1, Madin-Darby canine kidney strain II-multidrug resistance protein 1; PLB985-BCRP, The human myelomonoblastic leukemia cell line-breast cancer resistance protein. 
TABLE 1

$C_{50}$ and $E C_{50}$ values of roscovitine transport

\begin{tabular}{clcl}
\hline ABC Transporters & \multicolumn{1}{c}{ Assays } & $\mathrm{EC}_{50}$ & $\mathrm{IC}_{50}$ \\
\hline \multirow{3}{*}{ MDR1 } & \multicolumn{2}{c}{$\mu M$} \\
& ATPase assay & 4.2 & \\
& Vesicular transport assay & & 35.5 \\
BCRP & Calcein AM assay & 11.5 \\
& ATPase assay & 63 \\
& Hoechst assay & 38 \\
\hline
\end{tabular}

of $\mathrm{ABCB} 1$ and discuss how this seliciclib-ABCB1 interaction may affect seliciclib disposition.

\section{Materials and Methods}

Chemicals. Seliciclib (CYC202, R-roscovitine [2-(1-ethyl-2-hydroxyethylamino)-6-benzylamino-9-isopropylpurine]) powder was kindly provided by the Institute de Chimie Organique, Université René Descartes, Paris, France (Hervé Galons). [(2R)-Anti-5-\{3-[4-(10,11-difluoromethanodibenzosuber-5-yl)piperazin-1-yl]-2-hydroxypropoxy\}quinoline (LY335979) was synthesized as described previously (Barnett et al., 2004). $\left[{ }^{3} \mathrm{H}\right] \mathrm{NMQ}$ was from Dr. Csaba Tömböly (Biological Research Center, Budapest, Hungary), Ko134 was from Solvo Biotechnology (Szeged, Hungary). Advanced RPMI 1640 (Invitrogen, Carlsbad, CA) was from Csertex Ltd. (Budapest, Hungary). Fetal bovine serum (Lonza, Basel, Switzerland), Dulbecco's modified Eagle's medium (Lonza), and penicillin-streptomycin (Lonza) were purchased from Biocenter Kft. (Szeged, Hungary). The mouse anti-ABCB1 monoclonal antibody C-219 (Abcam) was purchased from Biomarker Kft., and the anti-mouse IgG-horseradish peroxidase (HRP) secondary antibody, a HRP-conjugated species-specific whole antibody was from Sigma Hungary (Budapest, Hungary). Western Lightning Plus-ECL (PerkinElmer Life and Analytical Sciences, Waltham, MA) was from Per-Form Hungary Kft. (Budapest, Hungary). Calcein AM (Invitrogen) was purchased from Invitrogen Hungary (Budapest, Hungary), verapamil, Hoechst 33342, and other chemicals were from Sigma Hungary (Budapest, Hungary).

Cell Lines. The chronic myeloid leukemia cell line, K562, and its ABCB1overexpressing variant K562-MDR were received as kind gifts from Professor Balazs Sarkadi (National Blood Transfusion Service, Budapest, Hungary); MDCKII-MDR1, PLB985-BCRP (Kis et al., 2009), and parental cells were kindly provided by Dr. Katalin Német (National Blood Transfusion Service). Cells were maintained in Advanced RPMI 1640 except MDCKII and MDCKII-MDR1 cells, which were in Dulbecco's modified Eagle's medium supplemented with $1 \mathrm{~g} / \mathrm{l}$ glucose and $1 \%$ nonessential amino acids. All media were supplemented with $10 \%$ (v/v) heat-inactivated fetal bovine serum, $2 \mathrm{mM}$ L-glutamine, and $100 \mu \mathrm{g} / \mathrm{ml}$ penicillin-streptomycin and were grown under standard conditions $\left(5 \% \mathrm{CO}_{2}\right.$ and $\left.37^{\circ} \mathrm{C}\right)$.

ATPase Activity. ABC transporter-overexpressing membrane preparations show vanadate-sensitive ATPase activity that is modulated by interacting compounds. ATPase activity was measured as described previously (von Richter et al., 2009). In brief, the rate of ATP hydrolysis was determined by measuring the liberation of inorganic phosphate using PREDEASY ATPase kits for ABCB1, ABCC1, ABCC2, and ABCG2-HAM from SOLVO Biotechnology (Budapest, Hungary) and used according to the manufacturer's instructions. Membrane vesicles were incubated with various concentrations of test drugs with or without $1.2 \mathrm{mM}$ sodium orthovanadate. ATPase activities were determined as the difference of inorganic phosphate liberation measured in the presence and absence of $1.2 \mathrm{mM}$ sodium orthovanadate, an inhibitor of ABC efflux pumps. Results are presented as vanadate-sensitive ATPase activities.

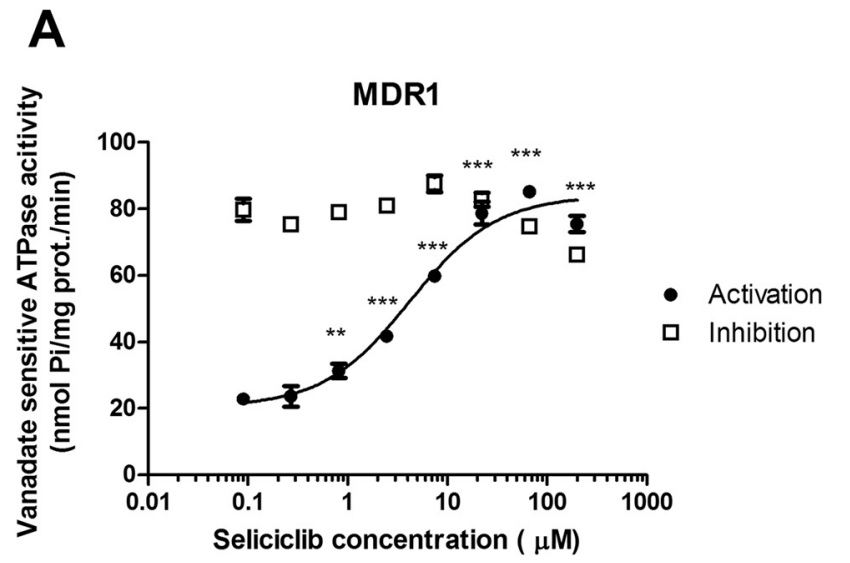

B
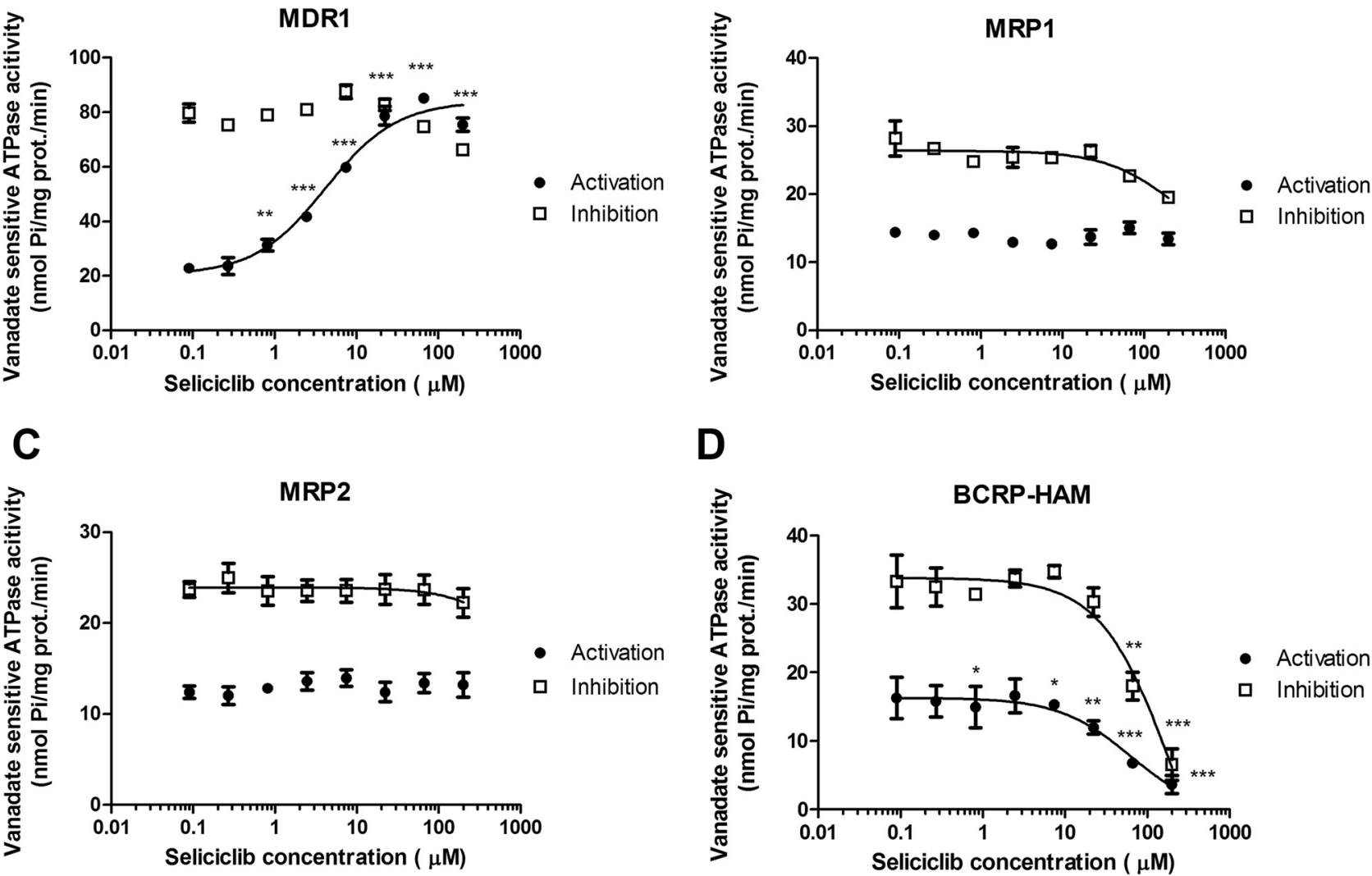

D

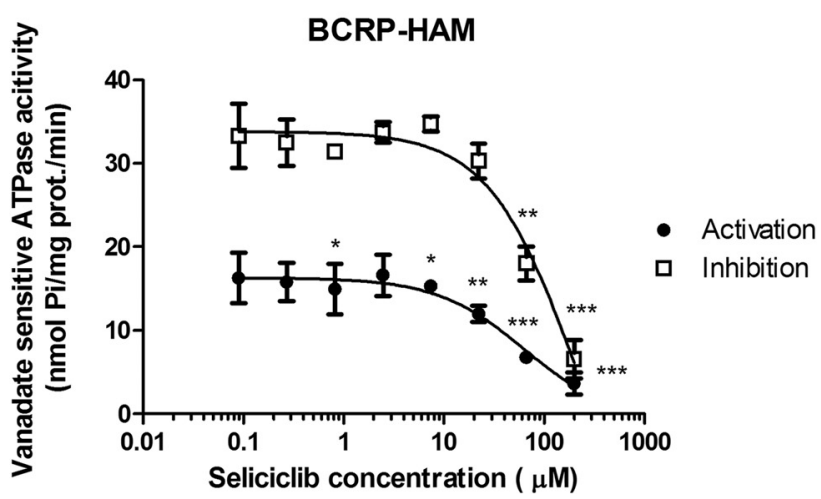

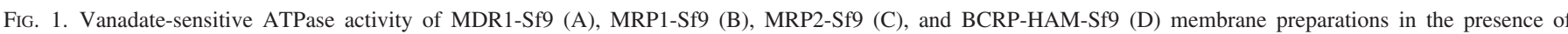

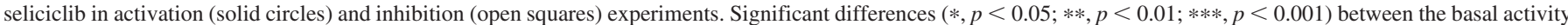

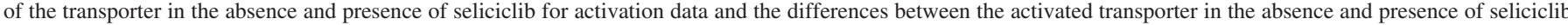
for inhibition data are indicated. MRP, multidrug resistance-associated protein. 
Vesicular Transport Assay. The interaction of seliciclib with the transporter was detected as the modulation of the initial rate of NMQ transport into the membrane vesicles. The vesicular transport assay was performed using a PREDIVEZ kit for human ABCB1 according to the manufacturer's recommendations. In brief, membrane fractions containing inside-out membrane vesicles were incubated in a 96-well plate in the presence or absence of ATP using $\left[{ }^{3} \mathrm{H}\right] \mathrm{NMQ}$ as the probe substrate. The transport was stopped by addition of cold washing buffer and consecutive rapid filtration through Millipore B glass fiber filters of a 96-well filter plate (Millipore Corporation, Billerica, MA). Filters were washed five times with $200 \mu \mathrm{l}$ of ice-cold wash buffer and dried, and the retained radioactivity was measured in scintillation cocktail (Packard UltimaGold; PerkinElmer Life and Analytical Sciences) using a Wallac MicroBeta TriLux liquid scintillation analyzer.

Hoechst Assay. Hoechst 33342 intercalates DNA, yielding a fluorescent product that can be detected. The presence of ABCG2 in the cell membrane strongly reduces Hoechst 33342 accumulation. Inhibitors of ABCG2 produce an increased rate of accumulation. The Hoechst assay was performed as described earlier (Kis et al., 2009). In brief, accumulation of Hoechst 33342 dye was measured in a fluorometer (Fluoroskan Ascent Type 374; Thermo Labsystems, Helsinki, Finland) at $350 \mathrm{~nm}$ (excitation) and $460 \mathrm{~nm}$ (emission) by using PLB985-BCRP cells. The cells were preincubated at $37^{\circ} \mathrm{C}$ in $1 \times$ Hanks' balanced salt solution with drugs for $30 \mathrm{~min}$. The Hoechst 33342 dye was added in $50 \mu \mathrm{l}$ at a final concentration of $12.5 \mu \mathrm{M}$. The fluorescence intensities were recorded for $15 \mathrm{~min}$. The positive control measurements to determine $100 \%$ inhibition were performed in the presence of $400 \mathrm{nM} \mathrm{Ko} 134$, a specific ABCG2 inhibitor (Allen et al., 2002).

Calcein Assay. Calcein AM penetrates the plasma membrane by passive diffusion. Intracellularly calcein AM is hydrolyzed by endogenous esterases, yielding a fluorescent product, calcein, which can be detected. The presence of $\mathrm{ABCB} 1$ in the cell membrane strongly reduces calcein accumulation. Inhibitors of $\mathrm{ABCB} 1$ produce an increased rate of accumulation. The calcein assay was performed as described earlier (von Richter et al., 2009). In brief, accumulation of the calcein dye was measured in a fluorimeter (Fluoroskan Ascent Type 374) at $485 \mathrm{~nm}$ (excitation) and $538 \mathrm{~nm}$ (emission) by using K562-MDR cells. Cells $(80,000 /$ well) were incubated in $100 \mu \mathrm{l}$ of Hanks' balanced salt solution in the presence of the test compound or positive control for $15 \mathrm{~min}$. After the incubation, calcein AM in $100 \mu \mathrm{l}$ of HBSS was added at a final concentration of $0.25 \mu \mathrm{M}$. Fluorescence intensities were recorded for $8 \mathrm{~min}$. The positive control measurements to determine $100 \%$ inhibition were obtained in the presence of $60 \mu \mathrm{M}$ verapamil.

Western Blotting. The proteins were separated using a $10 \%$ polyacrylamide gel and transferred to polyvinylidene difluoride membrane (Immobilon-P; Millipore Corporation) at $350 \mathrm{~mA}$ in a transfer buffer composed of $25 \mathrm{mM}$ Tris, 192 $\mathrm{mM}$ glycine, and $15 \%(\mathrm{v} / \mathrm{v})$ methanol, $\mathrm{pH}$ 8.3. The membrane was treated with blocking buffer (5\% nonfat dry milk powder and $0.5 \%$ bovine serum albumin in phosphate-buffered saline with $0.05 \%$ Tween 20 ) for $2 \mathrm{~h}$ at room temperature. The membrane was then incubated with the primary antibody, a mouse anti-ABCB1 monoclonal antibody C-219, diluted 1:3000 in blocking buffer for $2 \mathrm{~h}$ at room temperature. The membrane was washed three times for $10 \mathrm{~min}$ each with phosphate-buffered saline- $0.05 \%$ Tween 20 at room temperature. It was then incubated with the secondary antibody, anti-mouse IgG-HRP, a horseradish peroxidase-conjugated species-specific whole antibody diluted 1:5000 in blocking buffer for $1 \mathrm{~h}$ at room temperature. The membrane was subsequently washed as described above, and immunoreactive bands were visualized with enhanced chemiluminescence.

MDCKII Monolayer Assay. Transport assays across MDCKII-wt and MDCKII-MDR1 cells were performed described previously (von Richter et al., 2009). Cells were seeded on Millicell 24 (Millipore, Carrigtwohil, Ireland) devices according to the manufacturer's instructions. Seliciclib $(5 \mu \mathrm{M})$ was added without the ABCB1 inhibitor, LY335979 $(1 \mu \mathrm{M})$, to the medium at either the basolateral or apical compartment. Samples were taken from the receptor chamber at 15, 30, 60, and $120 \mathrm{~min}$. Concentrations of seliciclib were determined using an Agilent 1100 series high-performance liquid chromatograph equipped with a mass selective detector Quad VL System (Agilent, Waldbronn, Germany). Samples from the 60-min point were used for the apparent permeability coefficient $\left(P_{\text {app }}\right)$ calculations.

Cytotoxicity Assay. Cytotoxicity assays were performed by seeding HL60 (50,000 cells/well), HL60-MDR1 (50,000 cells/well), K562 (50,000 cells/well),
K562-MDR (50,000 cells/well), MDCKII-wt (1000 cells/well), and MDCKIIMDR1 (1000 cells/well) in 96-well plates containing the culture medium (200 $\mu \mathrm{l} /$ well). After $24 \mathrm{~h}$, drugs were prediluted in medium and added to the cells at different concentrations as shown in the figures. The cells were further incubated with the drug in a humidified tissue culture chamber $\left(37^{\circ} \mathrm{C}\right.$ and $\left.5 \% \mathrm{CO}_{2}\right)$ for $96 \mathrm{~h}$. Surviving cells were detected by the MTS method (http://www.promega.com). $\mathrm{IC}_{50}$ values were calculated from dose-response curves (i.e., cell survival versus drug concentration) obtained in triplicate experiments.

Data Analysis. All assays were run in duplicate unless indicated otherwise. The calcein and the Hoechst assays were analyzed using the slope of the curve determined without inhibitors $\left(R_{\text {base }}\right)$, the slope of the curve in the presence of the inhibitor $\left(R_{\max }\right)$, and the slope of the curve determined for any drug at the
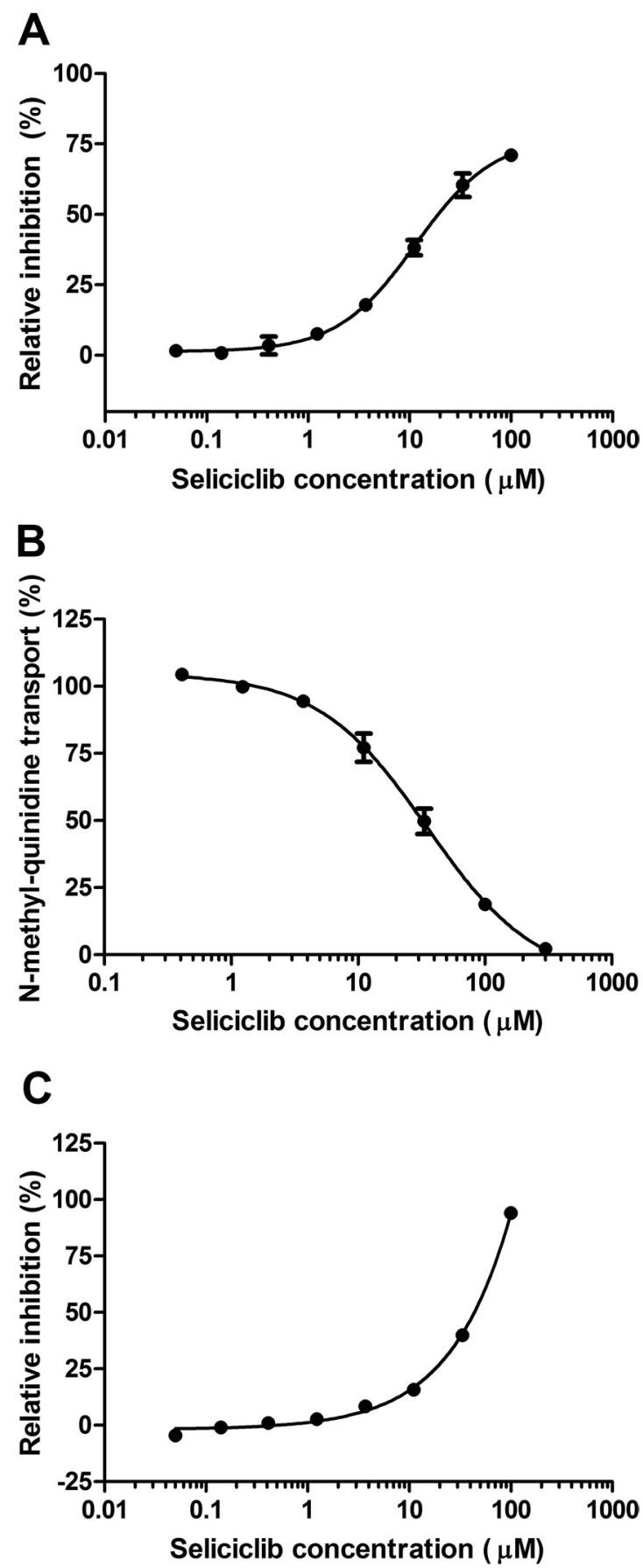

FIG. 2. Inhibition of calcein AM efflux from K562-MDR cells (A), ATP-dependent $N$-methylquinidine transport into MDR1-M inside-out vesicles (B), and Hoechst 33342 dye efflux from PLB985-BCRP cell by seliciclib (C). 
given drug concentration $\left(R_{\text {drug }}\right)$. The inhibition (percentage) of dye extrusion can be represented by the following formula:

$$
\text { Inhibition }(\%)=\frac{R_{\text {drug }}-R_{\text {base }}}{R_{\max }-R_{\text {base }}} \times 100
$$

$\mathrm{IC}_{50}$ values were derived from these curves.

For calculation of the $P_{\text {app }}$ the following equation was used:

$$
P_{\text {app }}=\frac{d Q}{d T} \times \frac{1}{A \times C_{0}}
$$

where $\mathrm{dQ}$ is the amount of test and $\mathrm{dT}$ is the incubation time. $C_{0}$ is the initial concentration of the compound in the donor compartment, and $A$ is the membrane surface area in square centimeters (standard: 0.7). The efflux ratio is given as the $P_{\text {app B-A }} / P_{\text {app A-B }}$ apparent permeability ratio, where A is apical and $\mathrm{B}$ is basolateral.

For curve fitting and $\mathrm{IC}_{50}$ calculations GraphPad Prism 4.0 software (GraphPad Software Inc., San Diego, CA) was used. Statistical analysis was performed using an unpaired $t$ test.

\section{Results}

To test interactions of seliciclib with efflux transporters present in the blood-brain barrier, ATPase assays were performed using Sf9 membranes overexpressing $\mathrm{ABCB} 1, \mathrm{ABCC} 1, \mathrm{ABCC} 2$, and $\mathrm{ABCG} 2$. Seliciclib activated the vanadate-sensitive ATPase activity of ABCB1 with an $\mathrm{EC}_{50}$ value of $4.2 \mu \mathrm{M}$ (Table 1) to the level observed in the presence of verapamil, the positive control (Fig. 1A). ABCG2 ATPase was not activated by seliciclib (Fig. 1D). However, the activated ABCG2 as well as the basal vanadate-sensitive ABCG2 ATPase was inhibited by seliciclib (Fig. 1D), albeit at a suprapharmacological concentration range (Table 1). ABCC1 only showed inhibition at very high concentrations (Fig. 1B), whereas ABCC2 did not interact at all (Fig. 1C).

To confirm interactions with $\mathrm{ABCB} 1$ a vesicular transport assay using NMQ as a probe and a calcein assay were performed. Both assays showed interaction (Fig. 2, A and B) with $\mathrm{IC}_{50}$ values of 35.5

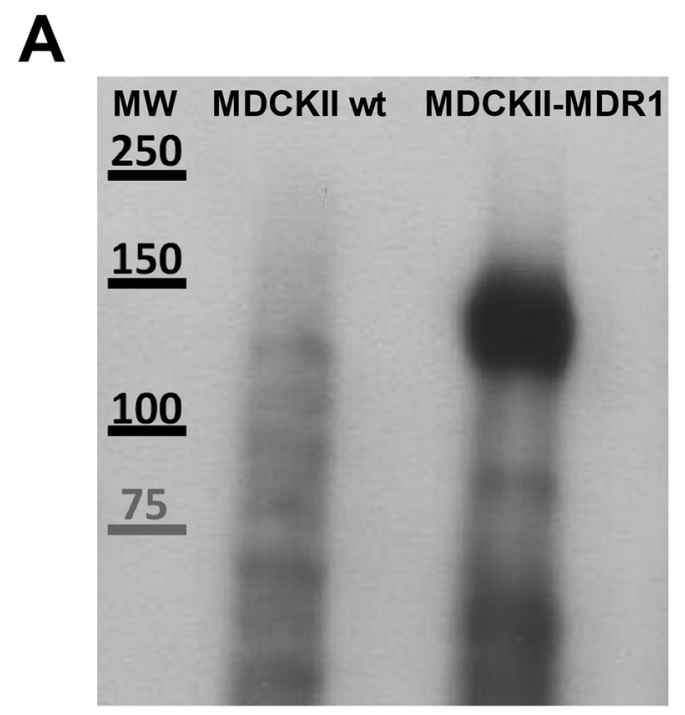

\section{C}
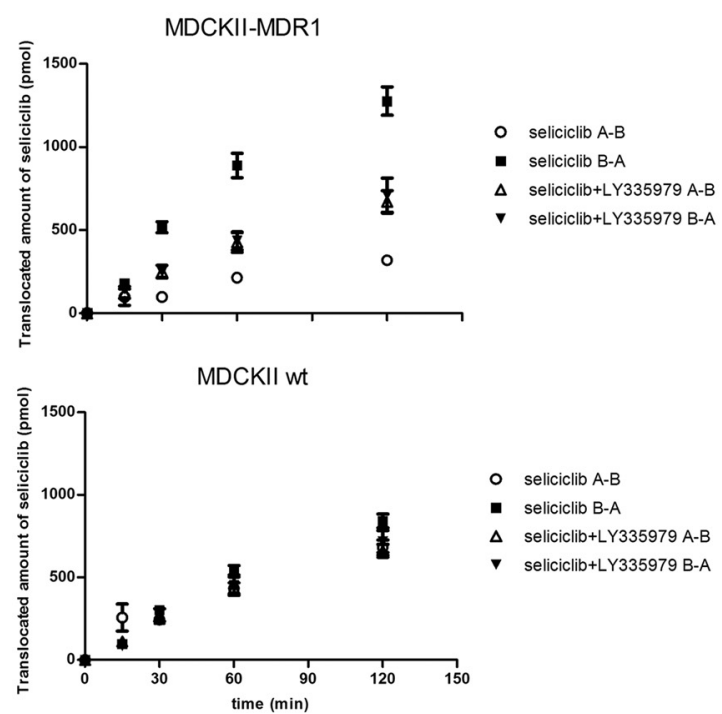

B

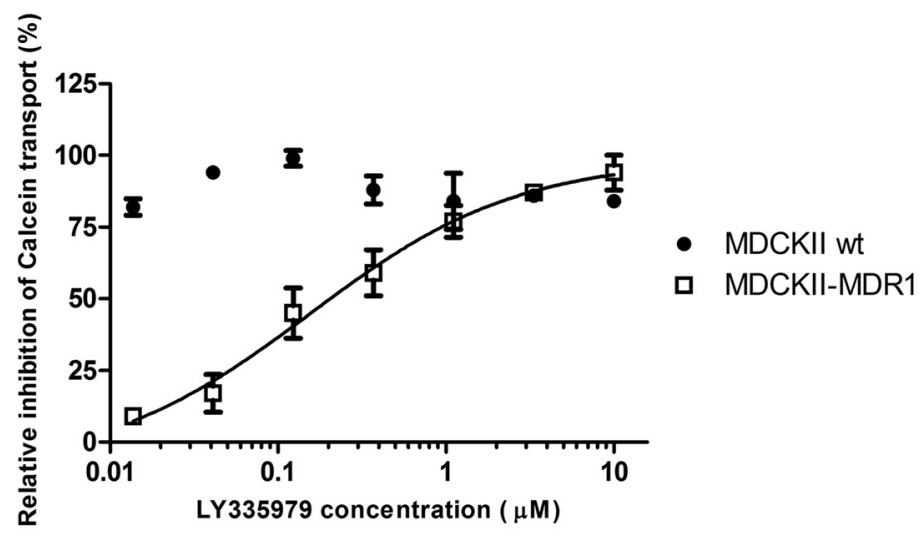

D

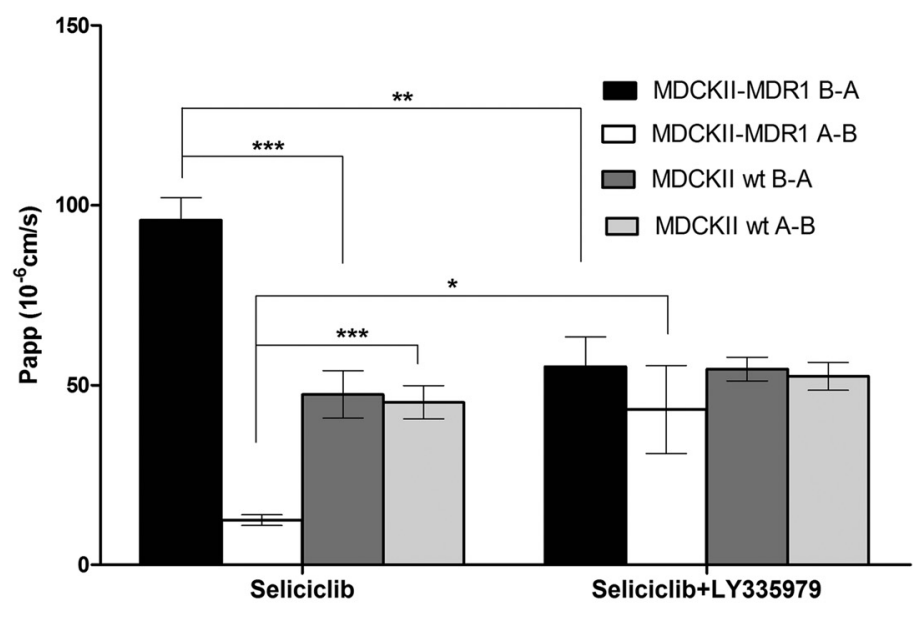

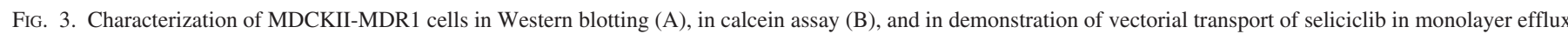

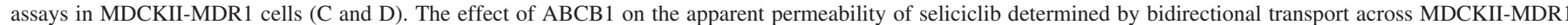

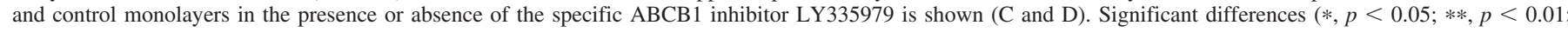
$* * *, p<0.001)$ are indicated. MW, molecular weight. 
and $11.5 \mu \mathrm{M}$, respectively (Table 1). ABCG2 inhibition by seliciclib was also confirmed in a Hoechst assay (Fig. 2C) with an $\mathrm{IC}_{50}$ of 38 $\mu \mathrm{M}$ (Table 1).

Activation of ABCB1 ATPase by seliciclib indicated that the drug is a transported substrate of ABCB1. To confirm the transport, MDCKII-MDR1 cells were used (Fig. 3). MDCKII-MDR1 cells greatly overexpress human MDR1 (Fig. 3A). Basal calcein fluorescence of MDCKII-MDR1 cells was much lower than basal calcein fluorescence of control cells but reached approximately the same level in the presence of LY335979 (Fig. 3B), an ABCB1-specific inhibitor (Dantzig et al., 2003). In addition, in MDCKII-MDR1 cells unlike in control cells (Fig. 3C), permeability of seliciclib was much greater in the basolateral to apical direction than in the apical to basolateral direction, resulting in an efflux ratio of approximately 8 in MDCKIIMDR1 cells. In the presence of LY335979, the observed efflux ratio in the MDCKII-MDR1 cells was 1.2 (Fig. 3D).

We tested whether ABCB1 overexpression would result in resistance to seliciclib using HL60-MDR1, K562-MDR, MDCKII-MDR1, and control cells. We found that overexpression of ABCB1 did not confer resistance to seliciclib because $\mathrm{IC}_{50}$ values in cytotoxicity tests were not significantly different for MDCKII-wt and MDCKII-MDR1 cells ( $4.9 \pm 1.3$ versus $7.1 \pm 1.6 \mu \mathrm{M}$, respectively), and addition of LY335979 did not affect susceptibility to seliciclib of either cell line
(Fig. 4A). In contrast, a marked difference was observed in susceptibility to doxorubicin (Fig. 4B) and paclitaxel (Fig. 4C). No statistically significant difference was observed in $\mathrm{IC}_{50}$ values for seliciclib in K562 and K562-MDR (45.9 \pm 5.94 versus $47.1 \pm 33.5 \mu \mathrm{M}$, respectively) or in HL60 and HL60-MDR1 (12.6 44.6 versus $17.5 \pm$ $7.5 \mu \mathrm{M}$, respectively) cells.

\section{Discussion}

Although seliciclib was taken up in the brain of rat pups via simple equilibrium diffusion, the brain/plasma AUC ratio was only $25 \%$ in adult rat brain (Vita et al., 2005; Sallam et al., 2008). This finding is in line with prior published data on the maturation of the blood-brain barrier, in which $\mathrm{ABC}$ transporters play an essential role. In the current study, we tested whether efflux transporters, thought to limit brain exposure to drugs would play a role in limiting seliciclib brain exposure. It is commonly accepted that ABCB1/Abcb1a and ABCG2/ $\mathrm{Abcg} 2$ are expressed in the luminal membrane of brain microcapillary endothelial cells (Roberts et al., 2008) and limit penetration of substrate drugs (Enokizono et al., 2007). Barrier function of ABCC1/ Abcc1 is controversial because it was shown to localize in the luminal membrane in humans (Nies et al., 2004) and more recently was found in the luminal membrane in rat brain microcapillary endothelial cells (Roberts et al., 2008). On the contrary, it is generally accepted that
A

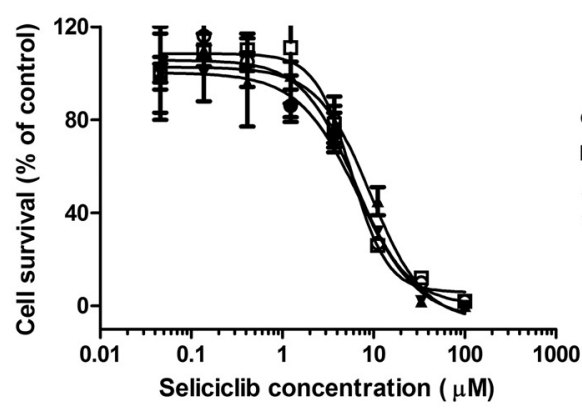

B

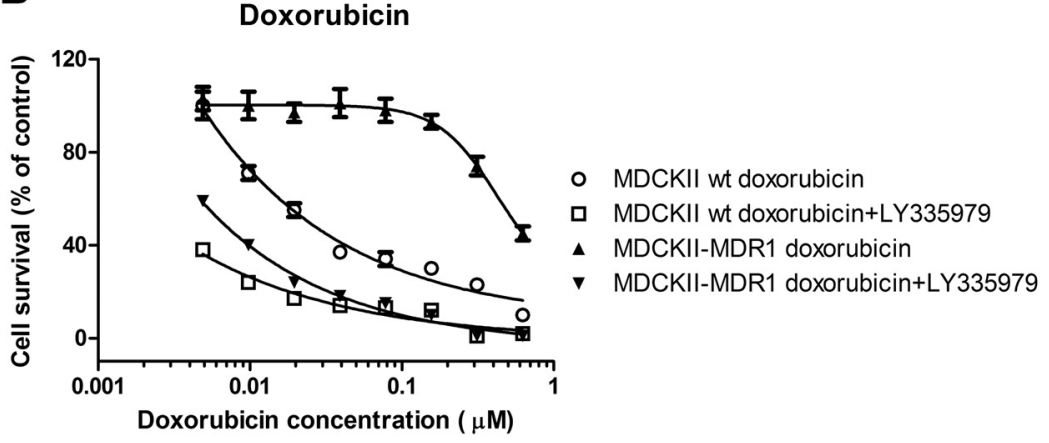

C

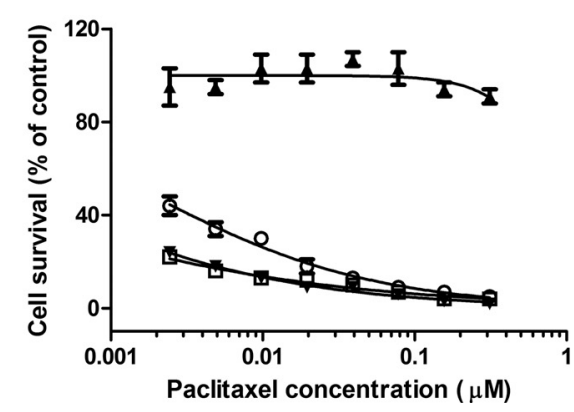

- MDCKII wt seliciclib

口 MDCKII wt seliciclib+LY335979

\ MDCKII-MDR1 seliciclib

V MDCKII-MDR1 seliciclib+LY335979
- MDCKII wt paclitaxel

口 MDCKII wt paclitaxel+LY335979

- MDCKII-MDR1 paclitaxel

V MDCKII-MDR1 paclitaxel+LY335979
FIG. 4. Effect of ABCB1 overexpression on cytotoxicity of substrate drugs. MDCKII-MDR1 and control cells were treated with seliciclib (A), doxorubicin (B), and paclitaxel (C) at concentrations indicated in the figure in the absence $(O, \mathbf{\Lambda})$ and presence $(\square, \boldsymbol{\nabla})$ of LY335979. Dose-response curves are shown. 
Abcc1 is expressed in the basolateral membrane of murine choroid plexus epithelial cells (Roberts et al., 2008) and protects brain from toxic stimuli (Wijnholds et al., 2000). The function of ABCC2/Abcc2 in the blood-brain barrier is even more controversial. The conclusion from multiple studies suggests that $\mathrm{ABCC} 2 / \mathrm{Abcc} 2$ may not play a substantial role in the blood-brain barrier under normal conditions but may get up-regulated and, thus, limit brain penetration of substrate drugs under pathological conditions (Hoffmann et al., 2006).

Our data clearly show that seliciclib is a selective substrate of ABCB1 because it activates the ABCB1 ATPase (Fig. 1A), and it shows an ABCB1-dependent vectorial transport in the MDCKIIMDR1 cells (Fig. 3, C and D). Seliciclib in phase I clinical trials reached a plasma concentration of approximately $10 \mu \mathrm{M}, 90 \%$ of which was protein-bound (Benson et al., 2007). This value is approximately $1 \log$ below the $\mathrm{EC}_{50}$ of $4.2 \mu \mathrm{M}$ for the seliciclib-ABCB1 interaction, a concentration range at which transporters exert significant effects on transcellular permeability of their substrates (Shirasaka et al., 2008). Note that the $\mathrm{AUC}_{\text {brain }} / \mathrm{AUC}_{\text {plasma }}$ value of seliciclib was approximately 1 in the 12-day-old rat pups, whereas it was approximately 0.2 in adult rats (Vita et al., 2005; Iurisci et al., 2006). The blood-brain barrier matures at 3 to 4 weeks postnatally, and it was hypothesized that an immature blood-brain barrier in pups might account for this difference (Sallam et al., 2008). No data comparing Abcb1a expression in brain microvascular endothelial cells in rat pups and in adult rats are available. In cerebellum, however, Abcbla expression is lower at 11 days than in adult animals (de Zwart et al., 2008). Therefore, it is conceivable that Abcbla is responsible for lower brain exposure in adult rats. Data demonstrating that seliciclib inhibits Abcb1-mediated rhodamine 123 transport in bovine brain microvascular endothelial cells substantiate this hypothesis (Bachmeier and Miller, 2005).

$\mathrm{ABCB} 1$ is also responsible for multidrug resistance to substrate drugs (Szakács et al., 2004). We have not observed ABCB1-mediated resistance to seliciclib-induced cell killing in three different cell lines, K562-MDR1 (Ye et al., 2009), HL-60-MDR1 (Rohlff et al., 1993), and MDCKII-MDR1 (Fig. 3, B-D), which display significant ABCB1-dependent resistance to substrate drugs. Seliciclib is a moderate to high passive permeability compound based on the permeability data of approximately $5 \times 10^{-5} \mathrm{~cm} / \mathrm{s}$ (Fig. 3D), high bioavailability (Benson et al., 2007), the $\log P$ value of 3.244 (Meijer et al., 2006), and the reasonable agreement between the membrane and cellular $\mathrm{IC}_{50}$ values $(35.5$ versus $11.5 \mu \mathrm{M})$. Therefore, the lack of a protective effect of ABCB1 against cell death inflicted by seliciclib may simply be explained by the passive permeability of the drug. In MCF7 cells, seliciclib displays greater cytotoxicity in the ABCB1overexpressing cells than in the control MCF7 line (Cappellini et al., 2009). This class of compounds has been termed MDR1-inverse because $\mathrm{ABCB} 1$ sensitizes cells to cytotoxicity by these compounds (Szakács et al., 2004). Thus, ABCB1 may play a dual role in HL60MDR1, K562-MDR, and MDCKII-MDR1 cells by reducing intracellular drug concentration and at the same time sensitizing cells to seliciclib. The two opposing effects may effectively cancel each other out in the cell lines used in this study.

Seliciclib also interacts with ABCG2 (Figs. 1 and 2). The interaction does not result in the activation of the ATPase; therefore, seliciclib is a likely inhibitor of the transporter. The observed $\mathrm{IC}_{50}$ values correlate with the low affinity observed for inhibition of ABCG2-mediated hematoporphyrin transport (An et al., 2009). The clinical free drug concentrations under current schedules (Weingrill et al., 2007) are way below the $\mathrm{IC}_{50}$ values for seliciclib-mediated ABCG2 inhibition, rendering this interaction as unlikely to be clinically relevant.
In conclusion, seliciclib is a high-affinity, selective ABCB1 substrate. This interaction is likely to affect disposition of the drug. $\mathrm{ABCB} 1$ overexpression, on the other hand, does not confer resistance to seliciclib, making the drug a favorable candidate to treat $\mathrm{ABCB} 1$ transporter-overexpressing tumors.

Acknowledgments. We acknowledge the expert help of Judit Janossy, Ph.D., Katalin Jakab, M.D., and Timea Rosta, M.Sc., in reviewing and preparing the article.

\section{References}

Allen JD, van Loevezijn A, Lakhai JM, van der Valk M, van Tellingen O, Reid G, Schellens JH, Koomen GJ, and Schinkel AH (2002) Potent and specific inhibition of the breast cancer resistance protein multidrug transporter in vitro and in mouse intestine by a novel analogue of fumitremorgin C. Mol Cancer Ther 1:417-425.

An R, Hagiya Y, Tamura A, Li S, Saito H, Tokushima D, and Ishikawa T (2009) Cellular phototoxicity evoked through the inhibition of human ABC transporter ABCG2 by cyclindependent kinase inhibitors in vitro. Pharm Res 26:449-458.

Bach S, Knockaert M, Reinhardt J, Lozach O, Schmitt S, Baratte B, Koken M, Coburn SP, Tang $\mathrm{L}$, Jiang T, et al. (2005) Roscovitine targets, protein kinases and pyridoxal kinase. J Biol Chem 280:31208-31219.

Bachmeier CJ and Miller DW (2005) A fluorometric screening assay for drug efflux transporter activity in the blood-brain barrier. Pharm Res 22:113-121.

Barnett CJ, Huff B, Kobierski ME, Letourneau M, and Wilson TM (2004) Stereochemistry of C-6 nucleophilic displacements on 1,1-difluorocyclopropyldibenzosuberanyl substrates. An improved synthesis of multidrug resistance modulator LY335979 trihydrochloride. J Org Chem 69:7653-7660.

Benson C, White J, De Bono J, O’Donnell A, Raynaud F, Cruickshank C, McGrath H, Walton M, Workman P, Kaye S, et al. (2007) A phase I trial of the selective oral cyclin-dependent kinase inhibitor seliciclib (CYC202; $R$-Roscovitine), administered twice daily for 7 days every 21 days. Br J Cancer 96:29-37.

Cappellini A, Chiarini F, Ognibene A, McCubrey JA, and Martelli AM (2009) The cyclindependent kinase inhibitor roscovitine and the nucleoside analog sangivamycin induce apoptosis in caspase-3 deficient breast cancer cells independent of caspase mediated Pglycoprotein cleavage: implications for therapy of drug resistant breast cancers. Cell Cycle 8:1421-1425.

Dantzig AH, de Alwis DP, and Burgess M (2003) Considerations in the design and development of transport inhibitors as adjuncts to drug therapy. Adv Drug Deliv Rev 55:133-150.

De Azevedo WF, Leclerc S, Meijer L, Havlicek L, Strnad M, and Kim SH (1997) Inhibition of cyclin-dependent kinases by purine analogues: crystal structure of human cdk2 complexed with roscovitine. Eur J Biochem 243:518-526.

de Zwart L, Scholten M, Monbaliu JG, Annaert PP, Van Houdt JM, Van den Wyngaert I, De Schaepdrijver LM, Bailey GP, Coogan TP, Coussement WC, et al. (2008) The ontogeny of drug metabolizing enzymes and transporters in the rat. Reprod Toxicol 26:220-230.

Enokizono J, Kusuhara H, and Sugiyama Y (2007) Effect of breast cancer resistance protein (Bcrp/Abcg2) on the disposition of phytoestrogens. Mol Pharmacol 72:967-975.

Hallaert DY, Jaspers A, van Noesel CJ, van Oers MH, Kater AP, and Eldering E (2008) c-Abl kinase inhibitors overcome CD40-mediated drug resistance in CLL: implications for therapeutic targeting of chemoresistant niches. Blood 112:5141-5149.

Hoffmann K, Gastens AM, Volk HA, and Löscher W (2006) Expression of the multidrug transporter MRP2 in the blood-brain barrier after pilocarpine-induced seizures in rats. Epilepsy Res 69:1-14.

Hsieh WS, Soo R, Peh BK, Loh T, Dong D, Soh D, Wong LS, Green S, Chiao J, Cui CY, et al. (2009) Pharmacodynamic effects of seliciclib, an orally administered cell cycle modulator, in undifferentiated nasopharyngeal cancer. Clin Cancer Res 15:1435-1442.

Iurisci I, Filipski E, Reinhardt J, Bach S, Gianella-Borradori A, Iacobelli S, Meijer L, and Lévi F (2006) Improved tumor control through circadian clock induction by Seliciclib, a cyclindependent kinase inhibitor. Cancer Res 66:10720-10728.

Kis E, Nagy T, Jani M, Molnár E, Jánossy J, Ujhellyi O, Német K, Herédi-Szabó K, and Krajcsi P (2009) Leflunomide and its metabolite A771726 are high affinity substrates of BCRP implications for drug resistance. Ann Rheum Dis 68:1201-1207.

Meijer L, Bettayeb K, and Galons H (2006) (R)-Roscovitine (CYC202, Seliciclib), in Inhibitors of Cyclin-Dependent Kinases as Anti-Tumor Agents (Smith PJ, Yue EW ed.) p. 187-225, CRC Press, Boca Raton FL.

Nies AT, Jedlitschky G, König J, Herold-Mende C, Steiner HH, Schmitt HP, and Keppler D (2004) Expression and immunolocalization of the multidrug resistance proteins, MRP1-MRP6 (ABCC1-ABCC6), in human brain. Neuroscience 129:349-360.

Okyar A and Lévi F (2008) Circadian clock control of cell cycle pathways: relevance for cancer chronotherapeutics, in Trends in Cell Cycle Research (Yoshida K, ed) p. 293-317, Research Signpost, Kerala, India.

Roberts LM, Black DS, Raman C, Woodford K, Zhou M, Haggerty JE, Yan AT, Cwirla SE, and Grindstaff KK (2008) Subcellular localization of transporters along the rat blood-brain barrier and blood-cerebral-spinal fluid barrier by in vivo biotinylation. Neuroscience 155:423-438.

Rohlff C, Safa B, Rahman A, Cho-Chung YS, Klecker RW, and Glazer RI (1993) Reversal of resistance to adriamycin by 8-chloro-cyclic AMP in adriamycin-resistant HL-60 leukemia cells is associated with reduction of type I cyclic AMP-dependent protein kinase and cyclic AMP response element-binding protein DNA-binding activities. Mol Pharmacol 43:372-379.

Sallam H, Jimenez P, Song H, Vita M, Cedazo-Minguez A, and Hassan M (2008) Age-dependent pharmacokinetics and effect of roscovitine on Cdk5 and Erk1/2 in the rat brain. Pharmacol Res 58:32-37.

Shirasaka Y, Sakane T, and Yamashita S (2008) Effect of P-glycoprotein expression levels on the concentration-dependent permeability of drugs to the cell membrane. J Pharm Sci 97:553565.

Szakács G, Annereau JP, Lababidi S, Shankavaram U, Arciello A, Bussey KJ, Reinhold W, Guo Y, Kruh GD, Reimers M, et al. (2004) Predicting drug sensitivity and resistance: profiling ABC transporter genes in cancer cells. Cancer Cell 6:129-137. 
Vita M, Abdel-Rehim M, Olofsson S, Hassan Z, Meurling L, Sidén A, Sidén M, Pettersson T, and Hassan M (2005) Tissue distribution, pharmacokinetics and identification of roscovitine metabolites in rat. Eur J Pharm Sci 25:91-103.

von Richter O, Glavinas H, Krajcsi P, Liehner S, Siewert B, and Zech K (2009) A novel screening strategy to identify ABCB1 substrates and inhibitors. Naunyn Schmiedebergs Arch Pharmacol 379:11-26.

Weingrill E, Wölfler A, Strunk D, Linkesch W, Sill H, and Liebmann PM (2007) Roscovitine in B-chronic lymphocytic leukemia cells: high apoptosis-inducing efficacy and synergism with alemtuzumab independent of the patients' pretreatment status. Haematologica 92:1286-1288. Wijnholds J, deLange EC, Scheffer GL, van den Berg DJ, Mol CA, van der Valk M, Schinkel AH, Scheper RJ, Breimer DD, and Borst P (2000) Multidrug resistance protein 1 protects the choroid plexus epithelium and contributes to the blood-cerebrospinal fluid barrier. J Clin Invest 105:279-285

Ye X, Liu T, Gong Y, Zheng B, Meng W, and Leng Y (2009) Lentivirus-mediated RNA interference reversing the drug-resistance in MDR1 single-factor resistant cell line K562/ MDR1. Leuk Res 33:1114-1119.

Address correspondence to: Dr. Peter Krajcsi, Solvo Biotehnology, 2 Gyár St., H-2040 Budaörs, Hungary. E-mail: krajcsi@solvo.com 
II. 


\title{
ABCG2 Modulates Chlorothiazide Permeability In Vitro-characterization of Its Interactions
}

\author{
Erzsébet BeÉry ${ }^{1}$, Zsuzsanna Rajnal ${ }^{1}$, Tibor AbONYI ${ }^{1}$, Ildikó MAKal ${ }^{1}$, Száva BánsáGHI ${ }^{1}$, \\ Franciska ERdő ${ }^{1}$, István SzIRÁkI ${ }^{1}$, Krisztina Herédi-Szabó ${ }^{1}$, Emese KIS ${ }^{1}$, Márton JaNI ${ }^{1}$, \\ János Márki-ZaY ${ }^{1}$, Gábor Tóth K. ${ }^{2}$ and Péter Krajcsi ${ }^{1, *}$ \\ ${ }^{1}$ Solvo Biotechnology, Szeged, Hungary \\ ${ }^{2}$ Department of Medical Chemistry, University of Szeged, Szeged, Hungary
}

Full text of this paper is available at http://www.jstage.jst.go.jp/browse/dmpk

\begin{abstract}
Summary: We are showing that chlorothiazide, a diuretic, is an ABCG2 substrate. It is a Biopharmaceutics Classification System/Biopharmaceutics Drug Distribution and Classification System (BCS/BDDCS) Class IV drug with low bioavailability. Therefore, we tested if chlorothiazide interacts with major apically located intestinal efflux transporters. Our data show that chlorothiazide is transported by ABCG2 with a $\mathrm{K}_{\mathrm{m}}$ value of $334.6 \mu \mathrm{M}$ and does not interact with $\mathrm{ABCB} 1$ or $\mathrm{ABCC} 2$. The chlorothiazide-ABCG2 interaction results in a vectorial transport in MDCKII-BCRP and Caco-2 cells with efflux ratios of 36 and 8.1 respectively. Inhibition of ABCG2 in Caco-2 cells reduced the efflux ratio to 1.4, suggesting that ABCG2 plays a role in limiting chlorothiazide bioavailability in humans.
\end{abstract}

Keywords: chlorothiazide; absorption; ABCG2 substrate; vesicular transport; MDCKII-BCRP; Caco-2; probe for regulatory studies

\section{Introduction}

Chlorothiazide is a thiazide-type diuretic drug. ${ }^{1}$ It is highly H-bonded and partly ionized at a physiological $\mathrm{pH}$, explaining the compound's low passive permeability. ${ }^{2)}$ Chlorothiazide has a low oral bioavailability. ${ }^{3)}$ As chlorothiazide is basically non-metabolized ${ }^{4)}$ this implicates a role as an efflux transporter. Chlorothiazide is classified as a Class IV drug, ${ }^{5}$ ) a class for which both influx and uptake transporters are suggested to play a role in the pharmacokinetics of member compounds. ${ }^{5}$

In the present work we tested if interaction of chlorothiazide with efflux transporters located in the apical membrane of enterocytes modulates chlorothiazide permeability. We are showing that chlorothiazide specifically interacts with ATP-binding cassette sub-family G member 2 (ABCG2/BCRP) and ABCG2 modulates permeability of chlorothiazide in human colon carcinoma cells (Caco-2) and Madin-Darby canine kidney type II (MDCKII) cells over-expressing the breast cancer resistance protein
(MDCKII-BCRP). In addition, we characterized the chlorothiazide-ABCG2 interaction employing a vesicular transport assay.

\section{Materials and Methods}

Materials: $\left[{ }^{3} \mathrm{H}\right] \mathrm{N}-$ Methyl-quinidine was purchased from Dr. Csaba Tömböly (Biological Research Center, Hungary). $\left[{ }^{3} \mathrm{H}\right]$ Estradiol-17- $\beta$-D-glucuronide $(41.8 \mathrm{Ci} / \mathrm{mmol})$ and $\left[{ }^{3} \mathrm{H}\right]-$ Estrone-3-sulfate $(54.3 \mathrm{Ci} / \mathrm{mmol})$ (PerkinElmer Life and Analytical Sciences, Boston, MA, USA) were purchased from Medinspect Kft. (Fót, Hungary). Ko143 was obtained from Professor Gerrit-Jan Koomen (U. Amsterdam, Amsterdam, The Netherlands).

Fetal bovine serum (FBS, Lonza, Basel, Switzerland), Eagle's Minimum Essential Medium (EMEM, Lonza), Dulbecco's Modified Eagle's Medium (DMEM, Lonza), and penicillin-streptomycin (Lonza) were purchased from Biocenter Kft. (Szeged, Hungary). Chlorothiazide and other chemicals were purchased from Sigma-Aldrich (Sigma Aldrich $\mathrm{Kft}$, Budapest, Hungary) and were of analytical grade.

Received July 13, 2011; Accepted November 16, 2011

J-STAGE Advance Published Date: November 29, 2011, doi:10.2133/dmpk.DMPK-11-NT-068

*To whom correspondence should be addressed: Peter Krajcsi, Ph.D., Solvo Biotehnology, 2 Gyár St. H-2040 Budaörs, Hungary, Tel. +36-23-503943, Fax.+36-23-503-941,E-mail:krajcsi@solvo.com

The work was supported by Hungarian National Office for Research and Technology [Grant XTTPSRT1] (Xenobiotic Transporter Technology Platform Therapeutic and Toxicological Applications), [Grant GOP 1.3.2. ] (Development of an in vivo technological platform for pharmaceutical applications by enhancing R\&D capacities). 
Membranes: Membrane vesicle preparations expressing the human $\mathrm{ABCB} 1, \mathrm{ABCC} 2$, and $\mathrm{ABCG} 2$ transporters were prepared by Solvo Biotechnology (Szeged, Hungary) from baculovirus-infected Sf9 cells (MDR1-Sf9, MRP2Sf9, and BCRP-HAM-Sf9, respectively) and from ABCG2 over-expressing mammalian cells (BCRP-M) and its control (M-Ctrl).

Cell lines: MDCKII cells were kindly provided by Professor Kai Simons at Max Planck Institute (Dresden, Germany) and the MDCKII-BCRP cells ${ }^{6}$ originally obtained from Professor Heyo Klaus Kroemer at University of Greifswald (Greifswald, Germany) were from Solvo Biotechnology. The Caco-2 cell line was obtained from American Type Culture Collection (ATCC). Cells were cultured in DMEM (MDCKII) and EMEM (Caco-2) containing $10 \%(\mathrm{v} / \mathrm{v})$ heat-inactivated FBS, $2 \mathrm{mM}$ L-glutamine and $100 \mu \mathrm{g} / \mathrm{ml}$ penicillin-streptomycin, supplemented with $1 \%$ non-essential amino acids. Cells were incubated at $37^{\circ} \mathrm{C}$ in a humidified atmosphere containing $5 \% \mathrm{CO}_{2}$.

Vesicular transport assay: Inhibition experiments using vesicular transport employing $\mathrm{ABCB} 1, \mathrm{ABCC} 2$ and ABCG2 over-expressing Sf9 membranes were performed according to the manufacturer's suggestions, using $4 \mathrm{mM}$ ATP and $\left[{ }^{3} \mathrm{H}\right] \mathrm{N}$-methyl-quinidine, $\left[{ }^{3} \mathrm{H}\right]$ Estradiol-17- $\beta$-D-glucuronide, and $\left[{ }^{3} \mathrm{H}\right]$ Estrone-3-sulfate as probe substrates for $\mathrm{ABCB} 1, \mathrm{ABCC} 2$, and $\mathrm{ABCG} 2$, respectively. The transport was stopped by addition of ice cold washing buffer and consecutive rapid filtration through class B $1 \mu \mathrm{m}$ pore size glass fiber filters, $0.65 \mu \mathrm{m}$ pore size Durapore membrane in a 96-well filter plate (MSFBN6B10, Millipore Corporation, Billerica, MA, USA). After washing the membranes with $200 \mu \mathrm{l}$ ice-cold wash buffer five times, filters were dried and radioactivity was measured in a scintillation cocktail (Packard UltimaGold; Perkin-Elmer, Waltham, MA, USA) using a Wallac MicroBeta TriLux (Perkin-Elmer) liquid scintillation counter. ATP-dependent transport was calculated by subtracting the values obtained in the presence of AMP from those in the presence of ATP.

Determination of chlorothiazide transport was carried out as described above using cold chlorothiazide. Quantitation of chlorothiazide was done by LC/MS as described below.

Vesicular transport assays were run in duplicate. Data are presented as mean \pm S.D.

Bioanalytical quantitation of chlorothiazide: Concentration of chlorothiazide in the samples was determined on an Agilent 1100-Series HPLC System equipped with a mass selective detector Quad VL System (Agilent, Santa Clara, CA, USA) purchased from Kromat $\mathrm{Kft}$. (Budapest, Hungary). The analytical column was a Synergy $2.5 \mu$ Fusion-RP 100 angstrom Mercury, $20 \times 4.0$ $\mathrm{mm}$ (Phenomenex, Torrance, CA, USA) from GenLab Kft (Budapest, Hungary) in combination with a Zorbax Eclipse Plus-C8 Narrow Bore Guard Column, $2.1 \times 12.5 \mathrm{~mm}$, 5Micron (Agilent) purchased from Kromat Kft (Budapest, Hungary). The mobile phases were $0.05 \%$ (v/v) acetic acid
(A) and acetonitrile (B) with an isocratic elution $(B=10 \%)$. The flow rate was $0.5 \mathrm{ml} / \mathrm{min}$ and the column oven temperature was $25^{\circ} \mathrm{C}$. Single ion monitoring was used for data acquisition (negative mode, $\mathrm{m} / \mathrm{z}=293.7$ ).

ATPase assay: ATPase activity was measured using the PREDEASY ATPase kit for ABCG2 from Solvo Biotechnology according to the manufacturer's instructions. In brief, in the activation mode the membrane vesicles $(4 \mu \mathrm{g} /$ well $)$ were incubated with various concentrations of the test drug with or without $1.2 \mathrm{mM}$ sodium orthovanadate for $10 \mathrm{~min}$ at $37^{\circ} \mathrm{C}$. ATPase activities were determined as the difference in inorganic phosphate liberation measured in the absence and presence of $1.2 \mathrm{mM}$ sodium orthovanadate (vanadatesensitive ATPase activity). In the inhibition mode, the transporter was turned on by addition of sulfasalazine $(10 \mu \mathrm{M})$, a reference substrate/activator, and inhibition was monitored in the presence of increasing concentrations of the test drug. The ATPase assay experiments were run in duplicate. Results are presented as vanadate-sensitive ATPase activities.

Monolayer assays: MDCKII and MDCKII-BCRP cells $\left(5 \times 10^{5}\right.$ cells/well) were plated onto polycarbonate permeable supports with $0.7 \mathrm{~cm}^{2}$ filter area and $0.4 \mu \mathrm{m}$ pore size (Millipore Millicell, Millipore Hungary, Budapest, Hungary). Media were replaced with fresh media on day three, and transport experiments were conducted on day four.

When using Caco- 2 cells, $6 \times 10^{4}$ cells per well were plated as described above. Media were replaced three times per week, and transport experiments were conducted on day 21-25.

All reaction mixtures were prepared in Hank's Balanced Saline Solution (HBSS), pH 7.4. Compounds were diluted from dimethyl sulfoxide (DMSO) stocks to $100 \mu \mathrm{M}$ (chlorothiazide) and $1 \mu \mathrm{M}$ (Ko143) final concentration. DMSO content was leveled below $0.5 \%(\mathrm{v} / \mathrm{v})$ in all wells. Ko143 was applied to both the donor and the receiver compartments.

Media were removed, and filters were rinsed twice with prewarmed $\left(37^{\circ} \mathrm{C}\right) \mathrm{HBSS}$. After a 15 -min incubation period, HBSS was removed and the reaction was started with addition of the appropriate reaction mixtures. Transport was carried out for $120 \mathrm{~min}$. Samples from donor compartments were taken at $0 \mathrm{~min}$, samples from receptor compartments were taken at 15, 30,60 and $120 \mathrm{~min}$.

Determination of cold chlorothiazide is described above.

Data analysis: Data analysis for membrane and monolayer assays employing Prism 4.0 (GraphPad Software, San Diego, CA, USA) was carried out as described earlier. ${ }^{7,8)}$

\section{Results}

To screen for interaction of chlorothiazide with secretory intestinal $\mathrm{ABC}$ transporters we used vesicular transport inhibition assays (Fig. 1). Chlorothiazide efficaciously inhibited ABCG2-mediated estrone-3-sulfate uptake (Fig. 1A) with an $\mathrm{IC}_{50}$ of $212.3 \pm 210.8 \mu \mathrm{M}$. No interaction with $\mathrm{ABCB} 1$ or $\mathrm{ABCC} 2$ was detected (Figs. 1B and 1C). 

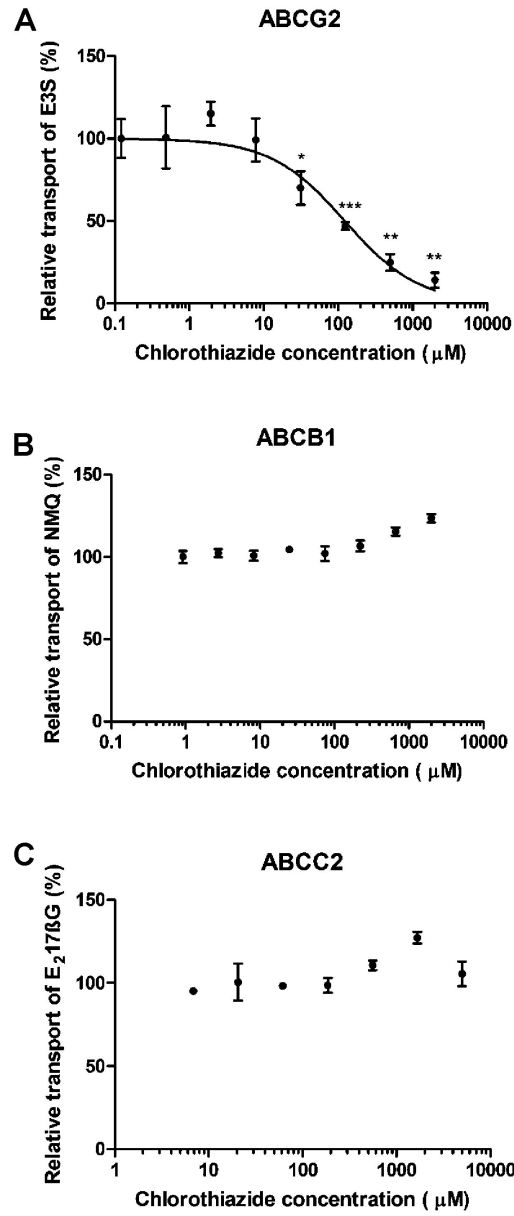

Fig. 1. ATP dependent transport of $\left[{ }^{3} \mathrm{H}\right]$ Estrone-3-sulfate, $\left[{ }^{3} \mathrm{H}\right] \mathrm{N}$ methyl-quinidine, and $\left[{ }^{3} \mathrm{H}\right]$ Estradiol-17- $\beta$-D-glucuronide into $(\mathrm{A})$ BCRP-HAM-Sf9, (B) MDR1-Sf9 and (C) MRP2-Sf9 vesicles respectively was measured in the presence of chlorothiazide at concentrations indicated in the figure

Significant differences between the activated control and datapoints $\left({ }^{*} p<0.05 ;{ }^{* *} p<0.01 ;{ }^{* * *} p<0.001\right)$ are indicated.

To characterize the interaction of chlorothiazide with ABCG2, ATPase and vesicular transport assays were used (Fig. 2). Chlorothiazide activated ABCG2 ATPase to positive control levels (Fig. 2A), indicating that it is an efficiently transported substrate of $\mathrm{ABCG} 2\left(\mathrm{EC}_{50}=327.2 \pm\right.$ $9.4 \mu \mathrm{M})$. The observed $\mathrm{K}_{\mathrm{m}}$ value in the vesicular transport experiment (Fig. 2B) was $334.6 \pm 325.0 \mu \mathrm{M}$, which correlated well with the $\mathrm{IC}_{50}$ in the inhibition experiment $(212.3 \pm 210.8 \mu \mathrm{M})$ as well as the ATPase $\mathrm{EC}_{50}$ data of $327.2 \pm 9.4 \mu \mathrm{M}$.

To confirm that this interaction may modulate absorptiondistribution-metabolism-excretion (ADME) properties of the drug, we carried out monolayer efflux experiments (Fig. 3). In the MDCKII-BCRP cells the corrected efflux ratio of around 36 was observed for the compound (Fig. 3A). This polarized transport in the B-A direction was inhibited down to the value observed in the parental cells (Fig. 3B) by
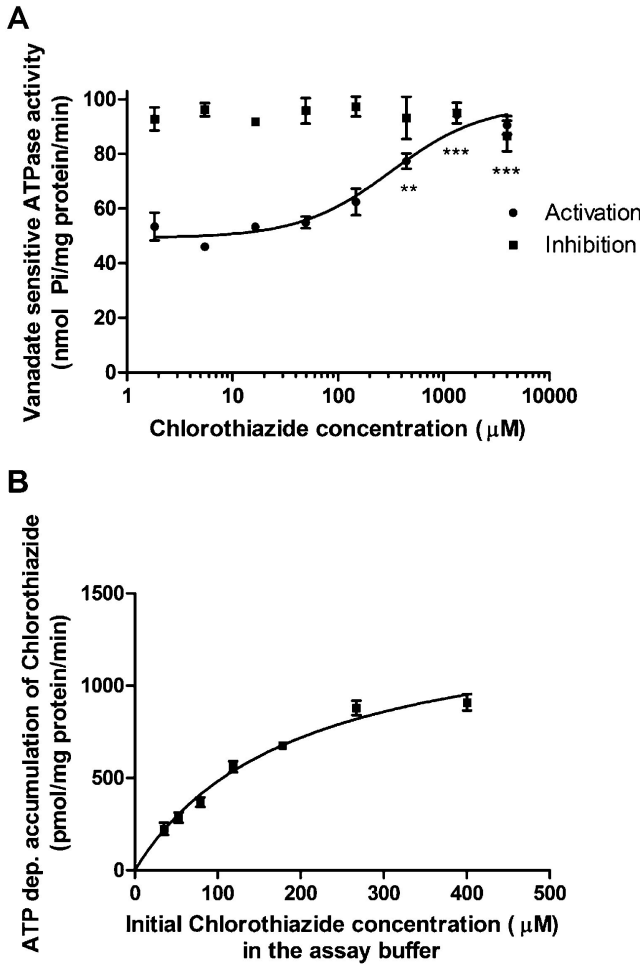

Fig. 2. ABCG2-overexpressing BCRP-M membranes were incubated with increasing concentrations of chlorothiazide and (A) vanadate-sensitive ATPase activity in activation (filled circles) and inhibition mode (filled squares) as well as (B) ATPdependent chlorothiazide transport into inside-out membrane vesicles was determined

Significant differences between the baseline and datapoints $\left({ }^{*} \mathrm{p}<0.05 ;{ }^{* *} \mathrm{p}<0.01 ;{ }^{* * *} \mathrm{p}<0.001\right)$ are indicated.

Ko143, an ABCG2 specific inhibitor. ${ }^{9)}$ In Caco-2 cells an efflux ratio of 8.1 was obtained, which decreased to 1.4 in the presence of Ko143 (Fig. 3C). In all experiments but the Caco-2 A-B direction the $P_{\text {app }}$ values changed upon Ko143 administration in a statistically significant manner. The Caco$2 \mathrm{~A}-\mathrm{B} \mathrm{P}_{\mathrm{app}}$ values increased upon Ko143 administration in all experiments (data not shown); however, the average increase was statistically insignificant (Fig. 3C).

\section{Discussion}

Chlorothiazide has a low oral bioavailability ${ }^{3)}$ with a saturable absorption. ${ }^{10,11)}$ However, even the highest bioavailabilities reported are in the $20-50 \%$ range. ${ }^{3,10-12)}$ This implies that an apically located efflux transporter may limit bioavailability of the compound.

We therefore tested if any of the three major intestinal, apically located efflux transporters-ABCB1, ABCG2 or $\mathrm{ABCC} 2$-modulates permeability of the drug in vitro. ${ }^{13)} \mathrm{A}$ vesicular transport inhibition assay showed a specific interaction with ABCG2 (Fig. 1). Chlorothiazide activated ABCG2 ATPase and showed a saturable transport in vesicular uptake experiments confirming that chlorothiazide is 
A

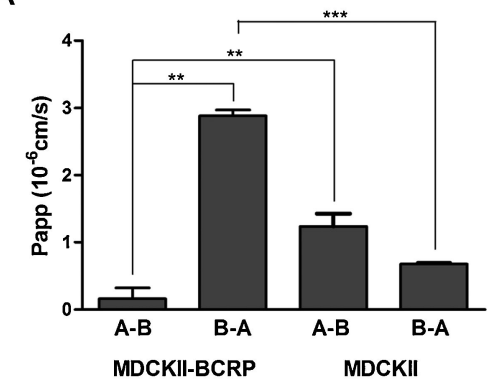

B

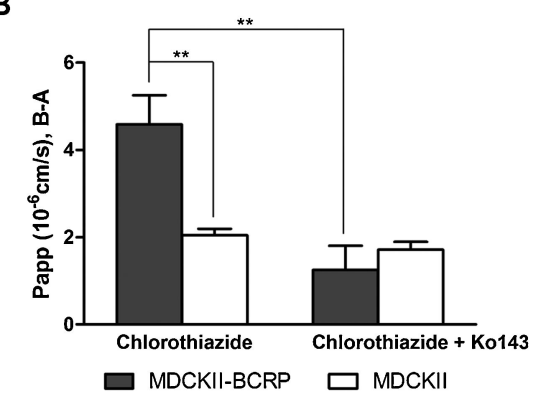

C

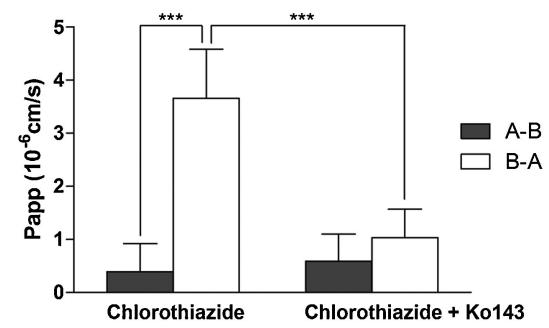

Fig. 3. (A) Bidirectional permeability of chlorothiazide in ABCG2 transfected and parental MDCKII monolayers, $(B)$ the effect of Ko143, an ABCG2-specific inhibitor, on the B-A permeability of chlorothiazide in ABCG2-transfected and parental MDCKII monolayers as well as (C) on the bidirectional permeability of chlorothiazide in Caco-2 monolayers was measured

Significant differences $\left({ }^{*} \mathrm{p}<0.05 ;{ }^{* *} \mathrm{p}<0.01\right.$; $\left.{ }^{* * *} \mathrm{p}<0.001\right)$ are indicated.

an ABCG2 substrate (Fig. 2). The ATPase $\mathrm{EC}_{50}$ and the vesicular transport $K_{m}$ values $(327.2 \pm 9.4 \mu \mathrm{M}$ and $334.6 \pm 325.0 \mu \mathrm{M}$, respectively) correlated well. Since in membrane assays kinetic values are not confounded by low permeability of tested drugs, this $\mathrm{K}_{\mathrm{m}}$ value likely reflects the affinity of chlorothiazide for ABCG2.

Monolayer efflux experiments in MDCKII-BCRP as well as in Caco-2 cells confirmed that ABCG2 modulates chlorothiazide permeability (Fig. 3). As Caco-2 cells are the most relevant in vitro human intestinal absorption models our data strongly suggest that ABCG2 is in part behind the low bioavailability of the drug. It is of note that chlorothiazide has low permeability when ABCG2 is inhibited (Fig. 3) and that certainly contributes to the low bioavailability of the drug.

Interestingly, hydrochlorothiazide, which is an ABCG2 substrate, ${ }^{14)}$ did not activate the ABCG2 ATPase to any significant extent (data not shown). It is likely that hydrochlorothiazide is transported at a lower rate by ABCG2 than chlorothiazide and that may explain the higher bioavailability (ca. $80 \%$ ) of the former drug. The physicochemical properties of the two drugs are clearly different with chlorothiazide being significantly more acidic $\left(\mathrm{pK}_{\mathrm{a} 1}=6.5\right)$ than hydrochlorothiazide $\left.\left(\mathrm{pK}_{\mathrm{a} 1}=7.9\right) .{ }^{15}\right)$ This suggests that ABCG2 may play a significant role in determining the fraction absorbed value and bioavailability of this group of drugs.

In sum, ABCG2 modulates the permeability of chlorothiazide in all three experimental systems tested. The experimental systems employed in this study comply with current regulatory guidance and suggest that chlorothiazide is a legitimate $\mathrm{ABCG} 2$ probe candidate for regulatory studies. Clinical studies to test if the $A B C G 2$ c.421C>A polymorphism affects chlorothiazide pharmacokinetics are warranted.

\section{References}

1) Novello, F. C. and Sprague, J. M.: Benzothiadiazine dioxides as novel diuterics. J. Am. Chem. Soc., 79: 2028-2029 (1957).

2) Miret, S., Abrahamse, L. and de Groene, E. M.: Comparison of in vitro models for the prediction of compound absorption across the human intestinal mucosa. J. Biomol. Screen., 9: 598-606 (2004).

3) Straughn, A. B., Melikian, A. P. and Meyer, M. C.: Bioavailability of chlorothiazide tablets in humans. J. Pharm. Sci., 68: 1099-1102 (1979).

4) Brettell, H. R., Aikawa, J. K. and Gordon, G. S.: Studies with chlorothiazide tagged with radioactive carbon (C14) in human beings. Arch. Intern. Med., 106: 57-63 (1960).

5) Shugarts, S. and Benet, L. Z.: The role of transporters in the pharmacokinetics of orally administered drugs. Pharm. Res., 26: 2039-2054 (2009).

6) Grube, M., Reuther, S., Meyer Zu Schwabedissen, H., Köck, K., Draber, K., Ritter, C. A., Fusch, C., Jedlitschky, G. and Kroemer, H. K.: Organic anion transporting polypeptide $2 \mathrm{~B} 1$ and breast cancer resistance protein interact in the transepithelial transport of steroid sulfates in human placenta. Drug Metab. Dispos., 35: 30-35 (2007).

7) Jani, M., Szabó, P., Kis, E., Molnár, E., Glavinas, H. and Krajcsi, P.: Kinetic characterization of sulfasalazine transport by human ATP-binding cassette G2. Biol. Pharm. Bull., 32: 497499 (2009).

8) Rajnai, Z., Méhn, D., Beéry, E., Okyar, A., Jani, M., Tóth, G. K., Fülöp, F., Lévi, F. and Krajcsi, P.: ATP-binding cassette B1 transports seliciclib (R-roscovitine), a cyclin-dependent kinase inhibitor. Drug Metab. Dispos., 38: 2000-2006 (2010).

9) Allen, J. D., van Loevezijn, A., Lakhai, J. M., van der Valk, M., van Tellingen, O., Reid, G., Schellens, J. H., Koomen, G. J. and Schinkel, A. H.: Potent and specific inhibition of the breast cancer resistance protein multidrug transporter in vitro and in mouse intestine by a novel analogue of fumitremorgin C. Mol. Cancer Ther., 1: 417-425 (2002).

10) Osman, M. A., Patel, R. B., Irwin, D. S., Craig, W. A. and Welling, P. G.: Bioavailability of chlorothiazide from 50, 100, and 250 MG solution doses. Biopharm. Drug Dispos., 3: 89-94 
(1982).

11) Adebayo, G. I. and Mabadeje, A. F.: Chlorothiazide absorption in humans-possible example of Michaelis-Menten kinetics. Pharmacology, 31: 181-188 (1985).

12) Hsu, F. H., Prueksaritanont, T., Lee, M. G. and Chiou, W. L.: The phenomenon and cause of the dose-dependent oral absorption of chlorothiazide in rats: extrapolation to human data based on the body surface area concept. J. Pharmacokinet. Biopharm., 15: 369-386 (1987).
13) Murakami, T. and Takano, M.: Intestinal efflux transporters and drug absorption. Expert Opin. Drug Metab. Toxicol., 4: 923-939 (2008).

14) Hasegawa, M., Kusuhara, H., Adachi, M., Schuetz, J. D., Takeuchi, K. and Sugiyama, Y.: Multidrug resistance-associated protein 4 is involved in the urinary excretion of hydrochlorothiazide and furosemide. J. Am. Soc. Nephrol., 18: 37-45 (2007).

15) www.drugbank.ca/drugs/DB00999. 
III. 


\title{
Synthesis and ABCG2 Inhibitory Activity of Novel Fumitremorgin C Analogs - Specificity and Structure Activity Correlations
}

\author{
Orsolya Szolomajer-Csikós ${ }^{\mathrm{a}}$, Erzsébet Beéry ${ }^{\mathrm{b}}$, Levente Kósa ${ }^{\mathrm{b}}$, Zsuzsanna Rajnai $^{\mathrm{b}}$, Márton Jani ${ }^{\mathrm{b}}$, \\ Anasztázia Hetényi ${ }^{\mathrm{a}}$, Katalin Tauber Jakab ${ }^{\mathrm{b}}$, Péter Krajcsi ${ }^{\mathrm{b},{ }^{*}}$ and Gábor K Tóth ${ }^{\mathrm{a}}$ \\ ${ }^{a}$ Department of Medical Chemistry, Faculty of General Medicine, University of Szeged, 6720 Szeged Dóm tér 8., \\ Hungary \\ ${ }^{b}$ Solvo Biotechnology, 6726 Szeged, Középfasor 52. Hungary
}

\begin{abstract}
The Ko family of fumitremorgin C analogs are potent and selective ABCG2 inhibitors. However, the most potent Ko compounds carry an ester linkage in their side-chain that makes them chemically and metabolically less stable. We have synthesized 16 tricyclic and 28 tetracyclic novel analogs devoid of ester linkages and tested them for ABCG2 inhibition potency and specificity. Unlike in the tricyclic analog group, potent ABCG2 inhibitory compounds were found among the tetracyclic analogs. The most potent compounds carried the $3 S, 6 S, 12 a S$ configuration. We observed a marked stereospecificity as compounds with the $3 \mathrm{~S}, 6 \mathrm{~S}, 12 \mathrm{aS}$ configuration were at least 18 -fold more potent inhibitors than their diastereoisomeric pairs with a $3 S, 6 R, 12 a S$ configuration. This stereospecificity was not observed in $\mathrm{ABCB} 1$ and $\mathrm{ABCC} 1$ inhibition. Therefore, a single chiral center confers specificity for ABCG2 over ABCB1 and ABCC1. This is quite unexpected considering the large multivalent drug binding site these transporters harbor.
\end{abstract}

Keywords: ABCG2 reversal, cancer, fumitremorgin $\mathrm{C}$ analogs, indolyl diketopiperazines, inflammatory diseases, multidrug resistance, structure-activity relationships.

\section{INTRODUCTION}

Clinical multidrug resistance (MDR) is a significant hurdle to cure [1-7]. The mechanism of resistance is called typical or classical multidrug resistance (MDR) when overexpression of a membrane efflux pump is involved in MDR. Efflux transporters actively pump drugs out of target cells and, thus, prevent drugs from reaching therapeutic intracellular concentrations. Overexpression of the three major $\mathrm{ABC}$ (ATP-binding cassette) transporters, i.e. ABCB1 (Permeability-glycoprotein (P-gp)), ABCC1 (multidrug-resistanceassociated protein 1 (MRP1)) and ABCG2 (breast cancer resistance protein (BCRP)) is frequently observed in cancer cell lines selected using chemotherapeutic drugs and is considered critical to clinical drug resistance in up to $40 \%$ of the cases [8]. The development of multidrug resistance in cancer is well documented and is a major cause of failure of antitumor chemotherapies. However, multidrug resistance is not restricted to oncological indications as multidrug resistance related to $\mathrm{ABC}$ transporters play a role in drug resistance in chronic inflammatory/autoimmune diseases [9-15]. This is of no surprise as the panel of drugs used in these indications partially overlaps the chemotherapeutic drug panel used in oncology.

Several studies have demonstrated that ABCG2 may play a role in drug-resistant haematological malignancies and

\footnotetext{
*Address correspondence to this author at the Solvo Biotechnology, Gyar u. 2., 2040-Budaörs, Hungary; Tel: +3623503940; Fax: +3623503941; E-mail: krajcsi@solvo.com
}

solid tumors [16]. The best studied neoplasias in this respect are acute leukemias. Benderra et al. demonstrated that ABCG2 expression was a prognostic factor for achievement of complete remission, disease-free survival and overall survival [17]. Another group established a positive correlation between ABCG2 levels and relapse/refractory status in acute myeloid leukemia (AML) [18]. Some reports suggested that ABCG2 overexpression was correlated with drug resistance in lung cancer cells and untreated non-small cell lung cancer tissues $[19,20]$.

ABCG2 confers resistance to agents such as irinotecan, topotecan, and mitoxantrone that are used in chemotherapy for a wide variety of cancers [16, 21]. Benderra and colleagues found clinical correlations between ABCG2 expression and treatment failure in patients receiving daunorubicin or mitoxantrone regimens but not with an idarubicin regimen [17].

More recently, it has been confirmed that tyrosine-kinase inhibitors (eg. imatinib, nilotinib, gefitinib) are high affinity ABCG2 substrates, hence ABCG2 likely plays a role in resistance to these drugs [22, 23].

ABCG2 has also been shown to transport diseasemodifying anti-rheumatic drugs (DMARDs) [24] such as leflunomide [25], sulfasalazine [26, 27]. It was shown that ABCG2 expression in sinovial macrophages is much greater in patients resistant to leflunomide and methotrexate two ABCG2 susbtrates than in patients susceptible to these drugs [28]. ABCG2 is over-expressed in stem cells, and it is commonly accepted that ABCG2 protects stem cells against toxic 
stimuli. Cancer stem cells have also been shown to overexpress ABCG2. This transporter may, thus, pose a significant barrier to more efficient treatment of cancer.

ABCG2 is limiting the uptake of several orally administered drug substrates resulting in reduced oral bioavailability aggravating target cell resistance further [21]. A wealth of clinical data is available on the effect of ABCG2 on pharmacokinetics of drugs as people carrying the $c .421 \mathrm{~A}$ allele show lower ABCG2 activity and show greater Cmax and AUC values than people of the $c .421 C C$ genotype [29].

One approach to treat multidrug resistance is the development of a reversal agent that specifically blocks the transporter and, therefore, makes the cytotoxic drug more potent. Despite initial optimism, the results of clinical trials using modulators of multidrug transporters have been disappointing overall. More than three decades have passed since the discovery of $\mathrm{ABCB} 1$, and despite development of three generations of inhibitors to reverse ABCB1-mediated resistance, no drugs have been approved for this indication. Several compound families have been shown to inhibit ABCG2. Lack of specificity seems to be a hurdle that most ABCG2 reversal agent candidates face. The first ABCG2 specific reversal agent was the mycotoxin fumitremorgin $\mathrm{C}$ (FTC), isolated from Aspergillus fumigatus. As this compound is neurotoxic in vivo [30], a focused library of FTC-type indolyl-diketopiperazines was synthetised [31]. The most potent members of the library Ko132, Ko134, and the analog Ko143 that was added later proved to be potent and non-toxic ABCG2 inhibitors in vivo in mice [32]. However, all three compounds harbor an ester linkage and, therefore, are chemically and metabolically unstable.

This study describes the synthesis and characterization of FTC-Ko analogs where ester linkage was replaced by amide or alkyl chains that are more stable chemically and metabolically. We also studied the specificity and structureactivity relationships of the compounds.

\section{MATERIALS AND METHODS}

\subsection{Chemicals Used for Chemical Synthesis and Analytics}

Chemicals were purchased from Sigma-Aldrich (SigmaAldrich Kft., Budapest, Hungary), Fluka (Sigma-Aldrich Kft., Budapest, Hungary), Merck (Merck Kft., Budapest, Hungary), Chem-Impex (Chem-Impex International INC, Wood Dale, USA), and Senn Chemicals (Senn Chemicals AG., Dielsdorf, Switzerland).

HPLC chromatographic conditions: The characterization of the fumitremorgin analogs was made by RP-HPLC using a Phenomenex Luna $5 \mu \mathrm{C} 18300 \AA$ column $(250 \times 10.0 \mathrm{~mm})$ and eluents (A) $0.1 \% \mathrm{TFA}$, (B) $80 \% \mathrm{MeCN} / 0.1 \% \mathrm{TFA}$. The flow rate was $1.0 \mathrm{ml} / \mathrm{min}$ and the detection was performed at $278 \mathrm{~nm}$. The crude fumitremorgin analogs were purified by RP-HPLC using Phenomenex Jupiter $10 \mu$ C18 $300 \AA$ $(250 \times 15 \mathrm{~mm})$ semi-preparative column and eluents described above. The flow rate was $4 \mathrm{ml} / \mathrm{min}$ and the detection was performed at $278 \mathrm{~nm}$. The applied equipment was Agilent 1100 analytical RP-HPLC instrument using a Shimadzu pump (LC-10AD), and a Shimadzu UV-VIS detector $\left(\mathrm{SPD}-10^{\circ} \mathrm{A}\right)$. All tested compounds possessed a purity of not less than $98 \%$. The MS spectra were recorded on Finnigan TSQ 7000, equipped with an ESI ion source. NMR spectra were recorded in DMSO at $298^{\circ} \mathrm{K}$ on a Bruker Avance III 600 spectrometer operating at $600.2 \mathrm{MHz}$ for $1 \mathrm{H}$ and 150.05 $\mathrm{MHz}$ for $13 \mathrm{C}$. Chemical shifts are reported in $\delta(\mathrm{ppm})$ relative to TMS as internal standard; the values of $\mathrm{J}$ are given in Hz. For the NOESY mixing time $610 \mathrm{~ms}$ were used; the number of scans was 64 . For all the 2D spectra, 2024 time domain points and 256 increments were applied. The processing was carried out by using a cosine-bell window function, with single zero filling and automatic baseline correction.

\subsection{Synthesis and Chemical Analysis of Compounds}

2.2.1. The Solid-Phase Synthesis of III.a1 (1S,3S,3'S), III.a1 (1R,3S,3'S); III.a2 (1S,3S,3'S), III.a2 (1R,3S,3'S); III.a3 (IS,3S,3'S), III.a3 (1R,3S,3'S); III.a4 (IS,3S,3'S), and III.a4 (1R,3S,3'S) Fumitremorgin Analogs

As a starting material we used Boc-Arg(Tos)-Merrifield resin $(4.00 \mathrm{~g}, 2.00 \mathrm{mmol})$ with loading of $0.50 \mathrm{mmol} / \mathrm{g}$. In the first step the Boc protecting group was removed with TFA/DCM solution $(10 \mathrm{ml}, 50 \mathrm{v} / \mathrm{v} \%)$ by stirring at room temparature for 5 and another $25 \mathrm{~min}$. The obtained deprotected resin was washed with $\mathrm{DCM}(3 \times 10 \mathrm{ml}), \mathrm{MeOH}$ $(3 \times 10 \mathrm{ml})$ and DCM $(3 \times 10 \mathrm{ml})$, neutralized with TEA/DCM $(2 \times 10 \mathrm{ml}, 10 \mathrm{v} / \mathrm{v} \%)$ and finally washed simmilarly as described above. Boc-Trp-OH $(1.82 \mathrm{~g}, 6.00 \mathrm{mmol})$ and DCC $(1.23 \mathrm{~g}, 6.00 \mathrm{mmol})$ was suspended in DCM and added to the previously washed and neutralized resin, and the reaction mixture was stirred at room temperature for $3 \mathrm{~h}$. After the coupling reaction the mixture was washed with DCM $(3 \times 10$ $\mathrm{ml}), \mathrm{MeOH}(3 \times 10 \mathrm{ml})$ and $\mathrm{DCM}(3 \times 10 \mathrm{ml})$. The coupling efficiency was monitored with the Kaiser test [33]. After a negative test the Boc protecting group was removed by using TFA/DCM solution $(10 \mathrm{ml}, 50 \mathrm{v} / \mathrm{v} \%)$, and the resin was washed with $\mathrm{DCM}(3 \times 10 \mathrm{ml}), \mathrm{MeOH}(3 \times 10 \mathrm{ml})$ and $\mathrm{DCM}$ $(3 \times 10 \mathrm{ml})$. In the next step, the resin was divided into four equal parts for the Pictet-Spengler condensation. Each part of the resin was treated with TFA/DCM solution $(10 \mathrm{ml}, 50$ $\mathrm{v} / \mathrm{v} \%)$, then acetaldehyde $(0.28 \mathrm{ml}, \quad 5.00 \mathrm{mmol})$, propionaldehyde $(0.36 \mathrm{ml}, 5.00 \mathrm{mmol})$, butyraldehyde $(0.45$ $\mathrm{ml}, 5.00 \mathrm{mmol})$, and benzaldehyde $(0.52 \mathrm{ml}, 5.00 \mathrm{mmol})$ was added to each part, and all the reaction mixtures were stirred at room temperature for $16 \mathrm{~h}$. After $16 \mathrm{~h}$, the resins were washed with $\mathrm{DCM}(3 \times 10 \mathrm{ml}), \mathrm{MeOH}(3 \times 10 \mathrm{ml})$ and $\mathrm{DCM}$ $(3 \times 10 \mathrm{ml})$. Cleavage of the analogs from the resin was performed by $\mathrm{HF}(20.00 \mathrm{ml})$ using a mixture of anisole $(0.40$ $\mathrm{ml})$, dimethylsulfide $(1.60 \mathrm{ml})$ and $p$-cresol $(0.40 \mathrm{ml})$ as scavangers for $45 \mathrm{~min}$ at $-5^{\circ} \mathrm{C}$. After cleavage the reaction mixture was evaporated in vacuo, the analogs were precipitated onto the resin in ice cold diethyl ether and lyophilized after solubilization in $\mathrm{MeCN}(10 \mathrm{ml})$ and $\mathrm{H}_{2} \mathrm{O}(50 \mathrm{ml})$.

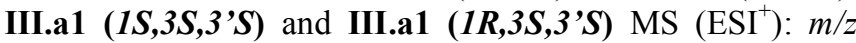
found $387\left([\mathrm{M}+\mathrm{H}]^{+}\right)$, RP-HPLC gradient $25-45 \%$ (B) 20 min, RP-HPLC retention time $t_{\text {RIII.a1 }}\left(I S, 3 S, 33^{\prime} \mathrm{s}\right)=8.78 \mathrm{~min}$, $\mathrm{t}_{\text {RIII.a1 }(I R, 3 S, 3, \mathcal{S})}=9.11 \mathrm{~min}, \mathrm{~m}_{\text {crude }}=0,19 \mathrm{~g}, \mathrm{~m}_{\text {pure }}=0,032 \mathrm{~g}$; III.a2 (1S,3S,3'S) and III.a2 (1R,3S,3'S) MS $\left(\mathrm{ESI}^{+}\right): \mathrm{m} / z$ found $401\left([\mathrm{M}+\mathrm{H}]^{+}\right)$, RP-HPLC gradient $15-30 \%$ (B) 15 min, RP-HPLC retention time $t_{\text {RIII.a2 }\left(I S, 3 S, 33^{\prime} \text { ' }\right)}=9.31 \mathrm{~min}$, 
$\mathrm{t}_{\text {RIII.a2 (IR,3S,3'S) }}=10.16 \mathrm{~min}, \mathrm{~m}_{\text {crude }}=0,12 \mathrm{mg}, \mathrm{m}_{\text {pure }}=0,025 \mathrm{~g}$, III.a3 (1S,3S,3'S) and III.a3 (1R,3S,3'S) MS (ESI $\left.{ }^{+}\right): \mathrm{m} / z$ found $415\left([\mathrm{M}+\mathrm{H}]^{+}\right)$, RP-HPLC gradient $20-30 \%$ (B) 10 min, RP-HPLC retention time $t_{\text {RIII.a3 }}(I S, 3 S, 3$ 's) $=6.13 \mathrm{~min}$, $\mathrm{t}_{\text {RIII.a3 (1R,3S,3'S) }}=6.46 \mathrm{~min}, \mathrm{~m}_{\text {crude }}=0.22 \mathrm{~g}, \mathrm{~m}_{\text {pure }}=0.04$ g,III.a4 (1S,3S,3'S) and III.a4 (1R,3S,3'S) MS (ESI $\left.{ }^{+}\right): m / z$ found $449\left([\mathrm{M}+\mathrm{H}]^{+}\right)$, RP-HPLC gradient $35-45 \%$ (B) 10 min, RP-HPLC retention time $t_{\text {RIII.a4 }}(I S, 3 S, 3$ 's) $=8.11 \mathrm{~min}$, $\mathrm{t}_{\text {RIII.a4 (1R,3S,3'S) }}=8.48 \mathrm{~min}, \mathrm{~m}_{\text {crude }}=0.18 \mathrm{~g}, \mathrm{~m}_{\text {pure }}=0.027 \mathrm{~g}$.

2.2.2. The Solid-phase Synthesis of III.b1 (1S,3S,3'S), III.b1 (1R,3S,3'S); III.b2 (1S,3S,3'S), III.b2 (1R,3S,3'S); III.b3 (1S,3S,3'S), III.b3 (1R,3S,3'S); III.b4 (1S,3S,3'S), and III.b4 (1R,3S,3'S) Fumitremorgin Analogs

Boc-Glu(OcHex)-Merrifield resin (2.22 g, $2.00 \mathrm{mmol})$ with loading $0.90 \mathrm{mmol} / \mathrm{g}$ was used as starting compound. These analogs were prepared by a procedure similar to that of used for III.a analogs. III.b1 (IS,3S,3'S) and III.b1 (1R,3S,3'S)MS (ESI $\left.{ }^{+}\right): m / z$ found $360\left([\mathrm{M}+\mathrm{H}]^{+}\right)$, RP-HPLC gradient $25-40 \%$ (B) $15 \mathrm{~min}, \mathrm{RP}-\mathrm{HPLC}$ retention time $\mathrm{t}_{\text {RIII.b1 }}$

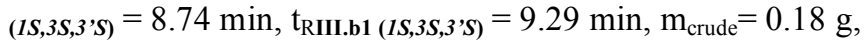
$\mathrm{m}_{\text {pure }}=0.033 \mathrm{~g}$; III.b2 (1S,3S,3'S) and III.b2 (1R,3S,3'S) MS $\left(\mathrm{ESI}^{+}\right): m / z$ found $374\left([\mathrm{M}+\mathrm{H}]^{+}\right)$, RP-HPLC gradient $15-30 \%$ (B) $15 \mathrm{~min}, \mathrm{RP}-H P L C$ retention time $\mathrm{t}_{\mathrm{RIII} . b 2}(1 S, 3 S, 3$ 's) $=5.66 \mathrm{~min}, \mathrm{t}_{\text {RIII.b2 }(1 R, 3 \mathrm{~S}, 3 \mathrm{~S} S)}=6.04 \mathrm{~min}, \mathrm{~m}_{\text {crude }}=0.23 \mathrm{~g}, \mathrm{~m}_{\text {pure }}=$ 0.048 g, III.b3 (1S,3S,3'S) and III.b3 (1R,3S,3'S) MS $\left(\mathrm{ESI}^{+}\right): m / z$ found $388\left([\mathrm{M}+\mathrm{H}]^{+}\right)$, RP-HPLC gradient $25-$ $40 \%$ (B) $15 \mathrm{~min}, \mathrm{RP}-H P L C$ retention time $\mathrm{t}_{\mathrm{RIII} . b 3}(1 \mathrm{~s}, 3 \mathrm{~s}, 3$ ' $\mathrm{S})=$ $8.02 \mathrm{~min}, \mathrm{t}_{\mathrm{RIII.b3}\left(1 R, 3 S, 3^{\prime} \mathrm{S}\right)}=8.66 \mathrm{~min}, \mathrm{~m}_{\text {crude }}=0.23 \mathrm{~g}, \mathrm{~m}_{\text {pure }}=$ 0.048 g,III.b4 (1S,3S,3'S) and III.b4 (1R,3S,3'S) MS $\left(\mathrm{ESI}^{+}\right): \mathrm{m} / z$ found $422\left([\mathrm{M}+\mathrm{H}]^{+}\right)$, RP-HPLC gradient $35-$ $45 \%$ (B) $10 \mathrm{~min}$, RP-HPLC retention time $\mathrm{t}_{\text {RIII.b4 }(1 S, 3 S, 3 \text { 's) }}=$ $8.51 \mathrm{~min}, \mathrm{t}_{\text {RIII.b4 }(1 R, 3 S, 3 \text { 's) }}=8.67 \mathrm{~min}, \mathrm{~m}_{\text {crude }}=0.19 \mathrm{~g}, \mathrm{~m}_{\text {pure }}=$ $0.027 \mathrm{~g}$.

2.2.3. The Solid-phase synthesis of III.c1 (1S,3S,3'S), III.c1 (1R,3S,3'S); III.c2 (1S,3S,3'S), III.c2 (1R,3S,3'S); III.c3 (1S,3S,3'S), III.c3 (1R,3S,3'S); III.c4 (1S,3S,3'S), and III.c4 (1R,3S,3 'S) Fumitremorgin Analogs

Boc-Asp(OcHex)-Merrifield resin (3.00 g, $2.00 \mathrm{mmol})$ was used as starting material with loading $0.66 \mathrm{mmol} / \mathrm{g}$. These compounds were synthesized by a procedure similar to that of used for III.a analogs. III.c1 (1S,3S,3'S) and III.c1 (1R,3S,3'S) MS (ESI $\left.{ }^{+}\right): m / z$ found $346\left([\mathrm{M}+\mathrm{H}]^{+}\right)$, RP-HPLC gradient 17-32\% (B) $15 \mathrm{~min}$, RP-HPLC retention

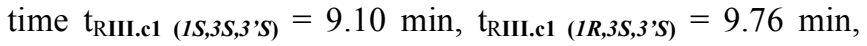
$\mathrm{m}_{\text {crude }}=0.19 \mathrm{~g}, \mathrm{~m}_{\text {pure }}=0.035 \mathrm{~g}$; III.c2 (1S,3S,3'S) and III.c2 $\left(\mathbf{1 R}, 3 \boldsymbol{S}, 3\right.$ 'S) MS $\left(\mathrm{ESI}^{+}\right): \mathrm{m} / z$ found $360\left([\mathrm{M}+\mathrm{H}]^{+}\right)$, RPHPLC gradient $15-30 \%$ (B) $15 \mathrm{~min}$, RP-HPLC retention time $\mathrm{t}_{\text {RIII.c2 }(1 S, 3 S, 3 ' S)}=7.03 \mathrm{~min}, \mathrm{t}_{\text {RIII.c2 }(1 R, 3 S, 3 ' s)}=7.44 \mathrm{~min}$, $\mathrm{m}_{\text {crude }}=0.17 \mathrm{~g}, \mathrm{~m}_{\text {pure }}=0.022 \mathrm{~g}$, III.c3 (1S,3S,3'S) and III.c3 $\left(\mathbf{1 R}, 3 \boldsymbol{S}, 3\right.$ 'S) MS $\left(\mathrm{ESI}^{+}\right): m / z$ found $374\left([\mathrm{M}+\mathrm{H}]^{+}\right)$, RPHPLC gradient $28-38 \%$ (B) $10 \mathrm{~min}$, RP-HPLC retention

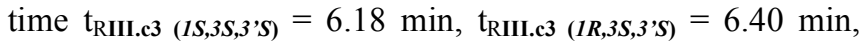
$\mathrm{m}_{\text {crude }}=0.29 \mathrm{~g}, \mathrm{~m}_{\text {pure }}=0.052 \mathrm{~g}$, III.c4 (IS,3S,3'S) and III.c4 $(1 R, 3 S, 3 ' S)$ MS $\left(\mathrm{ESI}^{+}\right): m / z$ found $408\left([\mathrm{M}+\mathrm{H}]^{+}\right)$, RPHPLC gradient $35-45 \%$ (B) $10 \mathrm{~min}$, RP-HPLC retention time $\mathrm{t}_{\text {RIII.c4 }(I S, 3 S, 3 ' S)}=8.09 \mathrm{~min}, \mathrm{t}_{\text {RIII.c4 }(1 R, 3 S, 3 ' S)}=8.11 \mathrm{~min}$, $\mathrm{m}_{\text {crude }}=0.16 \mathrm{~g}, \mathrm{~m}_{\text {pure }}=0.021 \mathrm{~g}$.
2.2.4. The Solid-phase Synthesis of III.d1 (1S,3S,3'S), III.d1 (1R,3S,3'S); III.d2 (1S,3S,3'S), III.d2 (1R,3S,3'S); III.d3 (1S,3S,3'S), III.d3 (1R,3S,3'S); III.d4 (1S,3S,3'S), and III.d4 (1R,3S,3'S) Fumitremorgin Analogs

As starting compound, we used Boc-Lys(2ClZ)Merriefield resin (3.23 g, $2.00 \mathrm{mmol})$ with loading 0.61 $\mathrm{mmol} / \mathrm{g}$. These analogs were prepared by a procedure similar to that of used for III.a analogs.III.d1 $(\mathbf{I S , 3 S , 3 ' S )}$ and III.d1 $(\mathbf{1 R}, 3 \boldsymbol{S}, 3$ 'S $)$ MS $\left(\mathrm{ESI}^{+}\right): \mathrm{m} / z$ found $359\left([\mathrm{M}+\mathrm{H}]^{+}\right)$, RP-HPLC gradient $17-32 \%$ (B) 15 min, RP-HPLC retention time $\mathrm{t}_{\text {RIII.d1 }(I S, 3 S, 3 \text { 'S) }}=8.28 \mathrm{~min}, \mathrm{t}_{\text {RIII.d1 }\left(I R, 3 S, 3{ }^{\prime} S\right)}=8.72 \mathrm{~min}$, $\mathrm{m}_{\text {crude }}=0.28 \mathrm{~g}, \mathrm{~m}_{\text {pure }}=0.045 \mathrm{~g}$; III.d2 (1S,3S,3'S) and III.d2 (1R,3S,3'S) MS (ESI $\left.{ }^{+}\right): m / z$ found $373\left([\mathrm{M}+\mathrm{H}]^{+}\right)$, RPHPLC gradient $15-30 \%$ (B) $15 \mathrm{~min}$, RP-HPLC retention time $\mathrm{t}_{\text {RIII.d2 }\left(I S, 3 S, 3{ }^{\prime} \boldsymbol{S}\right)}=8.49 \mathrm{~min}, \mathrm{t}_{\text {RIII.d2 }(\boldsymbol{I R , 3 S , 3} \boldsymbol{\prime} \boldsymbol{S})}=8.99 \mathrm{~min}$, $\mathrm{m}_{\text {crude }}=0.29 \mathrm{~g}, \mathrm{~m}_{\text {pure }}=0.038 \mathrm{~g}$, III.d3 (1S,3S,3'S) and III.d3 $\left(\mathbf{1 R}, 3 \boldsymbol{S}, 3\right.$ 'S) MS $\left(\mathrm{ESI}^{+}\right): m / z$ found $387\left([\mathrm{M}+\mathrm{H}]^{+}\right)$, RPHPLC gradient $35-45 \%$ (B) $10 \mathrm{~min}$, RP-HPLC retention time $\mathrm{t}_{\text {RIII.d3 }\left(I S, 3 S, 3{ }^{\prime} S\right)}=8.22 \mathrm{~min}, \mathrm{t}_{\text {RIII.d3 }\left(1 R, 3 S, 3{ }^{\prime} S\right)}=8.70 \mathrm{~min}$, $\mathrm{m}_{\text {crude }}=0.22 \mathrm{~g}, \mathrm{~m}_{\text {pure }}=0.041 \mathrm{~g}$, III.d4 $(\mathbf{I S}, 3 S, 3$ 'S $)$ and III.d4 $\left(\mathbf{1 R}, 3 \boldsymbol{S}, 3\right.$ 'S) MS $\left(\mathrm{ESI}^{+}\right): m / z$ found $421\left([\mathrm{M}+\mathrm{H}]^{+}\right)$, RPHPLC gradient $35-45 \%$ (B) $10 \mathrm{~min}$, RP-HPLC retention

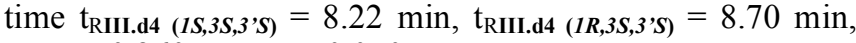
$\mathrm{m}_{\text {crude }}=0.260 \mathrm{~g}, \mathrm{~m}_{\text {pure }}=0.050 \mathrm{~g}$.

2.2.5. The Solution-phase Synthesis of 1c (3S,6S,12aS), 1c (3S,6R,12aS); $2 c$ (3S,6S,12aS), 2c (3S,6R,12aS); $4 d$ (3S,6S,12aS), 4d (3S,6R,12aS); $3 e 1$ (3S,6S,12aS), 3e1 (3S,6R,12aS); $3 e 2$ (3S,6S,12aS), $3 e 2$ (3S,6R,12aS); $3 e 3$ (3S,6S,12aS), $3 e 3$ (3S,6R,12aS); $3 e 4$ (3S,6S,12aS), $3 e 4$ (3S,6R,12aS); $3 e 5$ (3S,6S,12aS), $3 e 5$ (3S,6R,12aS); 3 e6 $(3 S, 6 S, 12 a S)$, and $3 e 6(3 S, 6 R, 12 a S)$ Fumitremorgin Ana$\operatorname{logs}$

Tryptophan methyl ester $\times \mathrm{HCl}(3.83 \mathrm{~g}, 15.00 \mathrm{mmol})$ was dissolved in DCM $(150 \mathrm{ml})$ and washed with aqueous sodium hydrogen carbonate $(3 \times 150 \mathrm{ml}, 10 \mathrm{~m} / \mathrm{v} \%)$ and saturated sodium chloride solutions $(2 \times 150 \mathrm{ml})$. The organic layer was dried $\left(\mathrm{Na}_{2} \mathrm{SO}_{4}\right)$, filtered, evaporated in vacuo and co-evaporated with $\mathrm{MeCN}$ to dryness. The obtained residue (2.54 g, $11.00 \mathrm{mmol})$ was dissolved in DCM $(200 \mathrm{ml})$ then isovaleraldehyde $(5.92 \mathrm{ml}, 55.00 \mathrm{mmol})$ and TFA $(4.23 \mathrm{ml}$, $55.00 \mathrm{mmol}$ ) was added, and the reaction mixture was stirred at room temperature for $16 \mathrm{~h}$. After $16 \mathrm{~h}$, the mixture was evaporated in vacuo, dissolved in ethyl acetate $(500 \mathrm{ml})$, and extracted with aqueous sodium hydrogen sulfate $(3 \times 100 \mathrm{ml}$, $10 \mathrm{~m} / \mathrm{v} \%)$, sodium hydrogen carbonate $(2 \times 150 \mathrm{ml}, 20 \mathrm{~m} / \mathrm{v} \%)$ and saturated sodium chloride solutions $(2 \times 100 \mathrm{ml})$. The obtained organic layer was dried $\left(\mathrm{Na}_{2} \mathrm{SO}_{4}\right)$, filtered and evaporated to dryness. Compounds a $(1 S, 3 S)$ and a $(1 R, 3 S)$ were divided into four equal parts for further reactions.

\subsubsection{The Synthesis of 1c (3S,6S,12aS) and 1c (3S,6R,12aS) Analogs}

Compounds a $(1 S, 3 S)$ and a $(1 R, 3 S)(0.50 \mathrm{~g}, 1.85 \mathrm{mmol})$ was dissolved in anhydrous DCM $(50 \mathrm{ml})$ than DIPEA (1.9 $\mathrm{ml}, 11.10 \mathrm{mmol}$ ) was added and the reaction mixture was stirred at room temperature for $30 \mathrm{~min}$ under Ar atmosphere. Fmoc-Homophe-OH (2.22 g, $5.55 \mathrm{mmol})$ amino acid and TCFH (1.55 g, $5.55 \mathrm{mmol})$ coupling reagent was dissolved in anhydrous DCM $(50 \mathrm{ml})$ and after $30 \mathrm{~min}$ preactivation, the solution was poured into the previously prepared solu- 
tion. The reaction mixture was stirred at room temperature for $10 \mathrm{~h}$ under Ar atmosphere, diluted with DCM (50 ml) and extracted with aqueous sodium hydrogen sulfate $(3 \times 100 \mathrm{ml}$, $10 \mathrm{~m} / \mathrm{v} \%)$, sodium hydrogen carbonate $(2 \times 150 \mathrm{ml})$ and saturated sodium chloride solutions $(2 \times 100 \mathrm{ml})$. The obtained organic layer was dried $\left(\mathrm{Na}_{2} \mathrm{SO}_{4}\right)$, filtered, and evaporated to dryness. The Fmoc deprotection and intramolecular cyclization was carried out in a one-pot reaction with piperidine/DCM $(5 \mathrm{ml}, 10 \mathrm{v} / \mathrm{v} \%)$. After $30 \mathrm{~min}$ the reaction mixture was treated with acetic acid $(\mathrm{pH}=4)$ and evaporated in vacuo to dryness.1c $(3 S, 6 S, 12 a S)$ and 1c $(3 S, 6 R, 12 a S)$ MS (ESI $\left.{ }^{+}\right): m / z$ found $415\left([\mathrm{M}+\mathrm{H}]^{+}\right), \mathrm{RP}-H P L C$ gradient $70-85 \%$ (B) $15 \mathrm{~min}, \mathrm{RP}-H P L C$ retention time $\mathrm{t}_{\mathrm{R} 1 \mathrm{c}(3 \mathrm{~S}, 6 \mathrm{~S}, 12 a S)}=$

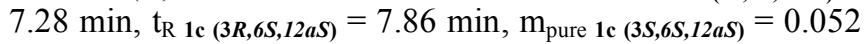
$\mathrm{g}, \mathrm{m}_{\text {pure } 1 \mathrm{c}(3 S, 6 R, 12 a S)}=0.03 \mathrm{~g}$.

\subsubsection{The Synthesis of $2 c$ (3S,6S,12aS) and $2 c$ (3S,6R,12aS) Analogs}

These analogs were prepared by a procedure similar to that of used for 1c $(3 S, 6 S, 12 a S)$ and $1 \mathrm{c}(3 S, 6 R, 12 a S)$ analogs, with the exception that Fmoc-Nva-(5-phenyl)-OH (2.30 g, $5.55 \mathrm{mmol})$ was coupled instead of Fmoc-Homophe-OH. 2c $(3 S, 6 S, 12 a S)$ and 2c $(3 S, 6 R, 12 a S) M S\left(\mathrm{ESI}^{+}\right): \mathrm{m} / z$ found $429\left([\mathrm{M}+\mathrm{H}]^{+}\right)$, RP- HPLC gradient 70-85\% (B) $15 \mathrm{~min}$, RP-HPLC retention time $t_{R} 2 c(3 s, 6 S, 12 a S)=7.85 \mathrm{~min}, t_{R} 2 c$ $(3 S, 6 R, 12 a S)=7.97 \mathrm{~min}, \mathrm{~m}_{\text {pure } 2 \mathrm{c}(3 S, 6 S, 12 a S)}=0.045 \mathrm{~g}, \mathrm{~m}_{\text {pure } 2 \mathrm{c}}$ $(3 S, 6 R, 12 a S)=0.037 \mathrm{~g}$.

2.2.8. The Synthesis of $3 e 1$ (3S,6S,12aS), $3 e 1$ (3S,6R,12aS); $3 e 2$ (3S,6S,12aS), $3 e 2$ (3S,6R,12aS); $3 e 3$ (3S,6S,12aS), $3 e 3$ (3S,6R,12aS); $3 e 4$ (3S,6S,12aS), $3 e 4$ (3S,6R,12aS); $3 e 5$ (3S,6S,12aS), $3 e 5$ (3S,6R,12aS); $3 e 6$ (3S,6S,12aS), and $3 e 6(3 S, 6 R, 12 a S)$ Fumitremorgin Ana$\operatorname{logs}$

The coupling reaction of the amino acid Fmoc-Dab(Boc)$\mathrm{OH}$ (2.44 g, $5.55 \mathrm{mmol})$, Fmoc deprotection and the intramolecular cyclization was similar that of used for 1c $(3 S, 6 S, 12 a S)$ and 1c $(3 S, 6 R, 12 a S)$ analogs. 3c $(3 S, 6 S, 12 a S)$ and 3c $(3 S, 6 R, 12 a S)$ MS $\left(\mathrm{ESI}^{+}\right): m / z$ found $454\left([\mathrm{M}+\mathrm{H}]^{+}\right)$, RP-HPLC gradient 20-100\% (B) $20 \mathrm{~min}$, RP-HPLC retention time $\mathrm{t}_{\mathrm{R} 3 \mathrm{c}(3 \mathrm{3S}, 6 \mathrm{~S}, \mathbf{1 2 a S})}=15.47 \mathrm{~min}, \mathrm{t}_{\mathrm{R} 3 \mathrm{c}(3 S, 6 R, 12 a S)}=16.08$ min, $m_{\text {crude }}=0.280 \mathrm{~g}$. After the obtained 3d $(3 S, 6 S, 12 a S)$ and 3d $(3 S, 6 R, 12 a S)$ intermedier were purified and deprotected at the side chains with TFA/DCM $(5 \mathrm{ml}, 50 \mathrm{v} / \mathrm{v} \%)$, the product was divided into six equal parts for further coupling reactions. 3d (3S,6S,12aS) and 3d (3S,6R,12aS) (0.014 g, 0.042 mmol) was dissolved in DCM $(5 \mathrm{ml})$, then TEA $(23.28 \mu 1$, $0.168 \mathrm{mmol}$ ) was added, and the mixture was stirred at room temperature for $30 \mathrm{~min}$, then the following reagents were added to each part: propionyl chloride (7.33 $\mu 1,0.084$ mmol), pivaloyl chloride $(10.44 \mu 1,0.084 \mathrm{mmol})$, acetic anhydride $(8.40 \mu \mathrm{l}, 0.084 \mathrm{mmol})$, benzoyl chloride $(8.43 \mu 1$, $0.084 \mathrm{mmol})$, isovaleroyl chloride $(10.33 \mu \mathrm{l}, 0.084 \mathrm{mmol})$, and caprylic acid $(13.31 \mu \mathrm{l}, 0.084 \mathrm{mmol})$. After $1 \mathrm{~h}$, acetic acid $(\mathrm{pH}=5)$ was added into the reaction mixtures, evaporated in vacuo, dissolved in $\mathrm{MeCN} / \mathrm{H}_{2} \mathrm{O}(5 \mathrm{ml}, 10 \mathrm{v} / \mathrm{v} \%)$, and lyophilized. 3e1 $(3 S, 6 S, 12 a S)$ and 3e1 (3S,6R,12aS) MS $\left(\mathrm{ESI}^{+}\right): \mathrm{m} / z$ found $359\left([\mathrm{M}+\mathrm{H}]^{+}\right)$, RP-HPLC gradient $60-$ $70 \%$ (B) $10 \mathrm{~min}, \mathrm{RP}-H P L C$ retention time $\mathrm{t}_{\mathrm{R}} 3 \mathrm{e} 1(3 \mathrm{~S}, 6 \mathrm{~S}, 12 a \mathrm{~S})=$ $4.21 \mathrm{~min}, \mathrm{t}_{\mathrm{R}} 3 \mathrm{e} 1{ }_{(3 S, 6 R, 12 a S)}=4.61 \mathrm{~min}, \mathrm{~m}_{\text {pure } 3 \mathrm{e} 1(3 S, 6 S, 12 a S)}=$ $0.0035 \mathrm{~g}, \mathrm{~m}_{\text {pure } 3 \mathrm{e} 1(3 S, 6 R, 12 a S)}=0.0026 \mathrm{~g} .3 \mathrm{e} 2(3 S, 6 S, 12 a S)$ and $3 \mathrm{e} 2(3 \mathrm{~S}, 6 \boldsymbol{R}, 12 a S) \mathrm{MS}\left(\mathrm{ESI}^{+}\right): \mathrm{m} / z$ found $373\left([\mathrm{M}+\mathrm{H}]^{+}\right)$, RP-
HPLC gradient $66-76 \%$ (B) $10 \mathrm{~min}$, RP-HPLC retention time $t_{\mathrm{R} 3 \mathrm{e} 2(3 S, 6 S, 12 a S)}=5.21 \mathrm{~min}, \mathrm{t}_{\mathrm{R} 3 \mathrm{e} 2(3 S, 6 R, 12 a S)}=5.36 \mathrm{~min}$, $\mathrm{m}_{\text {pure } 3 \mathrm{e} 2(3 S, 6 S, 12 a S)}=0.0014 \mathrm{~g}, \mathrm{~m}_{\text {pure } 3 \mathrm{e} 2(3 S, 6 R, 12 a S)}=0.0041 \mathrm{~g}$.

$3 \mathrm{e} 2(3 S, 6 S, 12 a S){ }^{1} \mathrm{H}$ NMR (DMSO- $\left.d_{6}\right) \delta 0.76(\mathrm{~d}, J=6.6$ $\mathrm{Hz}, 3 \mathrm{H}, \mathrm{ib}), 0.94$ (d, $J=6.5 \mathrm{~Hz}, 3 \mathrm{H}, \mathrm{ib}), 1.08$ (s, 9H, tb), $1.50-1.42(\mathrm{~m}, 1 \mathrm{H}, \mathrm{ib}), 1.54$ (ddd, $J=13.1,8.6,4.6 \mathrm{~Hz}$, $1 \mathrm{H}, \mathrm{ib}), 1.61$ (ddd, $J=13.1,8.7,4.5 \mathrm{~Hz}, 1 \mathrm{H}, \mathrm{ib}), 1.82$ (dt, $J=$ 13.5, 6.2 Hz, 1H, $\mathrm{CH}_{2}-\mathrm{CH}_{2}-\mathrm{NH}$ ), 2.07 (dt, $J=13.2,7.2 \mathrm{~Hz}$, $\left.1 \mathrm{H}, \mathrm{CH}_{2}-\mathrm{CH}_{2}-\mathrm{NH}\right), 2.84$ (dd, $\left.J=15.5,11.8 \mathrm{~Hz}, 1 \mathrm{H}, \mathrm{H}-12\right)$, $3.17\left(\mathrm{dt}, J=13.1,5.6 \mathrm{~Hz}, 1 \mathrm{H}, \mathrm{CH}_{2}-\mathrm{CH}_{2}-\mathrm{NH}\right), 3.30(\mathrm{dt}, J=$ 13.2, 7.1 Hz, $\left.1 \mathrm{H}, \mathrm{CH}_{2}-\mathrm{CH}_{2}-\mathrm{NH}\right), 3.36(\mathrm{dd}, J=15.6,5.1 \mathrm{~Hz}$, $1 \mathrm{H}, \mathrm{H}-12), 4.00$ (t, $J=5.7 \mathrm{~Hz}, 1 \mathrm{H}, \mathrm{H}-3), 4.15$ (dd, $J=11.7$, $4.9 \mathrm{~Hz}, 1 \mathrm{H}, \mathrm{H}-12 \mathrm{a}), 5.36$ (dd, $J=8.5,4.5 \mathrm{~Hz}, 1 \mathrm{H}, \mathrm{H}-6), 7.01$ $(\mathrm{t}, J=7.1 \mathrm{~Hz}, 1 \mathrm{H}, \mathrm{H}-10), 7.09-7.06(\mathrm{~m}, 1 \mathrm{H}, \mathrm{H}-9), 7.36(\mathrm{~d}, J$ $=8.0 \mathrm{~Hz}, 1 \mathrm{H}, \mathrm{H}-8), 7.53(\mathrm{dd}, J=9.8,6.7 \mathrm{~Hz}, 2 \mathrm{H}, \mathrm{H}-11$, $\left.\mathrm{CH}_{2}-\mathrm{CH}_{2}-\mathrm{NH}\right), 8.32$ (s, 1H, H-2), 11.10 (s, $\left.1 \mathrm{H}, \mathrm{H}-7\right) ;{ }^{13} \mathrm{C}$ NMR (DMSO- $\left.d_{6}\right) \delta \mathrm{C}: 21.8,22.6,24.2,24.6,27.9,30.3$, $36.0,46.1,50.6,52.2,55.7,105.8,111.8,118.2,119.2$, $121.3,126.3,135.5,136.2,169.8,170.2$

$3 \mathrm{e} 3(3 S, 6 S, 12 a S)$ and $3 \mathrm{e} 3(3 S, 6 R, 12 a S) \mathrm{MS}\left(\mathrm{ESI}^{+}\right): \mathrm{m} / z$ found $387\left([\mathrm{M}+\mathrm{H}]^{+}\right)$, RP-HPLC gradient 55-65\% (B) 10 $\min , \mathrm{RP}-H P L C$ retention time $\mathrm{t}_{\mathrm{R} 3 \mathrm{e} 3(3 S, 6 S, 12 a S)}=4.14 \mathrm{~min}, \mathrm{t}_{\mathrm{R} 3 \mathrm{e} 3}$ $(3 S, 6 R, 12 a S)=4.25 \mathrm{~min}, \mathrm{~m}_{\text {pure } 3 \mathrm{e} 3(3 S, 6 S, 12 a S)}=0.0025 \mathrm{~g}, \mathrm{~m}_{\text {pure } 3 \mathrm{e} 3}$ $(3 S, 6 R, 12 a S)=0.0036 \mathrm{~g}$.

$3 \mathrm{e} 3(3 \mathrm{~S}, 6 \mathrm{~S}, 12 \mathrm{aS}){ }^{1} \mathrm{H}$ NMR (DMSO- $\left.d_{6}\right) \delta 0.76(\mathrm{~d}, J=6.6$ $\mathrm{Hz}, 3 \mathrm{H}, \mathrm{ib}), 0.93$ (d, $J=6.5 \mathrm{~Hz}, 3 \mathrm{H}, \mathrm{ib}), 1.50-1.42(\mathrm{~m}, 1 \mathrm{H}$, ib), 1.54 (ddd, $J=13.1,8.6,4.6 \mathrm{~Hz}, 1 \mathrm{H}, \mathrm{ib}), 1.60$ (ddd, $J=$ 13.1, 8.6, $4.5 \mathrm{~Hz}, 1 \mathrm{H}, \mathrm{ib}), 1.84-1.75\left(\mathrm{~m}, 4 \mathrm{H}, \mathrm{CH}_{2}-\mathrm{CH}_{2}-\mathrm{NH}\right.$, $\mathrm{Me}), 2.05\left(\mathrm{td}, J=13.7,6.9 \mathrm{~Hz}, 1 \mathrm{H}, \mathrm{CH}_{2}-\mathrm{CH}_{2}-\mathrm{NH}\right), 2.84$ (dd, $J=15.5,11.8 \mathrm{~Hz}, 1 \mathrm{H}, \mathrm{H}-12), 3.17-3.11\left(\mathrm{~m}, 1 \mathrm{H}, \mathrm{CH}_{2}-\mathrm{CH}_{2}-\right.$ $\mathrm{NH}), 3.29\left(\mathrm{td}, J=13.4,6.7 \mathrm{~Hz}, 1 \mathrm{H}, \mathrm{CH}_{2}-\mathrm{CH}_{2}-\mathrm{NH}\right), 3.36$ $(\mathrm{dd}, J=15.6,5.1 \mathrm{~Hz}, 1 \mathrm{H}, \mathrm{H}-12), 4.01(\mathrm{t}, J=5.6 \mathrm{~Hz}, 1 \mathrm{H}, \mathrm{H}-$ 3), 4.14 (dd, $J=11.7,4.9 \mathrm{~Hz}, 1 \mathrm{H}, \mathrm{H}-12 \mathrm{a}), 5.36$ (dd, $J=8.5$, $4.5 \mathrm{~Hz}, 1 \mathrm{H}, \mathrm{H}-6), 7.01$ (dd, $J=10.9,3.9 \mathrm{~Hz}, 1 \mathrm{H}, \mathrm{H}-10$ ), 7.09-7.05 (m, 1H, H-9), $7.36(\mathrm{~d}, J=8.0 \mathrm{~Hz}, 1 \mathrm{H}, \mathrm{H}-8), 7.54$ $(\mathrm{d}, J=7.8 \mathrm{~Hz}, 1 \mathrm{H}, \mathrm{H}-11), 7.86\left(\mathrm{t}, J=5.4 \mathrm{~Hz}, 1 \mathrm{H}, \mathrm{CH}_{2}-\mathrm{CH}_{2}-\right.$ $\mathrm{NH}), 8.37$ (s, 1H, H-2), $11.09(\mathrm{~s}, 1 \mathrm{H}, \mathrm{H}-7) ;{ }^{13} \mathrm{C} \mathrm{NMR}$ $\left(\mathrm{DMSO}-d_{6}\right) \delta 21.3,22.1,22.6,23.7,24.1,29.7,35.2,45.7$, 50.0, 51.5, 55.2, 105.3, 111.4, 117.7, 118.7, 120.8, 125.8, $135.0,135.7,169.1,169.1,169.7$

$3 \mathrm{e} 3(3 \mathrm{~S}, 6 \boldsymbol{R}, 12 a S){ }^{1} \mathrm{H}$ NMR (DMSO-d $) \delta 0.92(\mathrm{~d}, J=6.1$ $\mathrm{Hz}, 3 \mathrm{H}, \mathrm{ib}), 1.06$ (d, $J=5.8 \mathrm{~Hz}, 3 \mathrm{H}, \mathrm{ib}), 1.66-1.58$ (m, 2H, ib, $\left.\mathrm{CH}_{2}-\mathrm{CH}_{2}-\mathrm{NH}\right), 1.74-1.67(\mathrm{~m}, 1 \mathrm{H}, \mathrm{ib}), 1.77$ (s, 3H, Me), 1.90-1.82 (m, 2H, ib), $2.76(\mathrm{dd}, J=14.8,12.2 \mathrm{~Hz}, 1 \mathrm{H}, \mathrm{H}-$ 12), 3.12-3.05 (m, $\left.1 \mathrm{H}, \mathrm{CH}_{2}-\mathrm{CH}_{2}-\mathrm{NH}\right), 3.25-3.18(\mathrm{~m}, 2 \mathrm{H}$, $\left.\mathrm{CH}_{2}-\mathrm{CH}_{2}-\mathrm{NH}, \mathrm{H}-12\right), 4.00-3.95$ (m, 1H, H-3), 4.32 (dd, $J=$ $11.9,4.3 \mathrm{~Hz}, 1 \mathrm{H}, \mathrm{H}-12 \mathrm{a}), 5.75$ (dd, $J=11.6,2.8 \mathrm{~Hz}, 1 \mathrm{H}, \mathrm{H}-$ 6), 6.98 (t, $J=7.4 \mathrm{~Hz}, 1 \mathrm{H}, \mathrm{H}-10), 7.07$ (t, $J=7.5 \mathrm{~Hz}, 1 \mathrm{H}, \mathrm{H}-$ 9), 7.32 (d, $J=8.1 \mathrm{~Hz}, 1 \mathrm{H}, \mathrm{H}-8), 7.42$ (d, $J=7.8 \mathrm{~Hz}, 1 \mathrm{H}, \mathrm{H}-$ 11), $7.86\left(\mathrm{t}, J=5.7 \mathrm{~Hz}, 1 \mathrm{H}, \mathrm{CH}_{2}-\mathrm{CH}_{2}-\mathrm{NH}\right), 8.42(\mathrm{~d}, J=2.8$ $\mathrm{Hz}, 1 \mathrm{H}, \mathrm{H}-2), 11.02(\mathrm{~s}, 1 \mathrm{HH}-7) ;{ }^{13} \mathrm{C}$ NMR (DMSO- $\left.d_{6}\right) \delta$ $22.4,23.0,23.9,25.1,27.9,35.3,36.3,39.6,39.7,39.9,40.0$, $40.1,40.3,40.4,42.7,47.7,52.3,52.9,105.2,111.6,118.3$, $119.2,121.6,126.5,134.8,136.4,165.8,167.0,170.1$

$3 \mathrm{e} 4(3 S, 6 S, 12 a S)$ and $3 \mathrm{e} 4(3 S, 6 R, 12 a S) \mathrm{MS}\left(\mathrm{ESI}^{+}\right): \mathrm{m} / \mathrm{z}$ found $421\left([\mathrm{M}+\mathrm{H}]^{+}\right)$, RP-HPLC gradient $65-75 \%$ (B) 10 $\min , \mathrm{RP}-H P L C$ retention time $\mathrm{t}_{\mathrm{R} 3 \mathrm{e} 4(3 \mathrm{~S}, 6 \mathrm{~S}, 12 a \mathrm{~S})}=5.51 \mathrm{~min}, \mathrm{t}_{\mathrm{R} 3 \mathrm{e} 4}$ $(3 S, 6 R, 12 a S)=5.71 \mathrm{~min}, \mathrm{~m}_{\text {pure } 3 \mathrm{e} 4(3 S, 6 S, 12 a S)}=0.0045 \mathrm{~g}, \mathrm{~m}_{\text {pure } 3 \mathrm{e} 4}$ $(3 S, 6 R, 12 a S)=0.0042 \mathrm{~g}$. 
3e4 (3S,6S,12aS) ${ }^{1} \mathrm{H}$ NMR (DMSO- $\left.d_{6}\right) \delta 0.75(\mathrm{~d}, J=6.5$ $\mathrm{Hz}, 3 \mathrm{H}, \mathrm{ib}), 0.94$ (d, $J=6.4 \mathrm{~Hz}, 3 \mathrm{H}, \mathrm{ib}), 1.51-1.41(\mathrm{~m}, 1 \mathrm{H}$, ib), $1.58-1.51(\mathrm{~m}, 1 \mathrm{H}, \mathrm{ib}), 1.64-1.58(\mathrm{~m}, 1 \mathrm{H}, \mathrm{ib}), 2.01-1.93$ (m, $\left.1 \mathrm{H}, \mathrm{CH}_{2}-\mathrm{CH}_{2}-\mathrm{NH}\right), 2.25-2.18\left(\mathrm{~m}, 1 \mathrm{H}, \mathrm{CH}_{2}-\mathrm{CH}_{2}-\mathrm{NH}\right)$, $2.86(\mathrm{dd}, J=15.3,11.9 \mathrm{~Hz}, 1 \mathrm{H}, \mathrm{H}-12), 3.37$ (dd, $J=15.6$, $4.9 \mathrm{~Hz}, 1 \mathrm{H}, \mathrm{H}-12$ ), 3.44 (td, $J=12.8,6.3 \mathrm{~Hz}, 1 \mathrm{H}, \mathrm{CH}_{2}-\mathrm{CH}_{2}-$ $\mathrm{NH}), 3.54$ (td, $\left.J=13.0,6.6 \mathrm{~Hz}, 1 \mathrm{H}, \mathrm{CH}_{2}-\mathrm{CH}_{2}-\mathrm{NH}\right), 4.11(\mathrm{t}, J$ $=5.4 \mathrm{~Hz}, 1 \mathrm{H}, \mathrm{H}-3), 4.18(\mathrm{dd}, J=11.6,4.8 \mathrm{~Hz}, 1 \mathrm{H}, \mathrm{H}-12 \mathrm{a})$, $5.38(\mathrm{dd}, J=8.3,4.3 \mathrm{~Hz}, 1 \mathrm{H}, \mathrm{H}-6), 7.01(\mathrm{t}, J=7.4 \mathrm{~Hz}, 1 \mathrm{H}$, $\mathrm{H}-10), 7.07$ (t, $J=7.4 \mathrm{~Hz}, 1 \mathrm{H}, \mathrm{H}-9), 7.36$ (d, $J=8.0 \mathrm{~Hz}, 1 \mathrm{H}$, $\mathrm{H}-8), 7.45$ (t, $J=7.5 \mathrm{~Hz}, 2 \mathrm{H}, \mathrm{Ar}), 7.51$ (t, $J=7.2 \mathrm{~Hz}, 1 \mathrm{H}$, Ar), 7.54 (d, $J=7.8 \mathrm{~Hz}, 1 \mathrm{H}, \mathrm{H}-11), 7.86(\mathrm{~d}, J=7.5 \mathrm{~Hz}, 2 \mathrm{H}$, $\mathrm{Ar}), 8.42(\mathrm{~s}, 1 \mathrm{H}, \mathrm{H}-2), 8.51\left(\mathrm{t}, J=5.0 \mathrm{~Hz}, 1 \mathrm{H}, \mathrm{CH}_{2}-\mathrm{CH}_{2}-\right.$ $\mathrm{N} H$ ), 11.10 (s, 1H, H-7); ${ }^{13} \mathrm{C}$ NMR (DMSO-d 6 ) $\delta 21.8,22.5$, 24.2, 24.6, 30.1, 36.5, 39.6, 39.7, 39.9, 40.0, 40.1, 40.3, 46.2, $50.6,52.1,55.7,105.8,111.9,118.3,119.2,121.3,126.3$, $127.7,128.7,131.5,135.0,135.5,136.2,166.7,169.8,170.3$.

3e4 (3S,6R,12aS) ${ }^{1} \mathrm{H}$ NMR (DMSO- $\left.d_{6}\right) \delta 0.92(\mathrm{~d}, J=6.1$ $\mathrm{Hz}, 3 \mathrm{H}, \mathrm{ib}), 1.06(\mathrm{~d}, J=5.8 \mathrm{~Hz}, 3 \mathrm{H}, \mathrm{ib}), 1.67-1.59(\mathrm{~m}, 2 \mathrm{H}$, ib, $\left.\mathrm{CH}_{2}-\mathrm{CH}_{2}-\mathrm{NH}\right), 1.90-1.83(\mathrm{~m}, 2 \mathrm{H}, \mathrm{ib}), 2.05-1.97(\mathrm{~m}, 1 \mathrm{H}$, ib), 2.82 (dd, $J=14.8,12.3 \mathrm{~Hz}, 1 \mathrm{H}, \mathrm{H}-12), 3.23$ (dd, $J=$ $15.2,4.2 \mathrm{~Hz}, 1 \mathrm{H}, \mathrm{H}-12), 3.46-3.33\left(\mathrm{~m}, 2 \mathrm{H}, \mathrm{CH}_{2}-\mathrm{CH}_{2}-\mathrm{NH}\right)$, 4.06-4.03 (m, 1H, H-3), 4.35 (dd, $J=11.9,4.3 \mathrm{~Hz}, 1 \mathrm{H}, \mathrm{H}-$ 12a), 5.76 (dd, $J=11.3,2.8 \mathrm{~Hz}, 1 \mathrm{H}, \mathrm{H}-6), 6.98$ (t, $J=7.4$ $\mathrm{Hz}, 1 \mathrm{H}, \mathrm{H}-10), 7.07$ (t, $J=7.5 \mathrm{~Hz}, 1 \mathrm{H}, \mathrm{H}-9), 7.32$ (d, $J=8.1$ $\mathrm{Hz}, 1 \mathrm{H}, \mathrm{H}-8), 7.45-7.39$ (m, 3H, Ph), 7.49 (t, $J=7.4 \mathrm{~Hz}, 1 \mathrm{H}$, $\mathrm{H}-11), 7.78$ (d, $J=7.3 \mathrm{~Hz}, 2 \mathrm{H}, \mathrm{Ph}), 8.46$ (t, $J=5.6 \mathrm{~Hz}, 1 \mathrm{H}$, $\left.\mathrm{CH}_{2}-\mathrm{CH}_{2}-\mathrm{NH}\right), 8.51(\mathrm{~d}, J=2.8 \mathrm{~Hz}, 1 \mathrm{H}, \mathrm{H}-2), 11.01(\mathrm{~s}, 1 \mathrm{H}$, H-7); ${ }^{13} \mathrm{C}$ NMR (DMSO- $d_{6}$ ) $\delta$ 13C: $22.0,23.4,24.6,27.4$, $35.7,39.1,39.2,39.4,39.5,39.7,39.8,39.9,42.3,47.2,51.9$, $52.6,104.7,111.1,117.8,118.7,121.1,126.1,127.1,128.2$, $131.1,134.2,134.3,135.9,165.4,166.5,166.6$

$3 \mathrm{e} 5(3 S, 6 S, 12 a S)$ and $3 \mathrm{e} 5(3 S, 6 R, 12 a S)$ MS $\left(\mathrm{ESI}^{+}\right): \mathrm{m} / \mathrm{z}$ found $439\left([\mathrm{M}+\mathrm{H}]^{+}\right)$, RP-HPLC gradient $53-68 \%$ (B) 10 min, RP-HPLC retention time $t_{R} 3 \mathrm{e} 5(3 S, 6 S, 12 a S)=8.35 \mathrm{~min}, \mathrm{t}_{\mathrm{R} 3 \mathrm{e} 5}$ $(3 S, 6 R, 12 a S)=8.56 \mathrm{~min}, \mathrm{~m}_{\text {pure }} 3 \mathrm{e5}(3 S, 6 S, 12 a S)=0.0029 \mathrm{~g}, \mathrm{~m}_{\text {pure }} 3 \mathrm{e} 5$ $(3 S, 6 R, 12 a S)=0.0057$ g.3e6 (3S,6S,12aS $), 3 \mathrm{e} 6(3 S, 6 R, 12 a S)$ MS $\left(\operatorname{ESI}^{+}\right): m / z$ found $481\left([\mathrm{M}+\mathrm{H}]^{+}\right), \mathrm{RP}-H P L C$ gradient $70-80 \%$ (B) 10 min, RP-HPLC retention time $t_{\mathrm{R}} 3 \mathrm{e}$ (3S,6S,12as) $=5.51 \mathrm{~min}, \mathrm{t}_{\mathrm{R} 3 \mathrm{e} 6}(3 \mathrm{~S}, 6 \mathrm{R}, 12 a \mathrm{~S})=5.86 \mathrm{~min}, \mathrm{~m}_{\text {pure }} 3 \mathrm{e} 6(3 \mathrm{~S}, 6 \mathrm{~S}, 12 a \mathrm{~S})=$ $0.0034 \mathrm{~g}, \mathrm{~m}_{\text {pure } 3 e 6(3 S, 6 R, 12 a S)}=0.0036 \mathrm{~g}$.

\subsubsection{The Synthesis of $4 d$ (3S,6S,12aS) and 4d (3S,6R,12aS) Analogs}

The coupling reaction of the amino acid Boc-Nle-OH $(1.28 \mathrm{~g}, 5.55 \mathrm{mmol})$ was similar to that of used for 1c $(3 S, 6 S, 12 a S)$ and 1c $(3 S, 6 R, 12 a S)$ analogs. The Boc deprotectionin the side chain of $4 \mathrm{~b}\left(1 S, 3 S, 2^{\prime} S\right)$ and $4 \mathrm{~b}$ $(1 R, 3 S, 2$ 'S $)$ intermediers was carried out by TFA/DCM (5 $\mathrm{ml}, 50 \mathrm{v} / \mathrm{v} \%)$. After $1 \mathrm{~h}$, the reaction mixtures were evaporated in vacuo. The obtained $4 \mathrm{c}(1 S, 3 S, 2 ' S)$ and $4 \mathrm{c}$ $\left(\mathbf{R}, 3 S, 2^{\prime} \boldsymbol{S}\right)$ intermediers were used for intramolecular cyclization with piperidine/DCM $(5 \mathrm{ml}, 10 \mathrm{v} / \mathrm{v} \%)$. Acetic acid $(\mathrm{pH}=4)$ was added into the reaction mixtures after $30 \mathrm{~min}$, evaporated in vacuo, dissolved in $\mathrm{MeCN} / \mathrm{H}_{2} \mathrm{O}$ (5 ml, 10 $\mathrm{v} / \mathrm{v} \%)$ and lyophilized.4d $(3 S, 6 S, 12 a S)$ and $4 \mathrm{~d}$ $(3 S, 6 R, 12 a S) M S\left(\mathrm{ESI}^{+}\right): m / z$ found $367\left([\mathrm{M}+\mathrm{H}]^{+}\right)$, RPHPLC gradient $70-80 \%$ (B) 10 min, RP-HPLC retention time $\mathrm{t}_{\mathrm{R}} 4 \mathrm{~d}(3 \mathrm{~S}, 6 \mathrm{~S}, 12 a S)=6.82 \mathrm{~min}, \mathrm{t}_{\mathrm{R} 4 \mathrm{~d}(3 S, 6 R, 12 a S)}=7.13 \mathrm{~min}, \mathrm{~m}_{\text {pure }}$ $4 \mathrm{~d}(3 S, 6 S, 12 a S)=0.0056 \mathrm{~g}, \mathrm{~m}_{\text {pure }} 4 \mathrm{~d}(3 S, 6 R, 12 a S)=0.0047 \mathrm{~g}$.
2.2.10. The Solution-phase Synthesis of $1 c^{\prime}(3 S, 6 S, 12 a S)$, $1 c^{\prime}(3 S, 6 R, 12 a S), 2 c^{\prime}(3 S, 6 S, 12 a S)$ and $2 c^{\prime}(3 S, 6 R, 12 a S)$ Analogs

These analogs were prepared by a procedure similar to that of used for 1c $(3 S, 6 S, 12 a S)$ and $1 \mathrm{c}(3 S, 6 R, 12 a S)$ analogs. Tryptophan methyl ester $\times \mathrm{HCl}(3.83 \mathrm{~g}, 15 \mathrm{mmol})$ was dissolved in DCM $(150 \mathrm{ml})$ and extracted with aqueous sodium hydrogen carbonate $(3 \times 150 \mathrm{ml}, 10 \mathrm{~m} / \mathrm{v} \%)$ and saturated sodium chloride solutions $(2 \times 150 \mathrm{ml})$. The organic layer was dried $\left(\mathrm{Na}_{2} \mathrm{SO}_{4}\right)$, filtered, evaporated in vacuo, and co-evaporated with $\mathrm{MeCN}$ to dryness. The residue obtained after evaporation $(2.20 \mathrm{~g}, 10.00 \mathrm{mmol})$ was divided into two equal parts. L-tryptophan methyl ester $(1.10 \mathrm{~g}, 5.00 \mathrm{mmol})$ was dissolved in DCM $(100 \mathrm{ml})$ then TFA $(1.91 \mathrm{ml}, 25.00$ $\mathrm{mmol}$ ) was added, and two different aldehydes were used for the Pictet-Spengler cyclization, benzaldehyde $(2.96 \mathrm{ml}, 25$ $\mathrm{mmol})$ and phenylacetaldehyde $(2.80 \mathrm{ml}, 25.00 \mathrm{mmol})$. The reaction mixture was evaporated in vacuo, after stirring at room temperature for $16 \mathrm{~h}$, dissolved in ethyl acetate $(500$ $\mathrm{ml}$ ), and extracted with aqueous sodium hydrogen sulfate $(3 \times 100 \mathrm{ml}, 10 \mathrm{~m} / \mathrm{v} \%)$, sodium hydrogen carbonate $(2 \times 150$ $\mathrm{ml})$, and saturated sodium chloride solutions $(2 \times 100 \mathrm{ml})$. The obtained organic layers were dried $\left(\mathrm{Na}_{2} \mathrm{SO}_{4}\right)$, filtered, and evaporated to dryness. The obtained 1a' $(\mathbf{I S , 3 S )}$ and 1a' $(1 R, 3 S)(0.80 \mathrm{~g}, 1.12 \mathrm{mmol}), 2 \mathrm{a}^{\prime}(1 S, 3 S)$ and $2 \mathrm{a}^{\prime}(1 R, 3 S)$ $(0.92 \mathrm{~g}, 1.26 \mathrm{mmol})$ intermediers were used for further coupling reaction with Fmoc-Glu(OtBu)-OH $\times \mathrm{H}_{2} \mathrm{O}(1.48 \mathrm{~g}, 3.36$ $\mathrm{mmol}$ and $1.67 \mathrm{~g}, 3.78 \mathrm{mmol})$. The coupling reaction, Fmoc deprotection, and intramolecular cyclization methods were similar to that of 1c $(3 S, 6 S, 12 a S)$ and 1c $(3 S, 6 R, 12 a S)$ analogs. 1c' $(3 S, 6 S, 12 a S)$ and $1 \mathrm{c}^{\prime}(3 S, 6 R, 12 a S)$ MS $\left(\mathrm{ESI}^{+}\right): \mathrm{m} / z$ found $460\left([\mathrm{M}+\mathrm{H}]^{+}\right)$, RP-HPLC gradient $85-100 \%$ (B) 15 $\min , \mathrm{RP}-H P L C$ retention time $t_{\mathrm{R}} 1 \mathrm{c}^{\prime}(3 S, 6 S, 12 a S)=5.49 \mathrm{~min}, \mathrm{t}_{\mathrm{R} 1 \mathrm{c}^{\prime}}$ ${ }_{(3 S, 6 R, 12 a S)}=5.67 \mathrm{~min}, \mathrm{~m}_{\text {pure }} 1 \mathrm{c}^{\prime}(3 S, 6 S, 12 a S)=0.015 \mathrm{~g}, \mathrm{~m}_{\text {pure }} 1 \mathrm{c}^{\prime}$ ${ }_{(3 S, 6 R, 12 a S)}=0.023$ g. 2c' $(3 S, 6 S, 12 a S)$ and $2 \mathrm{c}^{\prime}(3 S, 6 R, 12 a S)$ MS $\left(\mathrm{ESI}^{+}\right): m / z$ found $474\left([\mathrm{M}+\mathrm{H}]^{+}\right)$, RP-HPLC gradient $65-80 \%$ (B) $15 \mathrm{~min}, \mathrm{RP}-H P L C$ retention time $\mathrm{t}_{\mathrm{R}} 2 \mathrm{c}^{\prime}(3 \mathrm{~S}, 6 \mathrm{~S}, 12 a \mathrm{~S})$ $=6.88 \mathrm{~min}, \mathrm{t}_{\mathrm{R} 2 \mathrm{c}^{\prime}(3 \mathrm{~S}, 6 \mathrm{R}, 12 a \mathrm{~S})}=7.79 \mathrm{~min}, \mathrm{~m}_{\text {pure }} \mathbf{2 \mathrm { c } ^ { \prime }}(3 \mathrm{~s}, 6 \mathrm{GS}, 12 a \mathrm{~S})=$ $0.018 \mathrm{~g}, \mathrm{~m}_{\text {pure } 2 \mathrm{c}^{\prime}(3 \mathrm{~S}, 6 \boldsymbol{R}, \mathbf{1 2 a S})}=0.032 \mathrm{~g}$.

\subsection{Drugs and Chemicals Used for Assays}

Dulbecco's modified Eagle's medium (DMEM, Lonza, Switzerland) and Eagle's minimal essential medium (EMEM, Lonza, Switzerland), penicillin-streptomycin mixture (Lonza) was from Biocenter Kft (Szeged, Hungary). Hank's balanced salt solution without phenol red (Gibco), advanced RPMI 1640 (Gibco) was from Csertex Kft. (Budapest, Hungary). Ko134 was from Solvo (Szeged, Hungary). Fetal bovine serum, glutamine, non-essential amino acids, resazurin, Ko143, calcein AM, Hoechst 33342, BSA, verapamil, DMSO and other chemicals not listed here were purchased from Sigma Aldrich Kft. (Budapest, Hungary).

\subsection{Cell Lines and Culture Conditions}

The ABCB1-overexpressing chronic myeloid leukemia cell line K562-MDR [34], the ABCC1-overexpressing human promyelocytic leukemia HL60-MRP [35] cells and the ABCG2-overexpressing human breast cancer epithelial cells MCF7-MX were received as kind gifts from Professor Balázs Sarkadi (National Blood Transfusion Service, Buda- 
pest, Hungary). The murine leukemia P388 and P388/BCRP cells [36] were obtained from Professor Yoshikazu Sugimoto (Cancer Chemotherapy Center, Japanese Foundation for Cancer Research, Tokyo, Japan). The human diploid lung fibroblast MRC-5 cells were from Professor Éva Gönczöl (Béla Johan National Center for Epidemiology, Budapest, Hungary).

K562-MDR, HL60-MRP cells were maintained in advanced RPMI 1640 supplemented with $10 \%$ heat-inactivated fetal calf serum, $2 \mathrm{mM}$ L-glutamine and $100 \mu \mathrm{g} / \mathrm{ml}$ penicillin-streptomycin.

MCF7-MX cells were cultured in DMEM supplemented with $10 \%$ heat-inactivated fetal calf serum, $2 \mathrm{mM} \mathrm{L-}$ glutamine, $100 \mu \mathrm{g} / \mathrm{ml}$ penicillin-streptomycin and $1 \%$ nonessential amino acid.

P388 and P388/BCRP cells were cultured in RPMI1640 medium supplemented with $10 \%$ heat-inactivated fetal calf serum, $2 \mathrm{mM}$ L-glutamine, $100 \mu \mathrm{g} / \mathrm{ml}$ penicillinstreptomycin and $16 \mu \mathrm{M}$ mercaptoethanol.

MRC-5 cells were cultured is Medium199 completed with $2 \%$ heat-inactivated fetal calf serum, $2 \mathrm{mM} \mathrm{L-}$ glutamine, and $100 \mu \mathrm{g} / \mathrm{ml}$ penicillin-streptomycin and $1 \%$ non-essential amino acid.

All cells were cultured under standard cell culture conditions in a humidified atmosphere of $5 \%$ carbon dioxide in air at $37^{\circ} \mathrm{C}$.

\subsection{Hoechst Assay}

Hoechst 33342 nucleic acid stain emits blue fluorescence when bound to DNA. It is an excellent substrate of the ABCG2 transporter so in cells expressing ABCG2 the amount of intracellular Hoechst 33342 is strongly decreased. Inhibition of ABCG2 leads to increased accumulation of the dye and, therefore, increased cellular fluorescence. The assay was performed as described previously [25]. In brief, accumulation of Hoechst 33342 dye was measured by using MCF7-MX cells. The cells were preincubated in $150 \mu \mathrm{l}(1 \mathrm{x})$ Hank's balanced salt solution (HBSS), $\mathrm{pH} 7.4$, with drugs for $30 \mathrm{~min}$ at $37^{\circ} \mathrm{C}$. Then $50 \mu \mathrm{l}$ Hoechst 33342 dye was added at a final concentration of $50 \mu \mathrm{M}$. The positive control measurements to determine $100 \%$ inhibition were carried out in the presence of $1 \mu \mathrm{M}$ Ko134. The fluorescent signal was detected in a BMG Labtech FluoStar Optima fluorometer (BMG Labtech, Offenburg, Germany) at $350 \mathrm{~nm}$ (excitation) and $460 \mathrm{~nm}$ (emission).

\subsection{Calcein Assay}

Calcein-AM is a hydrophobic, non-fluorescent molecule that can easily permeate the cell membrane. Intracellularly calcein-AM is hydrolyzed by endogenous esterases, yielding membrane impermeable, fluorescent calcein. Overexpression of $\mathrm{ABCB} 1$ or $\mathrm{ABCC} 1$ inhibits calcein-AM permeation. Inhibition of the transporters by interacting drugs will result in increased calcein-AM permeation and increased cellular fluorescence. These experiments were carried out as described earlier [37]. In brief, 100,000 cells per well were incubated in $100 \mu$ l Hank's balanced salt solution in the presence of the test compound or positive control for 15 minutes. Then, calcein-AM in $100 \mu 1$ of HBSS was added at a final concentration of $250 \mathrm{nM}$. The positive control measurements to determine $100 \%$ inhibition were carried out in the presence of $60 \mu \mathrm{M}$ verapamil. Fluorescence intensities were recorded for 8 minutes in a fluorimeter (Fluoroskan Ascent Type 374) at $485 \mathrm{~nm}$ (excitation) and $538 \mathrm{~nm}$ (emission).

\subsection{Measurement of ABCG2 Reversing Activity}

To measure ABCG2 reversing activity cytotoxicity experiments were carried out using resazurin. Resazurin, a nonfluorescent indicator dye, is converted to bright redfluorescent resorufin via the reduction reactions of metabolically active cells [38]. The amount of fluorescence produced is proportional to the number of living cells and corresponds to the cells metabolic activity. P388 and P388-BCRP cells $(5,000$ cells/well $)$ were cultured on a $96-$ well flat bottom tissue culture plate. At 24 hours post-seeding cells were treated with various concentrations of SN-38 and in the presence or absence of test articles at concentrations shown in the figures. The cells were then incubated in a humidified tissue culture chamber $\left(37^{\circ} \mathrm{C}\right.$ and $\left.5 \% \mathrm{CO} 2\right)$ for $72 \mathrm{hrs}$. After rinsing with warm HBSS resazurin was added in $100 \mu \mathrm{l}$ HBSS at $90 \mu \mathrm{M}$ final concentration. Cells were incubated for three hours at $37^{\circ} \mathrm{C}$. Resorufin quantitation was performed in a BMG Labtech FluoStar Optima fluorimeter (BMG Labtech, Offenburg, Germany) with $584 \mathrm{~nm}$ excitation and 612 $\mathrm{nm}$ emission filter.

\subsection{Non-target Cytotoxicity Measurement}

Non-target cytotoxicity activity of drugs was evaluated using MRC-5, normal human fibroblasts. MRC-5 cells $(2,000$ cells/well) were seeded in a 96-well format. At 24 hours post-seeding cells were treated with various concentrations drugs and moved to a humidified tissue culture chamber. Cytotoxicity was measured at 72 hours post-treatment as described above.

\subsection{Data Analysis}

All assays were run in duplicate unless indicated otherwise. The Hoechst and the Calcein assays were analyzed using the slope of the curve determined without inhibitor $\left(R_{\text {base }}\right)$, the slope of the curve in the presence of the positive control inhibitor $\left(R_{\max }\right)$, and the slope of the curve determined for any drug at the given drug concentration $\left(R_{\mathrm{drug}}\right)$. The inhibition (percentage) of dye extrusion can be represented by the following formula:

$$
\text { Inhibiton (\%) }=\frac{R d r u g-\text { Rbase }}{R \max -\text { Rbase }} * 100
$$

$\mathrm{IC}_{50}$ values were derived and calculated from doseresponse curves.

For curve fitting and $\mathrm{IC}_{50}$ calculations GraphPad Prism 4.0 software (GraphPad Software Inc., San Diego, CA) was used. 
<smiles>CC(=O)[C@H](N)Cc1c[nH]c2ccccc12</smiles>

I.

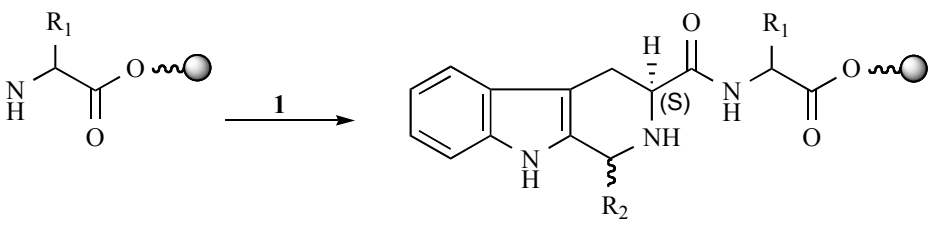

II.

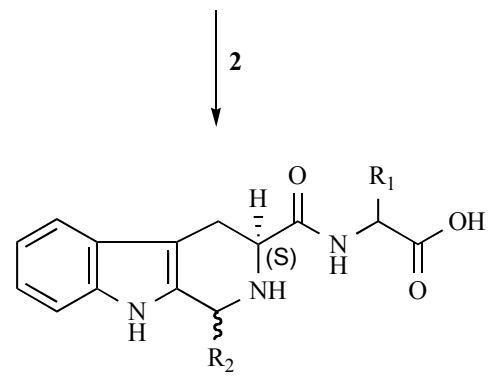

III.

Scheme 1. Reagents and conditions: 1.5 equiv. $\mathrm{R}_{2} \mathrm{CHO}, 5$ equiv. TFA, RT, 16 h, 2. F/anisole/dimethylsulfide/p-cresol 89/1.8/7.4/1.8 $(\mathrm{v} / \mathrm{v} / \mathrm{v} / \mathrm{v}),-5^{\circ} \mathrm{C}, 45 \mathrm{~min}$.

Table 1. Tricyclic fumitremorgin analogs

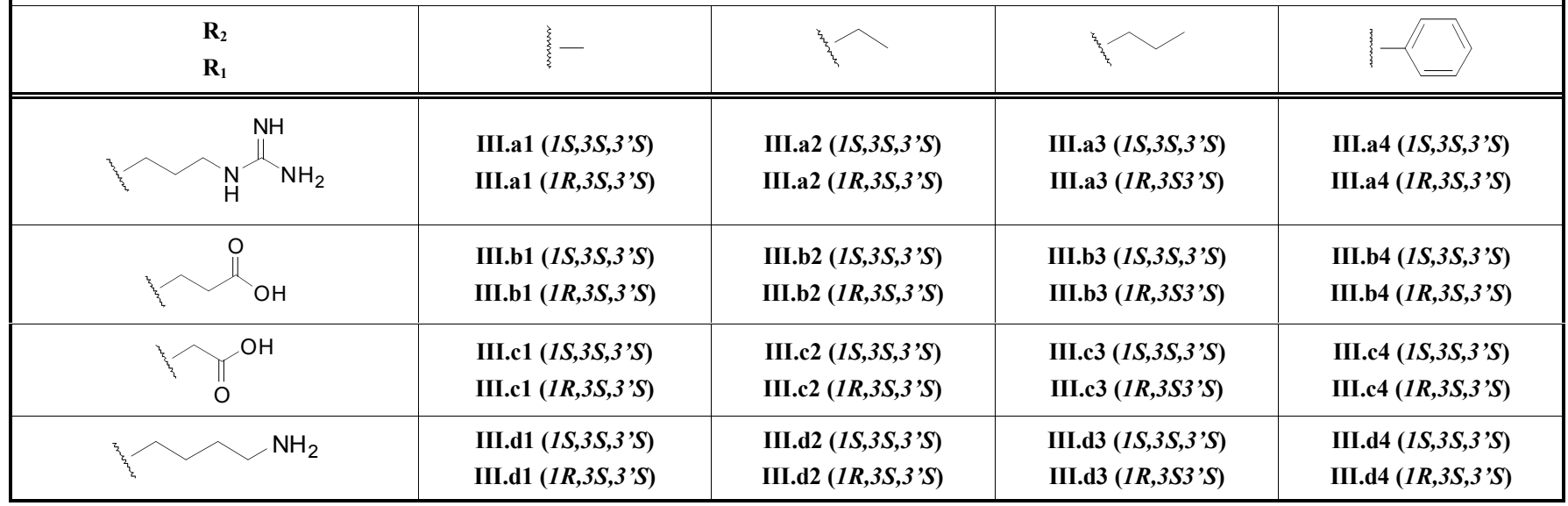

\section{RESULTS}

\subsection{Chemistry}

\subsubsection{Synthesis}

Fumitremorgin analogs belong to the class of indolyl diketopiperazine alkaloids containing 1,4-dioxo$2,3,6,7,12,12$ a-hexahydropyrazino [1'2':1,6]pyrido[3,4-

b]indole skeleton. The key transformation used for preparation of fumitremorgin analogs was the Pictet-Spengler condensation which involves the acid-catalyzed intramolecular ring closure between an iminium ion and an aromatic $\mathrm{C}$ nucleophile.

First solid-phase strategy was applied for the synthesis of fumitremorgin analogs. The core structure was constructed stepwise from an amino acid functionalized resin followed by Boc-Trp-OH coupling, and finally, aliphatic or aromatic aldehydes were applied in the Pictet-Spengler condensation. The general synthetic route is illustrated in Scheme 1.

Using solid-phase synthesis strategy, chloromethyl functionalized polystyrene resin (Merrifield resin) was esterified with four different Boc-protected amino acid: BocLys(2ClZ)-OH, Boc-Arg(Tos)-OH， Boc-Glu(OcHex)-OH and Boc-Asp(OcHex)-OH in the presence of KF. Loading was determined by Gisin [39]. The Boc protecting group was removed with TFA followed by neutralization with TEA. In each case, the next amino acid, Boc-Trp-OH was coupled in 3 equiv. with 3equiv. of DCC. The followed Bocdeprotection step resulted in compound I (Scheme 1). In the 


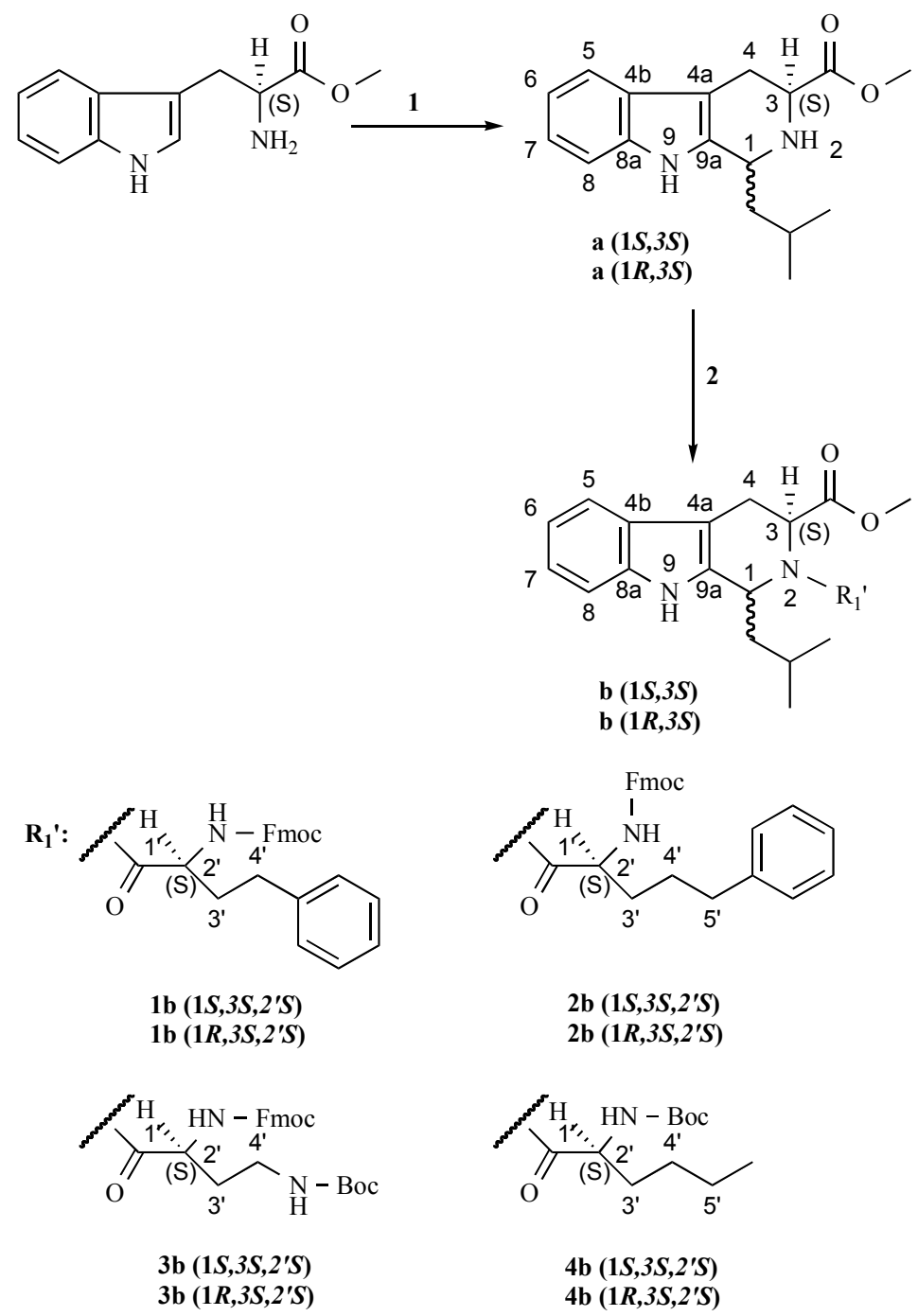

Scheme 2. Reagents and conditions: 1. 5 equiv. $\left(\mathrm{CH}_{3}\right)_{2} \mathrm{CH}-\mathrm{CH}_{2}-\mathrm{CHO}, 5$ equiv. TFA, DCM, RT, 16h, 2. 3 equiv. Fmoc-amino acid, 3 equiv. TCFH, 6 equiv. DIPEA, DCM, RT, 16h, Ar atmosphere.

next step four different aldehydes: acetaldehyde, butyraldehyde, propionaldehyde and benzaldehyde were applied to Pictet-Spengler condensation [40-43] then TFA was added, and the reaction mixtures were stirred at room temperature under inert conditions for 16 hours (II.).

Removal of side chain protecting groups and cleavage from the resin yielded the corresponding diastereoisomeric mixture of tricyclic fumitremorgin analogs (III.) (Table 1). The analogs described above were characterized by RPHPLC and ESI-MS.

Further incorporation of Fmoc-protected amino acids resulted in very low yields, probably due to severe steric hindrance of the secondary amino nitrogen of tetrahydro- $\beta$ carboline. Since acylation of the secondary amine of tetrahydro- $\beta$-carbolines obtained from Pictet-Spengler reaction was difficult under various reaction conditions, even with the most potent coupling reagents: TCFH $\left(N, N, N^{\prime}, N^{\prime}\right.$-tetramethyl-chloroformamidinium hexafluorophosphate), TFFH $\left(N, N, N^{\prime}, N^{\prime}\right.$-tetramethyl-fluoroformamidinium hexafluoro- phosphate), CIP (2-chloro-1,3-dimethylimidazolidium hexafluorophosphate), HATU [O-(7-Azabenzotriazol-1-yl)$N, N, N^{\prime}, N^{\prime}$-tetramethyluronium hexafluorophosphate [44, 45], the further fumitremorgin analogs were synthesized using solution-phase synthetic strategy.

In this case, the synthesis of fumitremorgin analogs started with the conversion of tryptophan-methylester with 5 equiv. of iso-valeraldehyde in the presence of 5 equiv. of trifluoroacetic acid (TFA) as catalyst, leading to the diastereoisomeric mixture of compounds a $(\mathbf{1 S , 3 S )}$ and a $(1 R, 3 S)$ (Scheme 2). To obtain the diketopiperazine ring of fumitremorgin analogs, the tetrahydro- $\beta$-carboline derivatives a $(\mathbf{1 S}, \mathbf{3 S})$, a $(\mathbf{1 R , 3 S})$ were converted by coupling of the amino acids followed by Fmoc deprotection and an intramolecular cyclization. Three different Fmoc-protected amino acids and one Boc-protected amino acid $\left(\boldsymbol{R}_{\boldsymbol{l}}\right)$ were chosen: Fmoc-Dab(Boc)-OH, Fmoc-Homophe-OH, FmocNva-(5-phenyl)-OH, Boc-Nle-OH. Coupling of the amino acids were performed with 3 equiv. of TCFH in the presence of 6 equiv. DIPEA under inert conditions for 16 hours. Incorporation of the amino acid residues $\left(\boldsymbol{R}_{\boldsymbol{1}}{ }^{\prime}\right)$ into the tetra- 

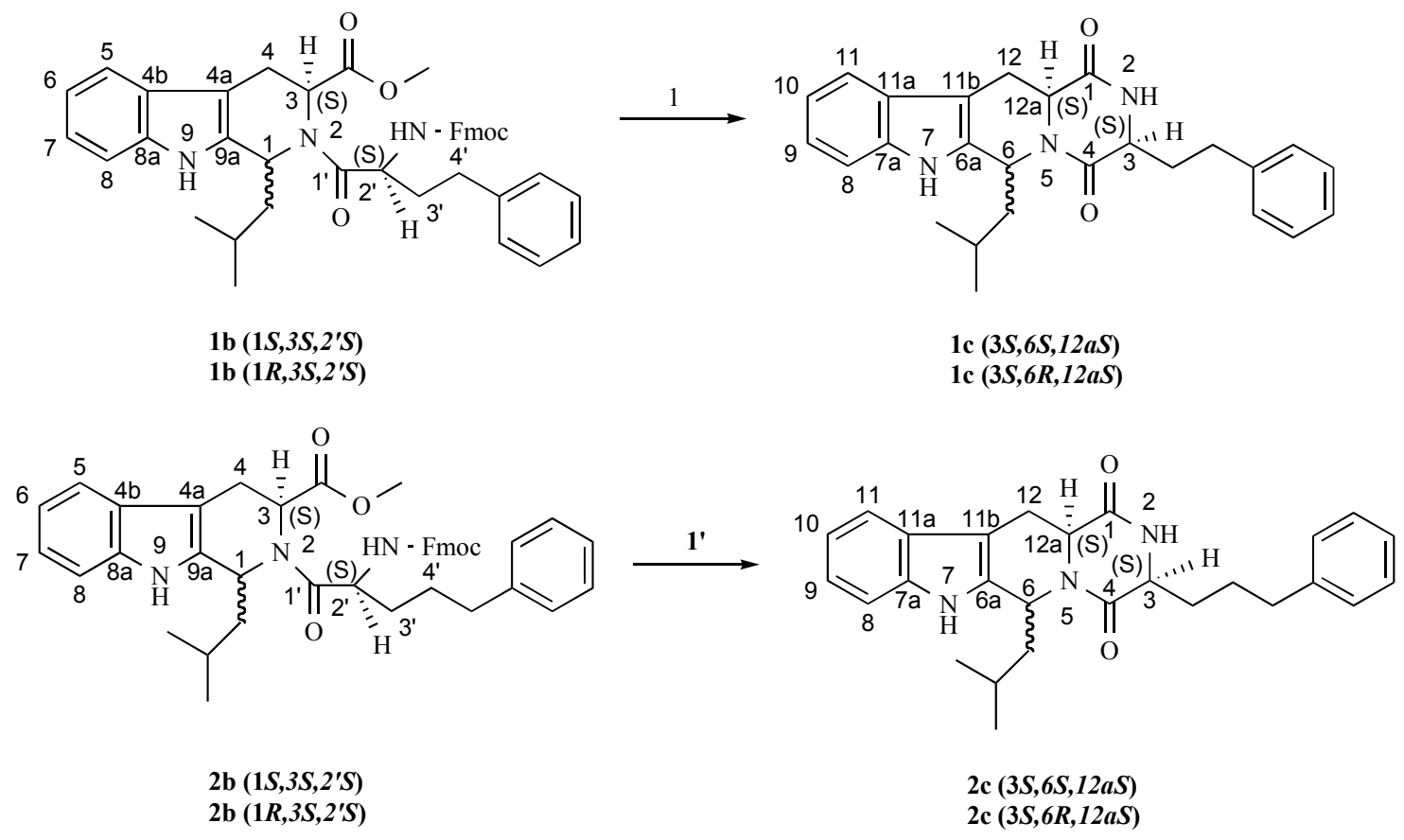

Scheme 3. Reagents and conditions: 1 . and 1'. 10\% piperidine, DCM, RT, $30 \mathrm{~min}$.

hydro- $\beta$-carboline derivative was successful, in each case (Scheme 2).

In the next step, Fmoc deprotection and subsequent intramolecular cyclization of compounds $1 \mathrm{~b}(1 S, 3 S, 2$ 'S $), 1 \mathrm{~b}$ (1R,3S,2'S), $2 \mathrm{~b}(1 S, 3 S, 2$ 'S), $2 \mathrm{~b}(1 R, 3 S, 2$ 'S), 3b (1S,3S,2'S) and $3 \mathrm{~b}(1 R, 3 S, 2 ' S)$ were carried out in a one-pot reaction at room temperature, with piperidine to obtain the desired products 1c $(3 S, 6 S, 12 a S), \quad 1 \mathrm{c}(3 S, 6 R, 12 a S), \quad 2 \mathrm{c}$ $(3 S, 6 S, 12 a S), 2 \mathrm{c}(3 S, 6 R, 12 a S), 3 \mathrm{c}(3 S, 6 S, 12 a S)$ and $3 \mathrm{c}$ $(3 S, 6 R, 12 a S)$, respectively (Schemes 3 and 4).

Compounds 3c $(3 S, 6 S, 12 a S)$ and 3c $(3 S, 6 R, 12 a S)$ were reacted further. After the Boc side chain protecting group was removed with TFA to permit additional amide linkage formation, six different reagents were used for the acylation of the side chain primary amino group: isovaleroyl chloride, benzoyl chloride, propionyl chloride, pivaloyl chloride, acetic anhydride, and caprilyc acid. In each reaction the derivatives 3c $(3 S, 6 S, 12 a S), 3 c(3 S, 6 R, 12 a S)$ were acylated with 2 equiv. of the above reagents in the presence of 2 equiv. TEA (Scheme 4).

In case of $4 \mathrm{~b}\left(1 S, 3 S, 2^{\prime} S\right)$ and $4 \mathrm{~b}(1 R, 3 S, 2 ' S)$ derivatives, Boc removal with concomitant intramolecular cyclization resulted in the formation of diastereoisomeric mixture of compounds $4 \mathrm{~d}(3 S, 6 S, 12 a S)$ and $4 \mathrm{~d}(3 S, 6 R, 12 a S)$ (Scheme 5).

To obtain further analogs, benzaldehyde and phenylacetaldehyde were used for the Pictet-Spengler condensation. These compounds were prepared using similar methodology to those described above. In each case, Fmoc-Glu(OtBu)-OH was coupled to a'(1S,3S), a' $(\mathbf{1 R , 3 S})$ and, after Fmoc deprotection, both of diastereoisomers c'(1S,6S,12aS), c' $(1 R, 6 R, 12 a S)$ were obtained (Scheme 6). The synthesized compounds using solution-phase chemistry were characterized by RP-HPLC and ESI-MS.

\subsubsection{Configuration}

The diastereomers of the formed cycloadducts were identified by NMR spectroscopy. The ${ }^{1} \mathrm{H}$ NMR spectra of $\mathbf{3 e 2}$ displayed two double doublets, at 2.84 and $3.36 \mathrm{ppm}$, due to H-12 with a coupling constant of 11.8 and $15.5 \mathrm{~Hz}$ and 5.1 and $15.6 \mathrm{~Hz}$, respectively. The geometries of the diastereomers were deduced from coupling constants of the H-12 double doublet and the presence or lack of the cross-peaks between $\mathrm{H}-12$ and $\mathrm{H}-12 \mathrm{a}$ anellation proton and $\mathrm{H}-12$ and $\mathrm{CH}-\mathrm{CH}_{2}-\mathrm{CH}-\left(\mathrm{CH}_{3}\right)_{2}$ in the NOESY spectra. The $\mathrm{H}-12$ double doublet has one big and one medium coupling constants due to the trans-cis arrangement around of the $\mathrm{H}-12 \mathrm{a}$ anellation proton. The stereochemistry of the new chiral center was established from 2D NMR NOESY measurements. NOESY experiments on $\mathbf{3 e 2}$ showed cross-peaks between the signals of $\mathrm{H}-12$ and $\mathrm{CH}-\mathrm{CH}_{2}-\mathrm{CH}-\left(\mathrm{CH}_{3}\right)_{2}$, and no interaction between 2.84 ppm of $\mathrm{H}-12$ proton and the $\mathrm{CH}$ anellation proton which proved the $\mathrm{S}$ configuration (Fig. 1).

\subsection{Biology}

\subsubsection{ABCG2 Inhibitory Activity}

Hoechst assay was used for the measurement of ABCG2 inhibitory activity of the new compounds. The Hoechst dye (Hoechst 33342) is a nonfluorescent dye that becomes fluorescent when bound to DNA. The dye is an ABCG2 substrate, therefore, its cellular permeation is limited in ABCG2 overexpressing cells. Inhibitors of the transporters lead to increased cellular accumulation and, consequently, increased fluorescence. MCF7-MX cells that specifically overexpress ABCG2 were used in the study. Inhibition experiments were not carried out on parental cells as they did not show appreciable dye transport activity (data not shown). 


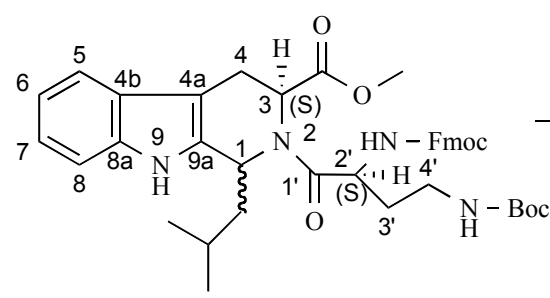

3b $\left(1 S, 3 S, 2^{\prime} S\right)$

$3 \mathrm{~b}(1 R, 3 S, 2 ' S)$

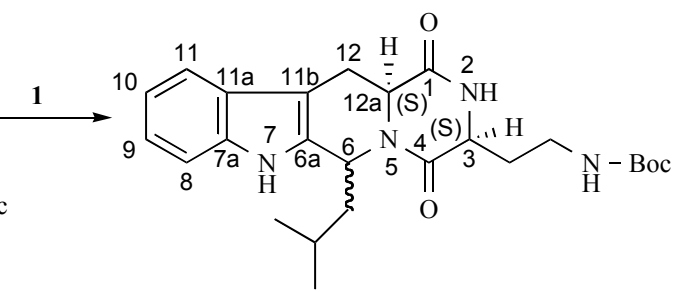

3c $(3 S, 6 S, 12 a S)$

$3 \mathrm{c}(3 S, 6 R, 12 a S)$

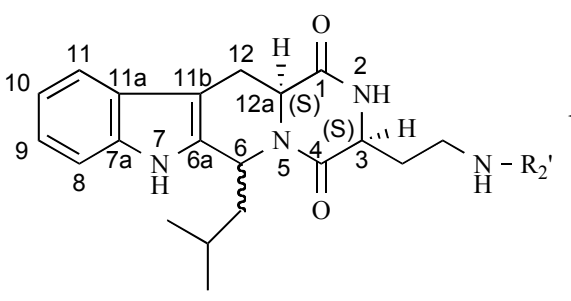

$3 \mathrm{e}(3 S, 6 S, 12 a S)$ 3e $(3 S, 6 R, 12 a S)$

$\mathrm{R}_{2}^{\prime}$ :

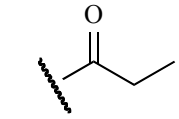

3e1 (3S,6S,12aS) 3e1 (3S,6R,12aS)<smiles>CC(=O)c1ccccc1</smiles>

$3 \mathrm{e} 4(3 S, 6 S, 12 a S)$ $3 \mathrm{e} 4(3 S, 6 R, 12 a S)$
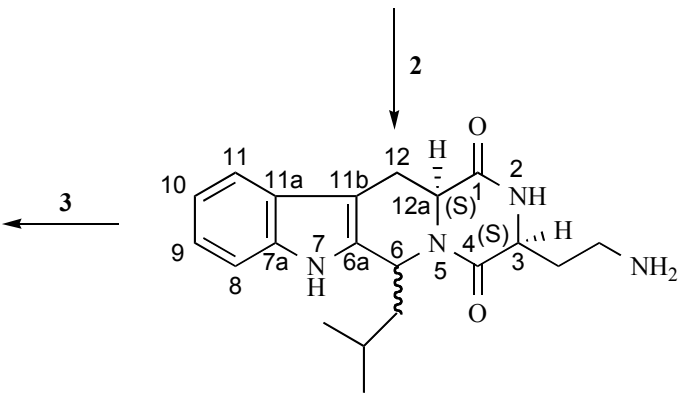

3d $(3 S, 6 S, 12 a S)$

3d $(3 S, 6 R, 12 a S)$

Scheme 4. Reagents and conditions: 1. 10\% piperidine, DCM, RT, 30 min., 2. 50\% TFA, DCM, RT, 1h, 3. 2.2 equiv. acylation reagent, 4

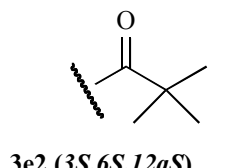

$3 \mathrm{e} 2(3 S, 6 S, 12 a S)$

$3 \mathrm{e} 2(3 S, 6 R, 12 a S)$

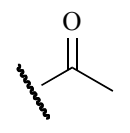

$3 \mathrm{e} 3(3 S, 6 S, 12 a S)$

$3 \mathrm{e} 3(3 S, 6 R, 12 a S)$ equiv. TEA, DCM, RT, $1 \mathrm{~h}$.

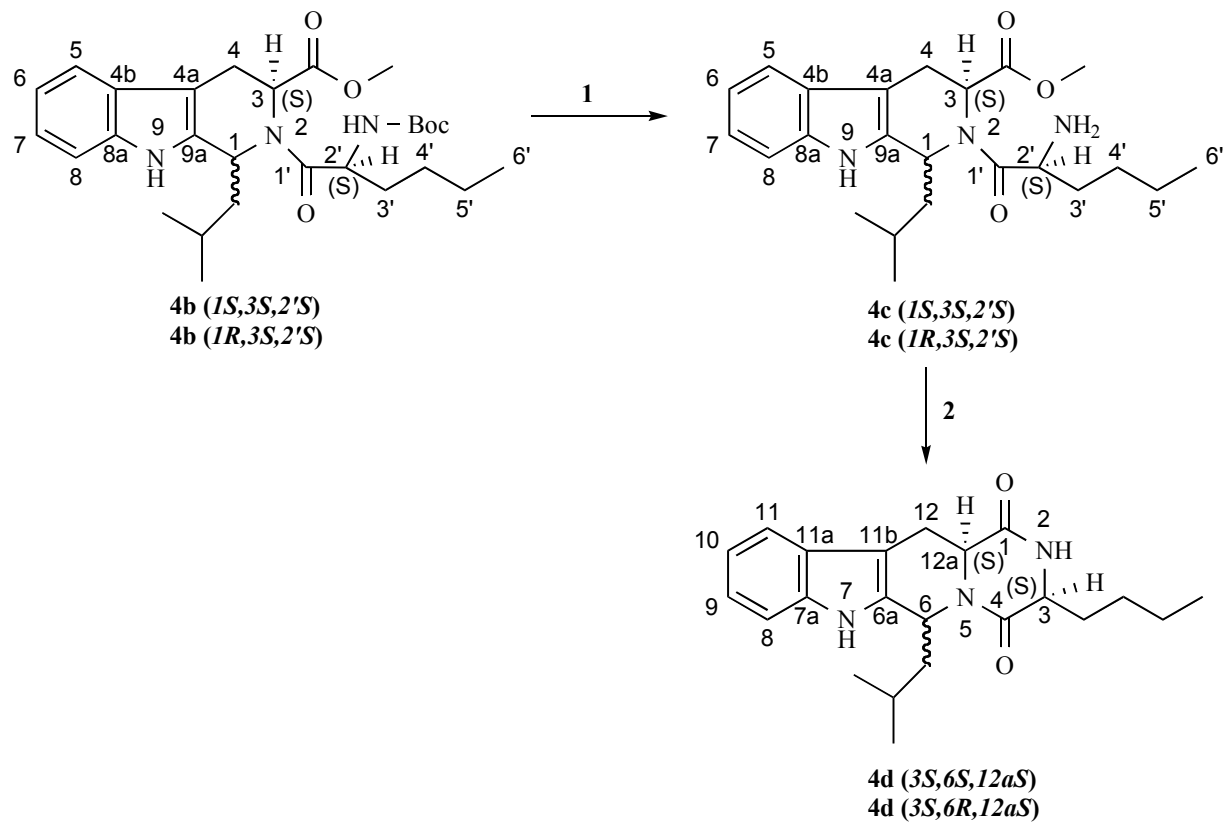

Scheme 5. Reagents and conditions: 1. 50\% TFA, DCM, RT, 1h, 2. 10\% piperidine, DMF, RT, 30 min. 


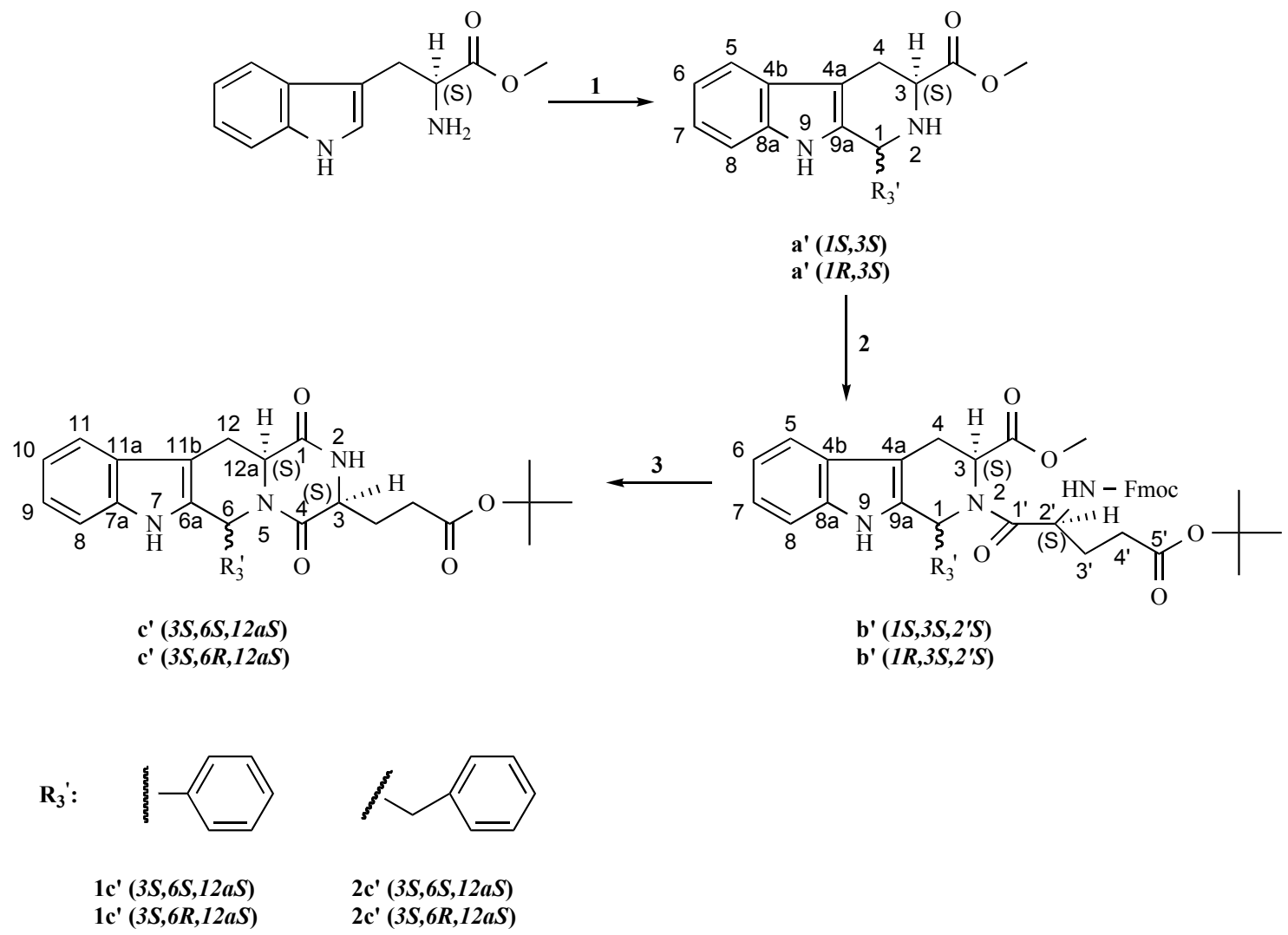

Scheme 6. Reagents and conditions: 1.5 equiv. $\mathrm{R}_{3}$ 'CHO, 5 equiv. TFA, DCM, RT, 16h, 2.3 equiv. Fmoc-Glu(OtBu) $\times \mathrm{H}_{2} \mathrm{O}, 3$ equiv. TCFH, 6 equiv. DIPEA, DCM, RT, 16h, Ar atm., 3. 10\% piperidine, DMF, RT, $30 \mathrm{~min}$.
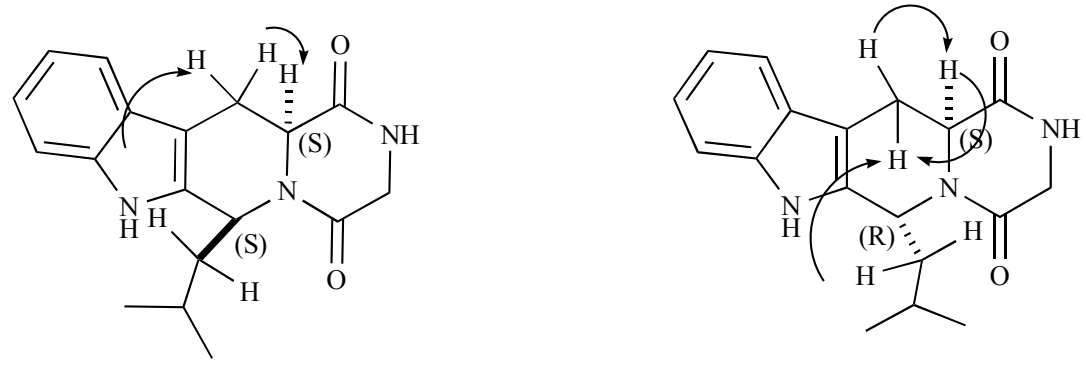

Fig. (1). The possible cross-peaks in the NOESY spectra for the formed new chiral center.

Ko134, a specific inhibitor of ABCG2, was used as a positive control, and inhibition by $1 \mu \mathrm{M}$ Ko134 was considered as $100 \%$ inhibition. As an initial screen, compounds were applied at a final concentration of $10 \mu \mathrm{M}$.

The tricyclic analogs, compounds IIIa-IIId showed no activity (data not shown). The inhibitory potencies of tetracyclic derivatives, compounds 1c $(3 S, 6 S, 12 a S)$, 2c $(3 S, 6 S, 12 a S), 3 \mathrm{e} 1 \quad(3 S, 6 S, 12 a S), 3 \mathrm{e} 2 \quad(3 S, 6 S, 12 a S), 3 \mathrm{e} 4$ $(3 S, 6 S, 12 a S), 3 \mathrm{e} 5(3 S, 6 S, 12 a S), 3 \mathrm{e} 6(3 S, 6 S, 12 a S), 4 \mathrm{~d}$ $(3 S, 6 S, 12 a S)$ and the diastereoisomeric mixtures 1c' $(3 S, 6 S, 12 a S ; 3 S, 6 R, 12 a S)$ as well as 2c' (3S,6S,12aS; $3 S, 6 R, 12 a S$ ) were comparable to that of Ko134 (Table 2). All the stereochemically pure compounds in this group had 3S, $6 S, 12 a S$ absolute configuration. Their diastereoisomeric counterparts displaying $3 S, 6 R, 12 a S$ absolute configuration with the exception of 3 e6 $(3 S, 6 R, 12 a S)$ showed no activity. One compound with an $3 S, 6 S, 12 a S$ absolute configuration $(3 \mathrm{e} 3(3 S, 6 S, 12 a S))$ showed partial activity.
Next, we determined the $\mathrm{IC}_{50}$ values for all compounds that displayed potent inhibition of $\mathrm{ABCG} 2$. The $\mathrm{IC}_{50}$ values of the diastereoisomeric pairs of some of the active compounds were also determined. Compounds 1c $(3 S, 6 S, 12 a S), 2 \mathrm{c}(3 S, 6 S, 12 a S), 3 \mathrm{e} 2(3 S, 6 S, 12 a S), 3 \mathrm{e} 4$ $(3 S, 6 S, 12 a S), 3 \mathrm{e} 5(3 S, 6 S, 12 a S), 3 \mathrm{e} 6(3 S, 6 S, 12 a S)$, and $4 \mathrm{~d}$ $(3 S, 6 S, 12 a S)$ had $\mathrm{IC}_{50}$ values in the nanomolar range. Among the compounds $3 \mathrm{e} 2 \quad(3 S, 6 R, 12 a S), \quad 3 \mathrm{e} 5$ $(3 S, 6 R, 12 a S), 3 \mathrm{e} 6(3 S, 6 R, 12 a S)$ that are diastereoisomeric pairs of $3 \mathrm{e} 2(3 S, 6 S, 12 a S), \quad 3 \mathrm{e} 5 \quad(3 S, 6 S, 12 a S), \quad 3 \mathrm{e} 6$ $(3 S, 6 S, 12 a S)$ respectively, only compound $3 \mathrm{e} 5(3 S, 6 R, 12 a S)$ displayed appreciable inhibition. Even in that case there was a 16-fold difference between the $\mathrm{IC}_{50}$ values of the $3 \mathrm{~S}, 6 \mathrm{~S}$, $12 a S(3 \mathrm{e} 5(3 S, 6 S, 12 a S))$ and the 3S, 6R, 12aS (3e5 $(3 S, 6 R, 12 a S))$ diastereoisomers (Table 2).

\subsubsection{Specificity of Inhibition}

To determine specificity of inhibitors, dye efflux assays were utilized to test $\mathrm{ABCB} 1$ and $\mathrm{ABCC} 1$ inhibitory activity 
Table 2. Dye Efflux Inhibition Data

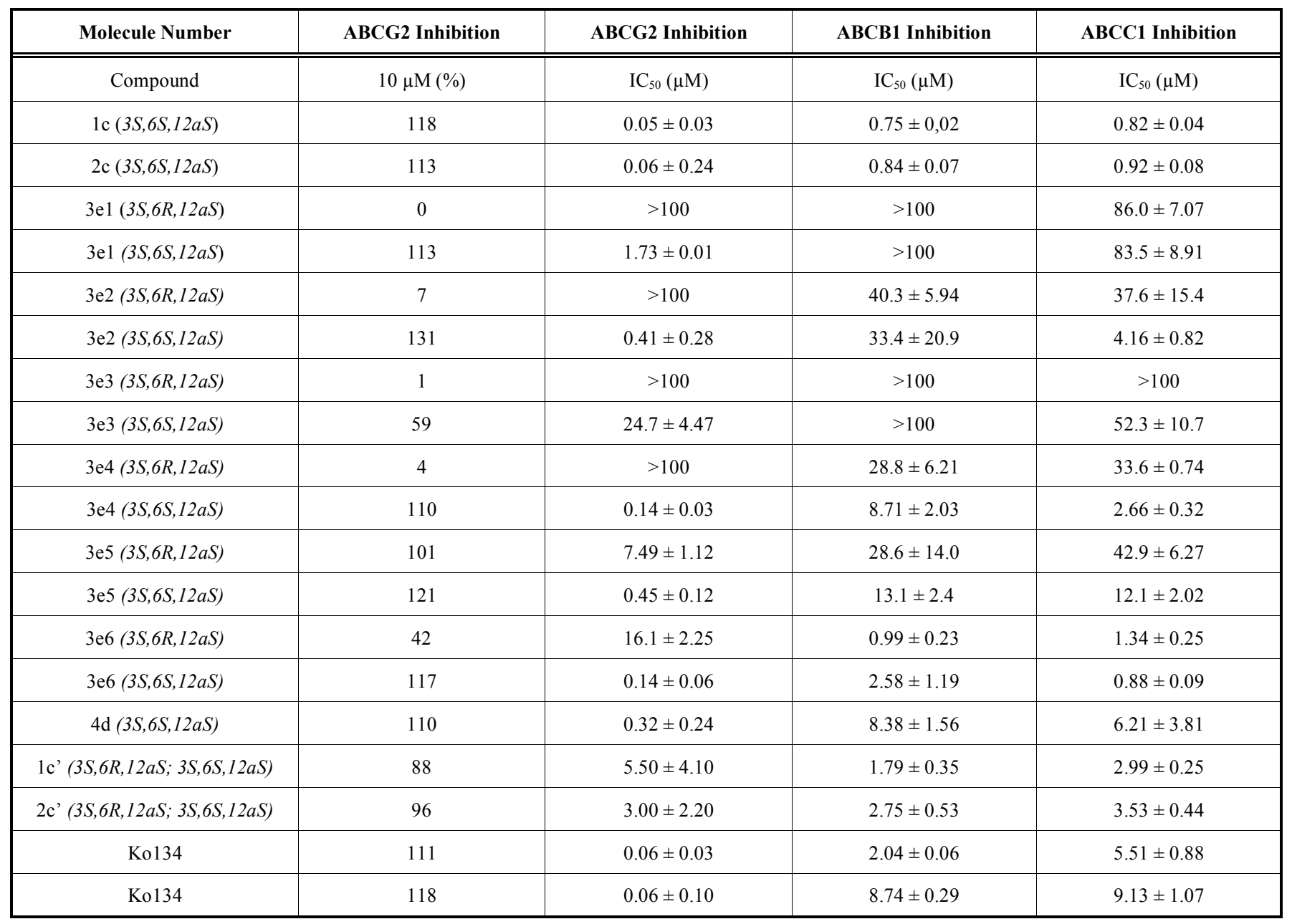

of the compounds. The dye efflux assay used was the Calcein assay. Calcein-AM, the non-fluorescent precursor of the fluorescent calcein is a substrate for both ABCB1 and ABCC1. ABCB1 overexpressing K562-MDR cells and ABCC1 overexpressing HL60-MRP cells provided transporter specificity. Cellular permeation of calcein-AM was limited in these cell lines unless the test compound blocked the transporter activity. In cells with blocked transporters, calcein-AM efficiently penetrated the plasma membrane then cleaved by intracellular esterases yielding the fluorescent calcein. Inhibition experiments were not carried out on parental cells as they did not show appreciable dye transport activity (data not shown). Compounds 1c $(3 S, 6 S, 12 a S), 2 \mathrm{c}(3 S, 6 S, 12 a S), 3 \mathrm{e} 2(3 S, 6 S, 12 a S), 3 \mathrm{e} 4$ $(3 S, 6 S, 12 a S)$, 3e5 $(3 S, 6 S, 12 a S), 3 \mathrm{e} 6(3 S, 6 S, 12 a S), 4 \mathrm{~d}$ $(3 S, 6 S, 12 a S)$ that had $\mathrm{IC}_{50}$ values in the nanomolar range, the diastereoisomeric mixtures 1c' $(3 S, 6 S, 12 a S$; $3 S, 6 R, 12 a S)$ as well as 2c' $(3 S, 6 S, 12 a S ; 3 S, 6 R, 12 a S)$ and compounds $3 \mathrm{e} 2$ (3S,6R,12aS), 3e5 (3S,6R,12aS), 3e6 $(3 S, 6 R, 12 a S)$, the diastereisoomeric pairs of compounds $3 \mathrm{e} 2$ $(3 S, 6 S, 12 a S), 3 \mathrm{e} 5(3 S, 6 S, 12 a S), 3 \mathrm{e} 6(3 S, 6 S, 12 a S)$ respectively were tested. Compound $3 \mathrm{e} 4(3 S, 6 S, 12 a S)$ showed the greatest specificity with about a 19-fold window against $\mathrm{ABCC} 1$ and a 62-fold window against ABCB1.
Interestingly, all these compounds showed very similar $\mathrm{IC}_{50}$ values both for $\mathrm{ABCB} 1$ and $\mathrm{ABCC} 1$ (Table 2, Fig. 2). The only exception was compound $3 \mathrm{e} 2(3 \mathrm{~S}, 6 \mathrm{~S}, 12 \mathrm{aS})$ that inhibited ABCC1 with about 8-fold more potently than it inhibited ABCB1 (Table 2). More significantly, the remarkable stereospecificity $(3 S, 6 S, 12 a S$ vs $3 S, 6 R, 12 a S)$ observed in ABCG2 inhibition was completely absent in inhibition of ABCB1 and ABCC1. Moreover, the compounds with $3 S, 6 R, 12 a S$ configuration did not exhibit ABCG2 specificity over ABCB1 and ABCC1. As expected [31], compounds 1c' $(3 S, 6 R, 12 a S ; 3 S, 6 S, 12 a S), 2 c$ ' $(3 S, 6 R, 12 a S ; 3 S, 6 S, 12 a S)$, both racemates that have a phenyl or benzyl instead of an isobutyl sidechain at C-6 displayed not only lower potency in inhibition of $\mathrm{ABCG} 2$ but no specificity for ABCG2 over ABCB1 and ABCC1 either (Table 2).

\subsubsection{Toxicity and Reversing Activity}

As compound 3e2 $(3 S, 6 S, 12 a S)$ showed remarkable specificity against both $\mathrm{ABCB} 1$ and $\mathrm{ABCC} 1$ and the lowest potency against $\mathrm{ABCB} 1$ among the compounds that inhibited $\mathrm{ABCG} 2$ with submicromolar $\mathrm{IC}_{50}$ values, it was further tested (Table 2). Compound $3 \mathrm{e} 2(3 S, 6 S, 12 a S)$ was equipotent with Ko134 in reversing ABCG2-mediated resistance against $\mathrm{SN}-38$, the active metabolite of irinotecan, 

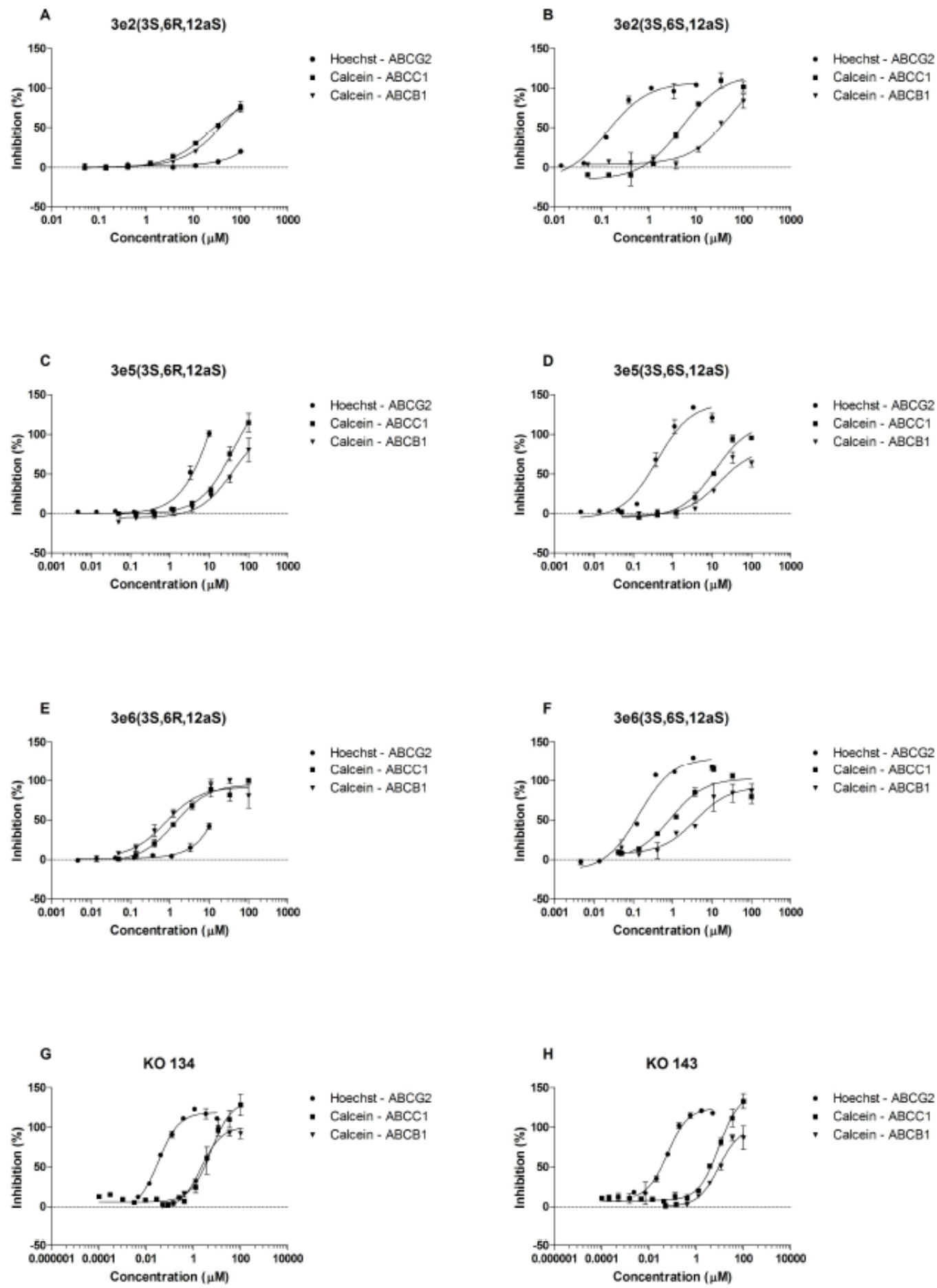

Fig. (2). Specificity studies with cell based dye efflux assays. MCF7-MX cells $(100,000$ cell/per well), K562-MDR cells (100,000 cell/well) or HL60-MRP cells (100,000 cell/well) were used for Hoechst assay, Calcein assay for ABCB1 and Calcein assay for ABCC1, respectively, as described in the Experimental section. The inhibition values (\%) were calculated and plotted against drug concentrations. Inhibition of ABCG2 by $1 \mu \mathrm{M}$ Ko134 and ABCB1 or ABCC1 by $60 \mu \mathrm{M}$ verapamil was considered $100 \%$.

in P388/BCRP cells (Table 3). At a concentration of $1 \mu \mathrm{M}$ both compounds completely reversed resistance to $\mathrm{SN}-38$ (Fig. 3B,C; Table 3) without having any effect on the parental P388 cells (Fig. 3D; Table 3). Compound 3e2 $(3 S, 6 S, 12 a S)$ similarly to Ko134 showed low toxicity to MRC-5 cells, a human diploid fibroblast cell line displaying about the same $\mathrm{EC}_{50}$ values (Fig. 4).

\section{DISCUSSION}

Significance of ABCG2 in MDR has received more and more recognition as it mediates MDR in various indications, and it is the pivotal transporter providing resistance to cancer stem cells against chemotherapeutic agents [46-48]. In keeping with this, reversal of resistance caused by ABCG2 overexpression is a very attractive option. 

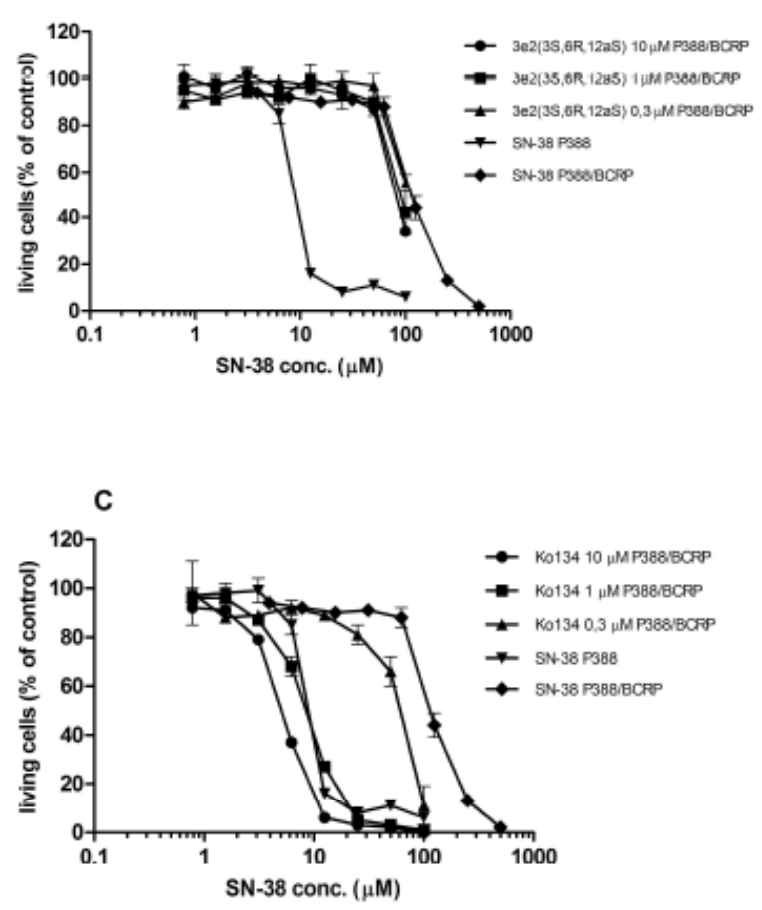

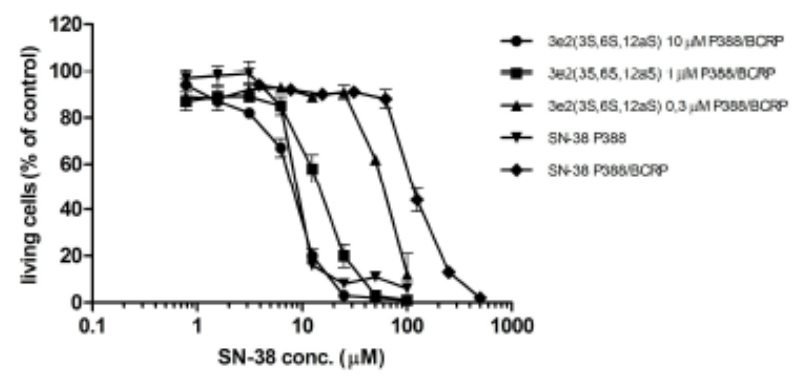

D

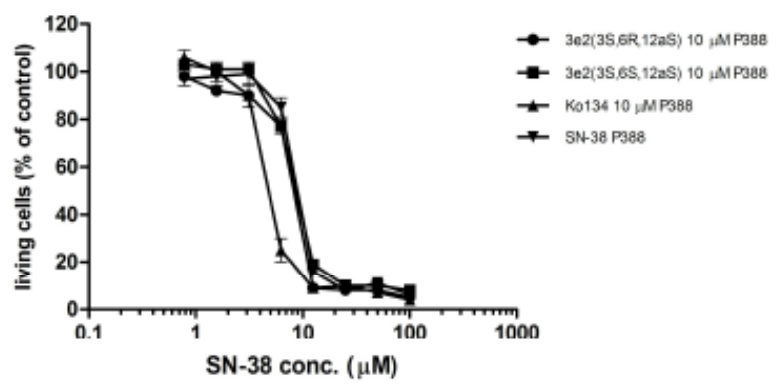

Fig. (3). Reversal of ABCG2-mediated resistance. (A-C) To determine sensitivity to SN-38 P388/BCRP cells (5,000 cells/well) in the ab-

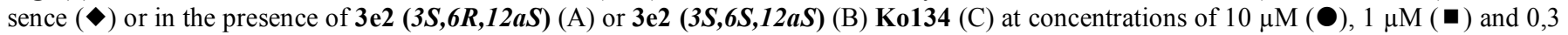
$\mu \mathrm{M}(\boldsymbol{\Delta})$ of modulators and sensitivity of P388 cells (5,000 cells/well) in the absence of modulators $(\boldsymbol{\nabla})$ were cultured in the presence of increasing concentrations of SN-38 for 3 days before cell survival was measured with the resazurin - resorufin assay. (D) For control experiments P388 cells were cultured in the absence $(\nabla)$ or presence of $10 \mu \mathrm{M}$ concentration of $3 \mathrm{e} 2(3 S, 6 R, 12 a S)(\bullet)$, or $3 \mathrm{e} 2(3 S, 6 S, 12 a S)(\square)$ or Ko134 (A) for 3 days at increasing doses of SN-38 before the resazurin - resorufin assay was carried out.

Table 3. Cytotoxicity and Drug Resistance Reversal Data

\begin{tabular}{|c|c|c|c|c|c|}
\hline Cell Line & \multicolumn{4}{|c|}{ P388/BCRP } & \multirow{2}{*}{$\begin{array}{c}\text { P388 } \\
-\end{array}$} \\
\hline \multirow{2}{*}{ Reversing agent } & $10 \mu \mathrm{M}$ & $1 \mu \mathrm{M}$ & $0.33 \mu \mathrm{M}$ & - & \\
\hline & \multicolumn{5}{|c|}{$\mathrm{EC}_{50}(\mu \mathrm{M})$} \\
\hline Ko143 & $4.73 \pm 1.23$ & $7.98 \pm 2.82$ & $58.1 \pm 13.7$ & $114 \pm 21$ & $9.71 \pm 2.77$ \\
\hline $3 \mathrm{e} 2(3 S, 6 S, 12 a S)$ & $6.79 \pm 4.35$ & $12.7 \pm 4.9$ & $61.9 \pm 21.3$ & $114 \pm 21$ & $9.71 \pm 2.77$ \\
\hline
\end{tabular}

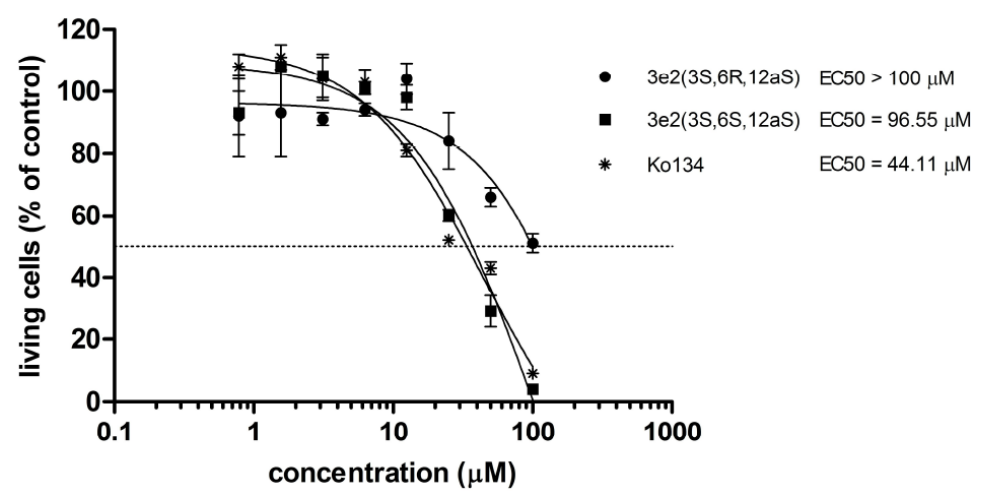

Fig. (4). Non-target cytotoxic effect of compounds. MRC-5 cells cells (2,000 cells/well) were cultured for 3 days with increasing concentrations of $3 \mathrm{e} 2(3 S, 6 R, 12 a S)(\bullet), 3 \mathrm{e} 2(3 S, 6 S, 12 a S)(\square)$ and $\mathrm{Ko134}(*)$ before the resazurin - resorufin assay was carried out.

Therefore, a large number of articles have been published identifying ABCG2 inhibitors $[49,50]$. In silico approaches utilizing direct and indirect modelling have been made [51]. A homology model based on crystal structure of a prokaryotic complete $\mathrm{ABC}$ protein, Sav1866 from
Staphylococcus aureus was created and blind docking of known ligands showed that at least two distinct binding sites exist [52]. Indirect approaches employing pharmacophore modelling [49], QSAR [53] or machine learning algorythms [54] were also published. Most ABCG2 datasets available 
for in silico modeling are comprised of congeneric series of compounds and the results from one series usually cannot be applied to another series of compounds [53]. Therefore, despite the accuracy of around $80 \%$ of some of the models in silico approaches have not replaced in vitro screening.

An ideal inhibitor with a clinical MDR reversal potential would have to meet several criteria. It is highly desirable that it inhibits transport of most of ABCG2 subtrates. This is a significant challenge as ABCG2 has multiple binding sites shown by displacement analysis [55-57] and docking [52]. We have selected the Hoechst dye as a probe which binds to the most promiscuous prazosin site [52, 55-57], and the assay is a truly high-throughput assay [25]. The FTC-Ko family has been shown to inhibit the ABCG2-mediated transport of those compounds that bind to the prazosin [58, 59], rhodamine [60] and mitoxantrone [58-61] sites. Therefore, it is possible that additional members of this segment of the chemical space will be general inhibitors, too. The other challenge is the specificity of inhibition. The more specific an inhibitor is, the lower the chance for toxicity. The FTC-Ko family proved to be a good starting point since these compounds displayed significant specificity that was confirmed in this study (Fig. 2).

Our data show that the FTC type diketo-piperazine ring structure is essential for activity as tricyclic analogues IIIaIIId showed no activity in the Hoechst assay. On the other hand, compounds that preserved the diketo-piperazine ring structure were all active provided they had an isobutyl group at C-6 and a 3S, 6S, 12aS configuration (Fig. 2). Based on previous data, compounds with $3 S, 6 R, 12 a S$ configuration were inactive as expected [31] except perhaps the partially active $3 \mathrm{e} 6(3 S, 6 R, 12 a S)$. But even in that case 3 e6 $(3 S, 6 S, 12 a S)$, the diastereoisomeric pair was more than 115fold more potent (Table 2). Remarkably, stereospecificity $(3 S, 6 S, 12 a S$ vs $3 S, 6 R, 12 a S)$ observed in ABCG2 inhibition was completely absent in inhibition of ABCB1 and $\mathrm{ABCC} 1$ (Fig. 2). Moreover, the compounds with $3 S, 6 \boldsymbol{R}$, $12 a S$ configuration did not exhibit ABCG2 specificity over $\mathrm{ABCB} 1$ and $\mathrm{ABCC} 1$. The fact that configuration at position 6 alone confers specificity for ABCG2 over ABCB1 and $\mathrm{ABCC} 1$ has not been described before. This specificity confined to a single chiral center is quite unexpected considering the previosly described broad substrate specificity of these ABC transporters $[49,50]$.

\section{CONCLUSION}

We have synthesized a set of novel FTC - Ko analogs with remarkable specificity towards ABCG2. As the lead candidate shows efficient reversing activity with low toxicity, it is likely that this group of novel compounds with increased stability have the potential to become clinical candidates provided they meet the in vivo criteria for clinical candidates. In addition, these compounds are useful tools to study ABCG2 function both in vitro.

\section{CONFLICT OF INTEREST}

The author(s) confirm that this article content has no conflicts of interest.

\section{ACKNOWLEDGEMENTS}

This work was supported by the following Hungarian grants: TUDAS-1-2006-0029, OMFB-00505/2007, IVDMDQ08, OM-00139/2008, XTTPSRT1, OM00230/2005, GOP-1.1.1-09/1-2009-0055. We thank Dr Zoltán Kele for performing the ESI MS measurements and Ms Timea Rosta for preparation of the manuscript.

\section{REFERENCES}

[1] Fletcher, J.I.; Haber, M.; Henderson, M.J.; Norris, M.D. ABC transporters in cancer: more than just drug efflux pumps. Nat. Rev. Cancer, 2010, 10, 147-56.

[2] Burger, H.; van Tol, H.; Brok, M.; Wiemer, E.A.; de Bruijn, E.A. Guetens, G.; de Boeck, G.; Sparreboom, A.; Verweij, J.; Nooter, K. Chronic imatinib mesylate exposure leads to reduced intracellular drug accumulation by induction of the ABCG2 (BCRP) and ABCB1 (MDR1) drug transport pumps. Cancer Biol. Ther., 2005 4, 747-52.

[3] Damiani, D.; Tiribelli, M.; Calistri, E.; Geromin, A.; Chiarvesio, A.; Michelutti, A.; Cavallin, M.; Fanin, R. The prognostic value of P-glycoprotein (ABCB) and breast cancer resistance protein (ABCG2) in adults with de novo acute myeloid leukemia with normal karyotype. Haematologica, 2006, 91, 825-8.

[4] Eechoute, K.; Sparreboom, A.; Burger, H.; Franke, R.M. Schiavon, G.; Verweij, J.; Loos, W.J.; Wiemer, E.A.; Mathijssen, R.H. Drug transporters and imatinib treatment: implications for clinical practice. Clin. Cancer Res., 2011, 17, 406-15.

[5] Gupta, S.; Burckhardt, G.; Hagos, Y. SLC22 transporter family proteins as targets for cytostatic uptake into tumor cells. Biol. Chem., 2011, 392, 117-24.

[6] Nobili, S.; Landini, I.; Giglioni, B.; Mini, E. Pharmacological strategies for overcoming multidrug resistance. Curr. Drug Targets, 2006, 7, 861-79.

[7] Perez-Tomas, R. Multidrug resistance: retrospect and prospects in anti-cancer drug treatment. Curr. Med. Chem., 2006, 13, 1859-76.

[8] Leonard, G.D.; Fojo, T.; Bates, S.E. The role of ABC transporters in clinical practice. Oncologist, 2003, 8, 411-24.

[9] Lagas, J.S.; van der Kruijssen, C.M.; van de Wetering, K.; Beijnen, J.H.; Schinkel, A.H. Transport of diclofenac by breast cancer resistance protein (ABCG2) and stimulation of multidrug resistance protein 2 (ABCC2)-mediated drug transport by diclofenac and benzbromarone. Drug Metab. Dispos., 2009, 37, 129-36.

[10] Lu, M.C.; Lai, N.S.; Li, K.J.; Hsieh, S.C.; Wu, C.H.; Yu, C.L. Increased multidrug resistance-associated protein activity in mononuclear cells of patients with systemic lupus erythematosus. Clin. Exp. Rheumatol., 2008, 26, 638-45.

[11] Richaud-Patin, Y.; Soto-Vega, E.; Jakez-Ocampo, J.; Llorente, L. P-glycoprotein in autoimmune diseases. Autoimmun Rev., 2004, 3, 188-92.

[12] Tsujimura, S.; Saito, K.; Nakayamada, S.; Nakano, K.; Tanaka, Y. Clinical relevance of the expression of P-glycoprotein on peripheral blood lymphocytes to steroid resistance in patients with systemic lupus erythematosus. Arthritis Rheum., 2005, 52, 1676-83.

[13] Tsujimura, S.; Saito, K.; Nawata, M.; Nakayamada, S.; Tanaka, Y. Overcoming drug resistance induced by P-glycoprotein on lymphocytes in patients with refractory rheumatoid arthritis. Ann. Rheum. Dis., 2008, 67, 380-8.

[14] van der Heijden, J.W.; Dijkmans, B.A.; Scheper, R.J.; Jansen, G. Drug Insight: resistance to methotrexate and other diseasemodifying antirheumatic drugs--from bench to bedside. Nat. Clin Pract. Rheumatol., 2007, 3, 26-34.

[15] Wolf, J.; Stranzl, T.; Filipits, M.; Pohl, G.; Pirker, R.; Leeb, B.; Smolen, J.S. Expression of resistance markers to methotrexate predicts clinical improvement in patients with rheumatoid arthritis. Ann. Rheum. Dis., 2005, 64, 564-8.

[16] Robey, R.W.; Polgar, O.; Deeken, J.; To, K.W.; Bates, S.E ABCG2: determining its relevance in clinical drug resistance. Cancer Metastasis Rev., 2007, 26, 39-57.

[17] Benderra, Z.; Faussat, A.M.; Sayada, L.; Perrot, J.Y.; Chaoui, D.; Marie, J.P.; Legrand, O. Breast cancer resistance protein and Pglycoprotein in 149 adult acute myeloid leukemias. Clin. Cancer Res., 2004, 10, 7896-902.

[18] van den Heuvel-Eibrink, M.M.; Wiemer, E.A.; Prins, A.; Meijerink, J.P.; Vossebeld, P.J.; van der Holt, B.; Pieters, R.; Sonneveld, P. Increased expression of the breast cancer resistance protein (BCRP) in relapsed or refractory acute myeloid leukemia (AML). Leukemia, 2002, 16, 833-9.

[19] Bessho, Y.; Oguri, T.; Achiwa, H.; Muramatsu, H.; Maeda, H.; Niimi, T.; Sato, S.; Ueda, R. Role of ABCG2 as a biomarker for 
predicting resistance to CPT-11/SN-38 in lung cancer. Cancer Sci., 2006, $97,192-8$

[20] Kawabata, S.; Oka, M.; Soda, H.; Shiozawa, K.; Nakatomi, K.; Tsurutani, J.; Nakamura, Y.; Doi, S.; Kitazaki, T.; Sugahara, K.; Yamada, Y.; Kamihira, S.; Kohno, S. Expression and functional analyses of breast cancer resistance protein in lung cancer. Clin. Cancer Res., 2003, 9, 3052-7.

[21] Doyle, L.A.; Ross, D.D. Multidrug resistance mediated by the breast cancer resistance protein BCRP (ABCG2). Oncogene, 2003, $22,7340-58$

[22] Hegedus, C.; Ozvegy-Laczka, C.; Apati, A.; Magocsi, M.; Nemet, K.; Orfi, L.; Keri, G.; Katona, M.; Takats, Z.; Varadi, A.; Szakacs, G.; Sarkadi, B. Interaction of nilotinib, dasatinib and bosutinib with ABCB1 and ABCG2: implications for altered anti-cancer effects and pharmacological properties. Br. J. Pharmacol., 2009, 158, 1153-64.

[23] Lemos, C.; Jansen, G.; Peters, G.J. Drug transporters: recent advances concerning BCRP and tyrosine kinase inhibitors. $B r . J$. Cancer, 2008, 98, 857-62.

[24] Jansen, G.; Scheper, R.J.; Dijkmans, B.A. Multidrug resistance proteins in rheumatoid arthritis, role in disease-modifying antirheumatic drug efficacy and inflammatory processes: an overview. Scand. .J Rheumatol., 2003, 32, 325-36.

[25] Kis, E.; Nagy, T.; Jani, M.; Molnar, E.; Janossy, J.; Ujhellyi, O.; Nemet, K.; Heredi-Szabo, K.; Krajesi, P. Leflunomide and its metabolite A771726 are high affinity substrates of BCRP: implications for drug resistance. Ann. Rheum. Dis., 2009, 68, 12017.

[26] Jani, M.; Szabo, P.; Kis, E.; Molnar, E.; Glavinas, H.; Krajcsi, P. Kinetic characterization of sulfasalazine transport by human ATPbinding cassette G2. Biol. Pharm. Bull., 2009, 32, 497-9.

[27] Pal, A.; Mehn, D.; Molnar, E.; Gedey, S.; Meszaros, P.; Nagy, T.; Glavinas, H.; Janaky, T.; von Richter, O.; Bathori, G.; Szente, L.; Krajcsi, P. Cholesterol potentiates ABCG2 activity in a heterologous expression system: improved in vitro model to study function of human ABCG2. J. Pharmacol. Exp. Ther., 2007, 321, 1085-94.

[28] van der Heijden, J.W.; Oerlemans, R.; Tak, P.P.; Assaraf, Y.G.; Kraan, M.C.; Scheffer, G.L.; van der Laken, C.J.; Lems, W.F.; Scheper, R.J.; Dijkmans, B.A.; Jansen, G. Involvement of breast cancer resistance protein expression on rheumatoid arthritis synovial tissue macrophages in resistance to methotrexate and leflunomide. Arthritis Rheum., 2009, 60, 669-77.

[29] Keskitalo, J.E.; Zolk, O.; Fromm, M.F.; Kurkinen, K.J.; Neuvonen, P.J.; Niemi, M. ABCG2 polymorphism markedly affects the pharmacokinetics of atorvastatin and rosuvastatin. Clin. Pharmacol. Ther., 2009, 86, 197-203.

[30] Plate, R.; Hermkens, P.H.H.; Behm, H.; Ottenheijm, H.C.J. Tremorgenic Mycotoxins: Synthesis of 6Demethoxyfumitremorgin C. J. Org. Chem., 1987, 52 560-64.

[31] van Loevezijn, A.; Allen, J.D.; Schinkel, A.H.; Koomen, G.J. Inhibition of BCRP-mediated drug efflux by fumitremorgin-type indolyl diketopiperazines. Bioorg. Med. Chem. Lett., 2001, 11, 2932 .

[32] Allen, J.D.; van Loevezijn, A.; Lakhai, J.M.; van der Valk, M.; van Tellingen, O.; Reid, G.; Schellens, J.H.; Koomen, G.J.; Schinkel, A.H. Potent and specific inhibition of the breast cancer resistance protein multidrug transporter in vitro and in mouse intestine by a novel analogue of fumitremorgin C. Mol. Cancer Ther., 2002, 1, 417-25.

[33] Kaiser, E.; Colescott, R.L.; Bossinger, C.D.; Cook, P.I. Color test for detection of free terminal amino groups in the solid-phase synthesis of peptides. Anal. Biochem., 1970, 34, 595-8.

[34] Homolya, L.; Hollo, M.; Muller, M.; Mechetner, E.B.; Sarkadi, B. A new method for a quantitative assessment of P-glycoproteinrelated multidrug resistance in tumour cells. Br. J. Cancer, 1996, 73, 849-55.

[35] Hollo, Z.; Homolya, L.; Hegedus, T.; Sarkadi, B. Transport properties of the multidrug resistance-associated protein (MRP) in human tumour cells. FEBS Lett., 1996, 383, 99-104.

[36] Yanase, K.; Tsukahara, S.; Asada, S.; Ishikawa, E.; Imai, Y.; Sugimoto, Y. Gefitinib reverses breast cancer resistance proteinmediated drug resistance. Mol. Cancer Ther., 2004, 3, 1119-25.

[37] von Richter, O.; Glavinas, H.; Krajcsi, P.; Liehner, S.; Siewert, B.; Zech, K. A novel screening strategy to identify ABCB1 substrates and inhibitors. Naunyn Schmiedebergs Arch. Pharmacol., 2009, 379, 11-26.

[38] Perrot, S.; Dutertre-Catella, H.; Martin, C.; Rat, P.; Warnet, J.M. Resazurin metabolism assay is a new sensitive alternative test in isolated pig cornea. Toxicol. Sci., 2003, 72, 122-9.

[39] Gisin, B.F.; Merrifield, R.B. Carboxyl-catalyzed intramolecular aminolysis. A side reaction in solid-phase peptide synthesis. J. Am. Chem. Soc., 1972, 94, 3102-6.
[40] Kaljuste, K.; Undén, A. Solid Phase Synthesis of 1,2,3,4 Tetrahydro-.beta.-carbolines; Implications for Combinatorial Chemistry. Tetrahedron Lett., 1995, 36, 9211-14.

[41] Mayer, J.P.; Bankaitis-Davis, D.; Zhang, J.; Beaton, G.; Bjergarde K.; Andersen, C.M.; Goodman, B.A.; Herrera, C.J. Application Of The Pictet-Spengler Reaction In Combinatorial Chemistry. Tetrahedron Lett., 1996, 37, 5633-36.

[42] Mohan, R.; Chou, Y.-L.; Morrissey, M.M. Pictet-Spengler Reaction on Solid Support: Synthesis of 1,2,3,4-Tetrahydro- $\beta$ Carboline Libraries. Tetrahedron Lett., 1996, 37, 3963-66.

[43] Yang, L.; Guo, L. Pictet-Spengler Reaction On Solid Support Tetrahedron Lett., 1996, 37, 5041-44.

[44] Akaji, K.; Kuriyama, N.; Kimura, T.; Fujiwara, Y.; Kiso, Y. Anchoring of Fmoc amino acid to 4-alkoxybenzyl alcohol resin using a new esterification reagent. Tetrahedron Lett., 1992, 33 3177-80.

[45] Carpino, L.A.; El-Faham, A. Tetramethylfluoroformamidinium hexafluorophosphate: A rapid-acting peptide coupling reagent for solution and solid phase peptide synthesis. J. Am. Chem. Soc., 1995, 117, 5401-02.

[46] Ding, X.W.; Wu, J.H.; Jiang, C.P. ABCG2: a potential marker of stem cells and novel target in stem cell and cancer therapy. Life Sci., 2010, 86, 631-7.

[47] Scharenberg, C.W.; Harkey, M.A.; Torok-Storb, B. The ABCG2 transporter is an efficient Hoechst 33342 efflux pump and is preferentially expressed by immature human hematopoietic progenitors. Blood, 2002, 99, 507-12.

[48] Zhou, S.; Schuetz, J.D.; Bunting, K.D.; Colapietro, A.M.; Sampath, J.; Morris, J.J.; Lagutina, I.; Grosveld, G.C.; Osawa, M.; Nakauchi, H.; Sorrentino, B.P. The ABC transporter Bcrp1/ABCG2 is expressed in a wide variety of stem cells and is a molecular determinant of the side-population phenotype. Nat. Med., 2001, 7, 1028-34

[49] Matsson, P.; Englund, G.; Ahlin, G.; Bergstrom, C.A.; Norinder, U.; Artursson, P. A global drug inhibition pattern for the human ATP-binding cassette transporter breast cancer resistance protein (ABCG2). J. Pharmacol. Exp. Ther., 2007, 323, 19-30.

[50] Matsson, P.; Pedersen, J.M.; Norinder, U.; Bergstrom, C.A.; Artursson, P. Identification of novel specific and general inhibitors of the three major human ATP-binding cassette transporters P-gp, BCRP and MRP2 among registered drugs. Pharm. Res., 2009, 26, 1816-31.

[51] Nicolle, E.; Boumendjel, A.; Macalou, S.; Genoux, E.; AhmedBelkacem, A.; Carrupt, P.A.; Di Pietro, A. QSAR analysis and molecular modeling of ABCG2-specific inhibitors. Adv. Drug. Deliv. Rev., 2009, 61, 34-46.

[52] Hazai, E.; Bikadi, Z. Homology modeling of breast cancer resistance protein (ABCG2). J. Struct. Biol., 2008, 162, 63-74.

[53] Gandhi, Y.A.; Morris, M.E. Structure-activity relationships and quantitative structure-activity relationships for breast cancer resistance protein (ABCG2). AAPS J., 2009, 11, 541-52.

[54] Demel, M.A.; Schwaha, R.; Kramer, O.; Ettmayer, P.; Haaksma, E.E.; Ecker, G.F. In silico prediction of substrate properties for ABC-multidrug transporters. Expert Opin. Drug Metab. Toxicol. 2008, 4, 1167-80.

[55] Clark, R.; Kerr, I.D.; Callaghan, R. Multiple drugbinding sites on the R $482 \mathrm{G}$ isoform of the ABCG2 transporter. Br. J. Pharmacol., 2006, 149, 506-15.

[56] Ejendal, K.F.; Diop, N.K.; Schweiger, L.C.; Hrycyna, C.A. The nature of amino acid 482 of human ABCG2 affects substrate transport and ATP hydrolysis but not substrate binding. Protein Sci., 2006, 15, 1597-607.

[57] Ejendal, K.F.; Hrycyna, C.A. Differential sensitivities of the human ATP-binding cassette transporters ABCG2 and P-glycoprotein to cyclosporin A. Mol. Pharmacol., 2005, 67, 902-11.

[58] Giri, N.; Agarwal, S.; Shaik, N.; Pan, G.; Chen, Y.; Elmquist, W.F. Substrate-dependent breast cancer resistance protein (Bcrp1/Abcg2)-mediated interactions: consideration of multiple binding sites in in vitro assay design. Drug. Metab. Dispos., 2009, 37, 560-70.

[59] Robey, R.W.; Honjo, Y.; van de Laar, A.; Miyake, K.; Regis, J.T. Litman, T.; Bates, S.E. A functional assay for detection of the mitoxantrone resistance protein, MXR (ABCG2). Biochim. Biophys. Acta, 2001, 1512, 171-82.

[60] Minderman, H.; Suvannasankha, A.; O'Loughlin, K.L.; Scheffer, G.L.; Scheper, R.J.; Robey, R.W.; Baer, M.R. Flow cytometric analysis of breast cancer resistance protein expression and function. Cytometry, 2002, 48, 59-65.

[61] Ozvegy-Laczka, C.; Hegedus, T.; Varady, G.; Ujhelly, O.; Schuetz, J.D.; Varadi, A.; Keri, G.; Orfi, L.; Nemet, K.; Sarkadi, B. Highaffinity interaction of tyrosine kinase inhibitors with the ABCG2 multidrug transporter. Mol. Pharmacol., 2004, 65, 1485-95. 